Portland State University

PDXScholar

Winter 3-11-2015

\title{
A Novel Approach to Flow and Sediment Transport Estimation in Estuaries and Bays
}

Hamed Moftakhari Rostamkhani

Portland State University

Follow this and additional works at: https://pdxscholar.library.pdx.edu/open_access_etds

Part of the Sedimentology Commons

Let us know how access to this document benefits you.

\section{Recommended Citation}

Moftakhari Rostamkhani, Hamed, "A Novel Approach to Flow and Sediment Transport Estimation in Estuaries and Bays" (2015). Dissertations and Theses. Paper 2185.

https://doi.org/10.15760/etd.2182

This Dissertation is brought to you for free and open access. It has been accepted for inclusion in Dissertations and Theses by an authorized administrator of PDXScholar. Please contact us if we can make this document more accessible: pdxscholar@pdx.edu. 
A Novel Approach to Flow and Sediment Transport Estimation in Estuaries and Bays

by

Hamed Moftakhari Rostamkhani

A dissertation submitted in partial fulfillment of the requirements for the degree of

Doctor of Philosophy

in

Civil and Environmental Engineering

Dissertation Committee:

David A. Jay, Chair

Stefan A. Talke, Co-Chair

David H. Schoellhamer

John Rueter

Portland State University

2015 
(C) 2015 Hamed Moftakhari Rostamkhani 


\section{Abstract}

Reliable estimates of river discharge and sediment transport to the ocean from large tidal rivers are vital for water resources management, efficient river and harbor management, navigational purposes, and climate analyses. Due to the difficulties inherent in measuring tidal-river discharge, hydrological and sedimentological records are typically too short to adequately characterize long-term (decadal) trends. Also, uncertainties associated with observation and calibration of hydrological models suggest a need for more accurate methods based on longer records of hydrodynamic parameters (e.g. tides). Tidal theory indicates that tides and river discharge interact through quadratic bed friction, which diminishes and distorts the tidal wave as discharge increases. In this study, using tidal constituents, astronomical forcing and a model of the frictional interaction of flow and tides, I propose a novel Tidal Discharge Estimate (TDE) to predict freshwater discharge with an approximate averaging interval of 18 days for time periods with tidal data but no river flow records. Next, using continuous wavelet analysis of tidal properties, I develop a method of estimating river discharge using tides measured on multiple gages along tidal rivers to improve the time-resolution and accuracy of TDE. The applicability of the Multiple-gauge Discharge Estimate (MTDE) is first demonstrated in the two largest tidalfluvial systems of the Pacific Northwest, the Columbia River Estuary (CRE) and Fraser River Estuary (FRE). A numerical model of an idealized estuary with similar forcing as the FRE and CRE is next run under different hydrologic and morphologic scenarios to 
evaluate the effect of convergence, friction, and river flow variations on the applicability of MTDE.

The TDE method was applied to the San Francisco Bay, using the continuous hourly tide record available since 1858. Results show that TDE reproduces known San Francisco (SF) Bay delta inflows from 1930-present with a Nash-Sutcliffe coefficient of 0.81 and is a useful method for hindcasting historical flows from 1858 - 1929, a period that predates direct measurement of delta discharge. I also recover and digitize $\sim 80$ years of Sacramento River daily water level data between 1849 and 1946, from which river discharge to SF Bay is estimated on a daily basis, after adjusting for changes to the river channel. This discharge combined with Net Delta Outflow Index estimates $(1930-2011)$ and flow estimates from tidal data $(1858$ - 2011) provides a more accurate version of SF Bay historic daily inflows from 1849 - 2011.

Next, the history of sediment transport and discharge into SF Bay from 1849-present is reevaluated using the daily discharge estimates. A non-stationary rating curve between river flow and sediment transport is developed, with net sedimentation observed during five bathymetric surveys that were used to constrain the total integrated sediment discharge. Results show that $\sim 1600 \pm 320$ million-tons of sediment have been delivered to SF Bay between 1850 and 2011. There has been an approximately $25-30 \%$ reduction of annual flow since the $19^{\text {th }}$ century, along with decreased sediment supply. This has resulted in a $\sim 60 \%$ reduction in annual sediment delivery to SF Bay. The annual hydrograph of inflow to SF Bay and the seasonality of sediment flux have changed considerably over time, due to both human alteration and climate change. Significant 
historic spring-melt peak floods have disappeared in the modern system and now peak flows mostly occur in winter. My flow estimation methods also confirm that the flood of January 1862 had the largest daily sediment load and the second largest daily discharge since 1849. 


\section{Dedication}

I dedicate this dissertation to those whom I love:

my Mom and Dad,

my Mother-in-law and Father-in-law,

and my sweetheart Farnaz... 


\section{Acknowledgments}

In the course of this work, I had the pleasure of working with many fine people. David Jay has been my advisor for almost 4 years, and his friendly and non-authoritarian approach has allowed me to find my own way, even as I was being guided. I learnt a lot from him, on top of all professional ethics principles. I was also lucky enough to have an awesome co-advisor, Stefan Talke, whose ideas and ongoing encouragement helped me immensely throughout. I wish to thank the other members of Coastal, Estuarine and Riverine Processes (CERP) group, more specifically Keith Leffler and Adam Devlin, for sharing ideas, experiences and friendship.

I am grateful to David Schoellhamer at the USGS in Portland, OR for his contribution to the work, and his many experiences that shared with me in different aspects of the project. Mathieu Marineau at USGS in Sacramento, CA is acknowledged for sharing digitized water level data observed in Sacramento River (1849 - 1892). Leon Hunsaker is acknowledged as the source of the Logan hydrograph from 1849-1862.

I am thankful to John Rueter for agreeing to serve in the committee as GO representative. I wish to thank Masseeh College Faculties and Staff, specifically Helen Frey and Megan Falcone, who have been encouraging and supportive over the past four years. I wish to thank Ren Su, Dean of MCECS, and Dr. Fariborz Maseeh for their partial financial support throughout my graduate studies. 
Last but not least, I'd like thank my family in back-home for all their supports and encouragements, my darling for all her patience, and my little silly lions, Ali and Mateen. Love you all $\odot$ 


\section{Table of Contents}

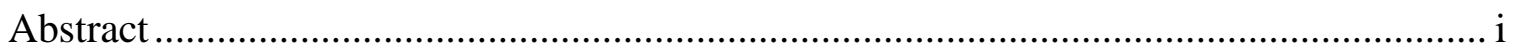

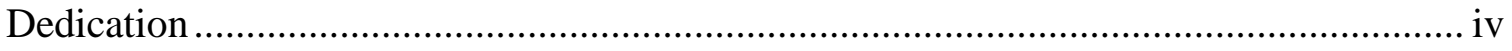

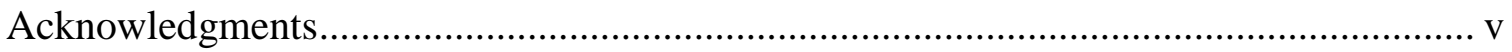

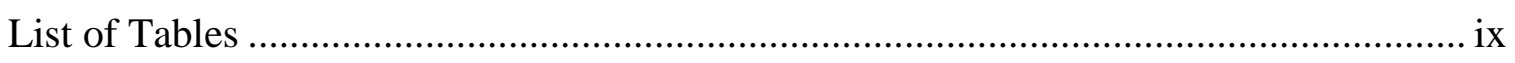

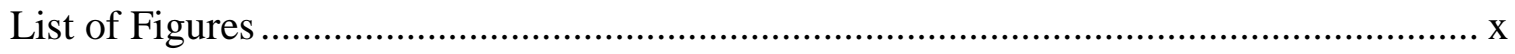

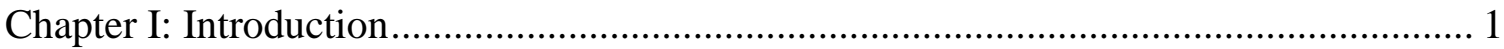

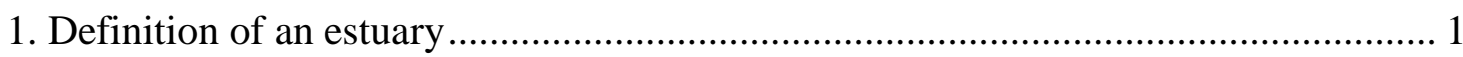

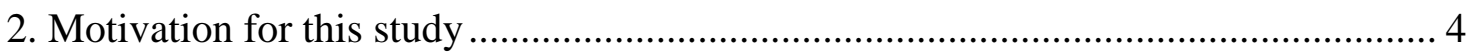

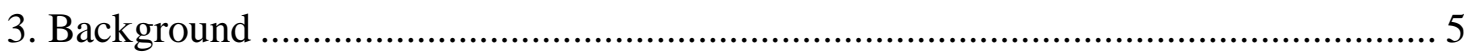

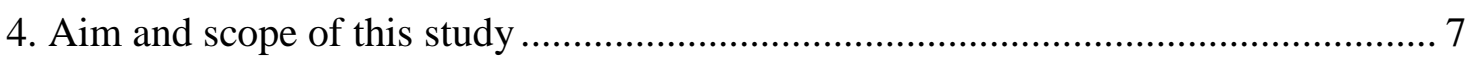

Chapter II: A Novel Approach to Flow Estimation in Tidal Rivers ................................. 12

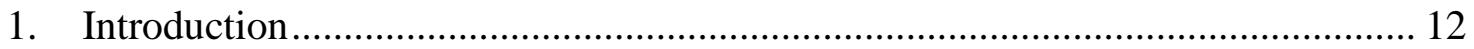

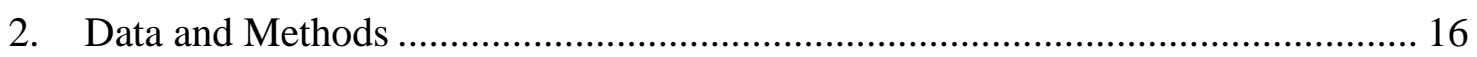

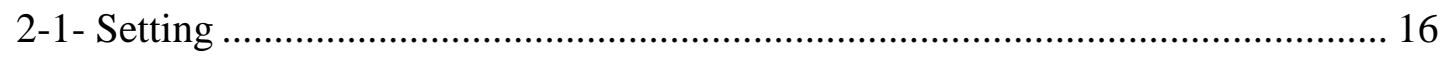

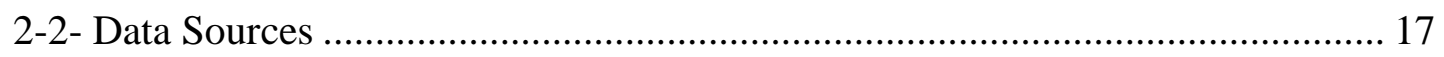

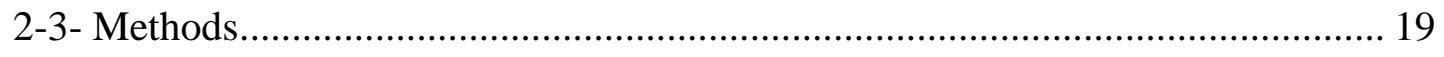

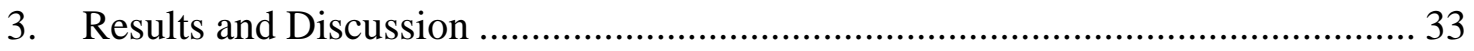

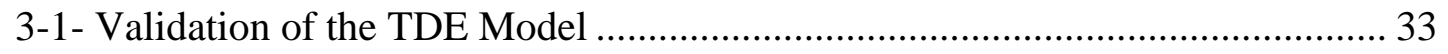

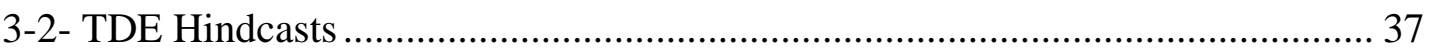

3-3- Error Analysis ............................................................................................... 40

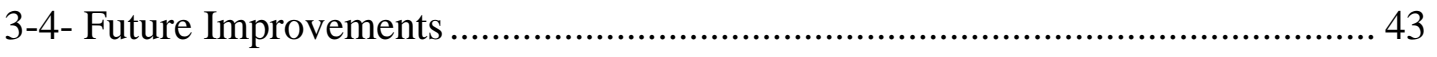

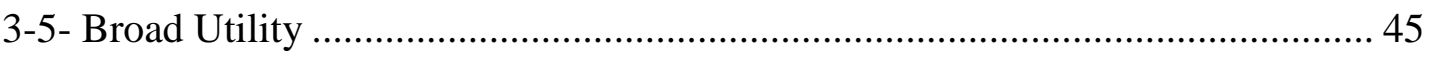

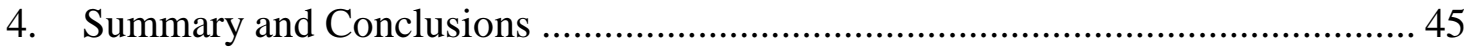

Chapter III: River Flow Estimation in Estuaries Using Multiple-Tide Gages Distributed

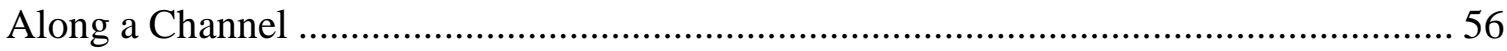

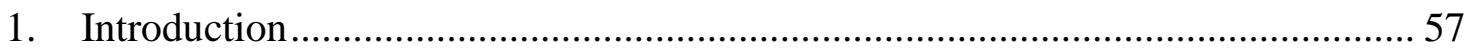




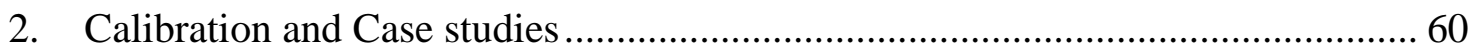

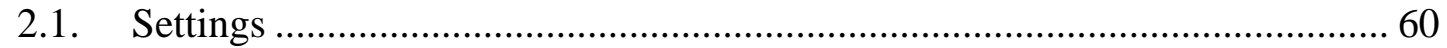

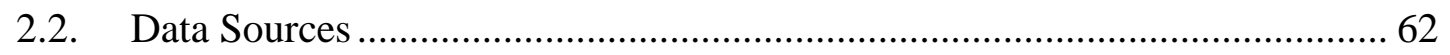

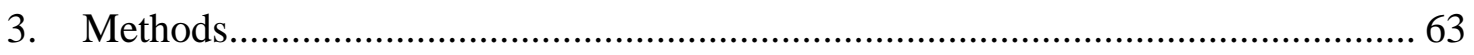

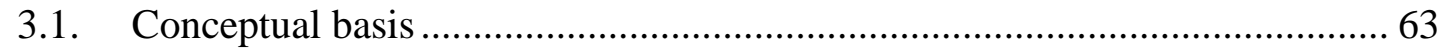

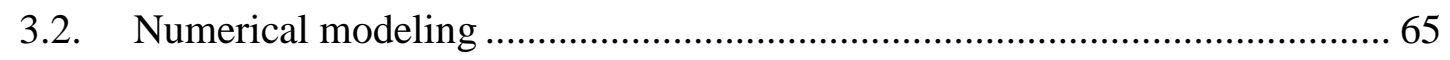

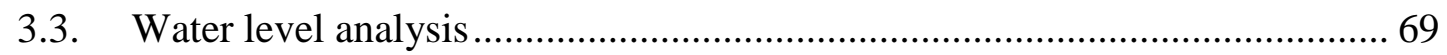

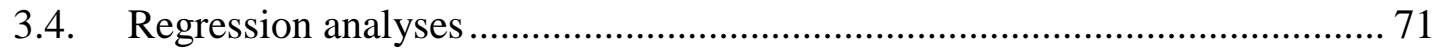

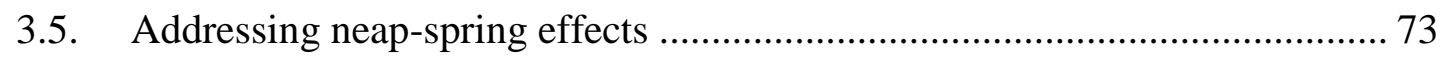

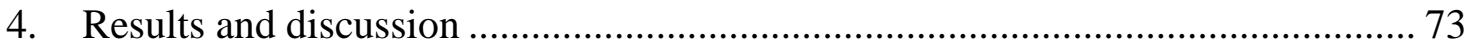

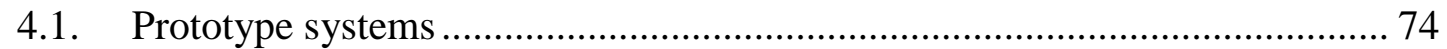

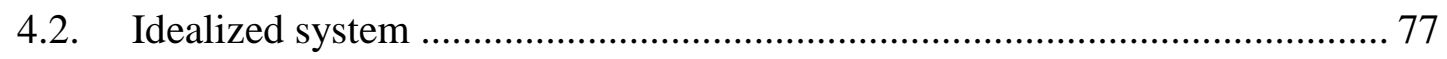

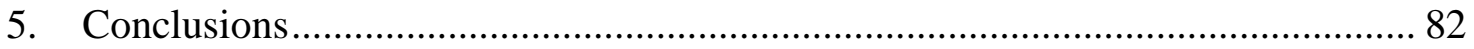

Chapter IV: Estimation of Historic Flows and Sediment Loads to San Francisco Bay ... 91

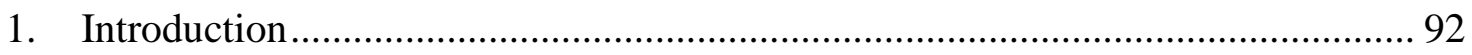

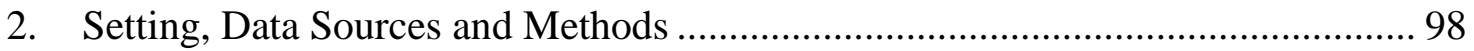

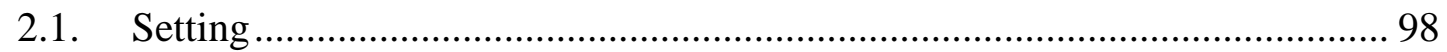

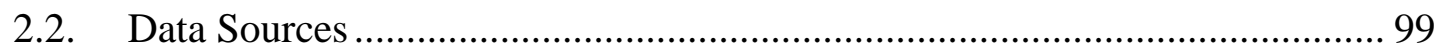

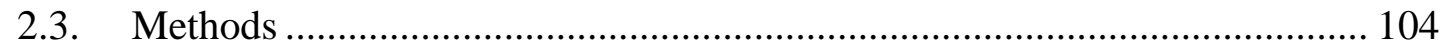

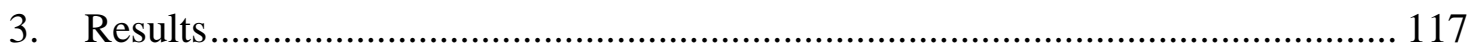

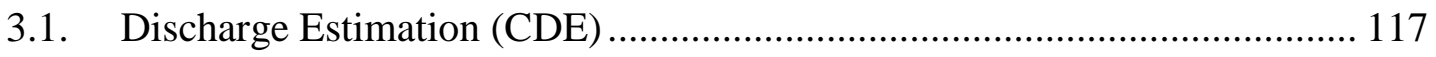

3.2. Sediment Transport Estimation ............................................................ 119

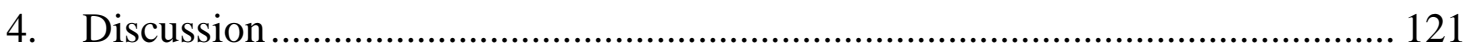

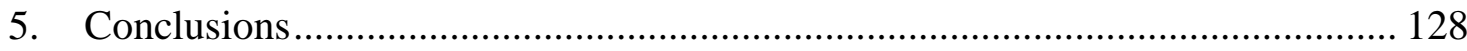

Chapter V: Concluding Remarks and Future Directions .......................................... 139

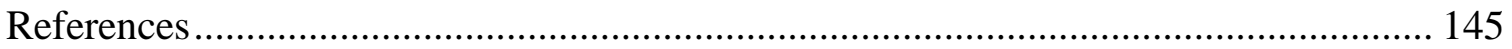




\section{List of Tables}

Table 2-1: TDE Hindcasts for different scenarios vs. observed ................................... 47

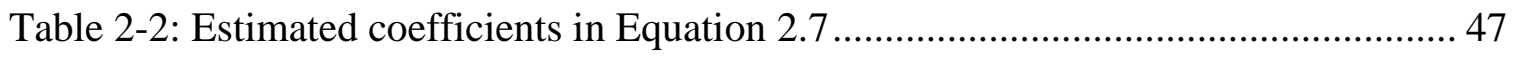

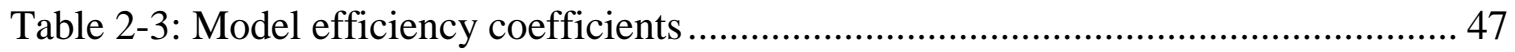

Table 3-1: Nondimensional master variables used in modeling, and their ranges ........... 84

Table 3-2: Tidal constituent properties at the ocean boundary ..................................... 84

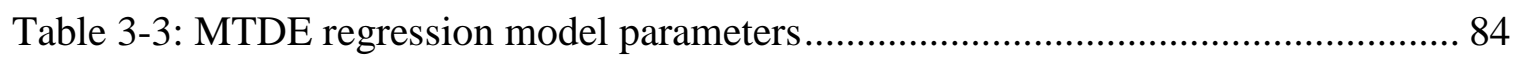

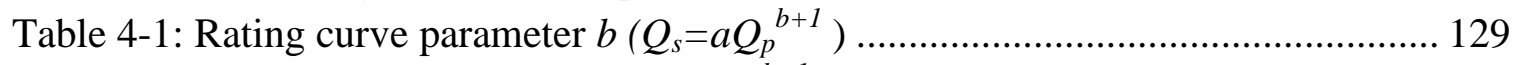

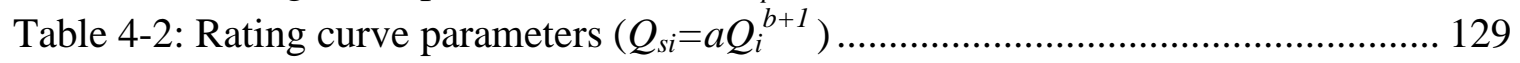

Table 4-3: Surface area and along channel variation of MLLW in the modern SF Bay 129 


\section{List of Figures}

Page number

Figure 1-1: Modification of progressive tidal wave by nonlinearities 10

Figure 1-2: An overview of the structure of this dissertation 11

Figure 2-1: Example of the interaction of tides with river flow 48

Figure 2-2: San Francisco Bay delta watershed boundaries and tributaries $\quad 49$

Figure 2-3: $\left|A D_{M_{2}}\right|$ with and without piecewise detrending 50

Figure 2-4: Nonlinear regression; (a) $\mathrm{M}_{4} / \mathrm{M}_{2}{ }^{2}$ versus NDOI, (b) $\mathrm{M}_{2}$ admit. versus NDOI

Figure 2-5: a) Distribution of coefficients $\alpha, \beta$ and $\gamma$ in (7); b) estimated NDOI for high-flow periods and $95 \%$ confidence interval limits vs. $\left|A D_{M_{2}}\right|$

Figure 2-6: Root mean square error (RMSE) during low flow periods $\quad 52$

Figure 2-7: Comparison of estimated flows with observations 53

Figure 2-8: Red Bluff flow vs. bin-averaged NDOI for the period 1930-1944 and TDE estimates for the period of 1891-1944 53

Figure 2-9: Annual averaged TDE flow estimates vs. annual averaged Eight-River flow index

Figure 2-10: Annual precipitation at San Francisco vs. hindcast annual average TDE for $1858-2010$

Figure 2-11: TDE hindcasts of annual hydrographs, 1858-2010

54

Figure 2-12: a) TDE hindcasts of flow by year-day averaged over 40yrs for 1858-1898 and 1968-2008, b) TDE hindcasts of $97.5 \%$ flow exceedance by year day, for the same periods

55

Figure 3-1: Map of the study area; Panel(a): The watershed boundaries for Fraser river and Columbia River, and location of panels (b) and (c); Panel (b): Fraser river lower estuary; Panel (c): Columbia river lower estuary

Figure 3-2: (a) Idealized bathymetry and (b) the plan view of the grid 
Figure 3-3: Panel (a) measured river flow at the upstream boundary under different scenarios of gradually varying high flow event (e.g. "slow" freshet and "fast" floods); Panel (b) measured water-level at the ocean boundary 86

Figure 3-4: Spectral analysis results for Fraser River and Columbia River $\quad 86$

$\begin{array}{ll}\text { Figure 3-5: Prototype function in CWT } & 87\end{array}$

Figure 3-6: Regression analysis results, Fraser $\quad 87$

Figure 3-7: Regression analysis results, Columbia River $\quad 87$

Figure 3-8: Fraser River validation $\quad 88$

Figure 3-9: Columbia River validation $\quad 88$

Figure 3-10: a) conceptual along-channel variation of tidal amplitude; b) variation of semidiurnal tidal amplitude (e.g. $\mathrm{D}_{2}$ amplitude) along channel $\quad 89$

Figure 3-11: Idealized numerical modeling results 89

Figure 3-12: Along-channel variation in stokes drift flow compensation; (a) during a low flow event, and (b) during a high flow event 90

Figure 4-1: San Francisco Bay study area and the eight rivers used for the Eight-RiverIndex drain the Central Valley through SF Bay to the Pacific Ocean 130

Figure 4-2: (a): daily observed Sacramento water level (WL) variation, 1849 - 1949. (b): variation of annual minimum WL with time. (c): WL range adjustment scale. (d): Adjusted WL for the effects of sedimentation and/or leveeing, with reference to 1930's

Figure 4-3: (a): Calibrated Discharge-WL rating curve at Sacramento, CA during the peak of hydraulic mining activities (solid line) vs dredged channel fifty-years later (dashdot line). (b): WL-NDOI rating curve calibrated to daily data over 1930 - $1944 \quad 131$

Figure 4-4: Original TDE (solid line) and adjusted temporally downscaled TDE (dotted line) vs NDOI estimate (circles)

132

Figure 4-5: The relationship between mean and standard deviation within an 18-day calculating window

Figure 4-6: Sediment transport rating curve; bin-averaged NDOI vs sediment load from Sacramento and San Joaquin rivers

133 
Figure 4-7: Estimated yearly maximum discharge (Panel a), rating curve parameters (Panel b) and sediment load (Panel c) to SF Bay (1849 - 2011)

Figure 4-8: (a): checks the applicability of SDE; (b) compares daily SDE for WY 1945 1946 to NDOI to validate the model

Figure 4-9: Validation of CDE via comparison to four hydrologic measures

Figure 4-10: Monthly-averaged CDE vs monthly mean discharge (aka Six-River index) from the Central Valley and adjusted downscaled TDE

Figure 4-11: Estimated annual load vs annual SSC load observed at Sacramento, CA $(1956-2011)$

Figure 4-12: (a): CDE; (b): daily sediment transport to SF Bay

Figure 4-13: comparison of our cumulative sediment load estimate (aka reality scenario) with the previous studies and load under the assumption that rating curve parameters remain the same as pre-Gold rush values

Figure 4-14: Contribution of high flow days in total sediment load

Figure 4-15: Panel (a): CDE by year-day, averaged over 1849 - 1945, and 1946 - 2011; Panel (b): Sediment load estimates by year-day, averaged over the same periods 138 


\section{Chapter I: Introduction}

\section{Definition of an estuary}

Estuaries can be defined in a variety of ways depending on scientific discipline and study purpose. In general, they are locations where fresh river water and saline sea water meet and interact [Dyer, 1973]. A more widely accepted classic definition defines estuaries as semi-enclosed coastal bodies of water, with free communication to the ocean, and within which ocean water is measurably diluted by freshwater derived from land [Cameron and Pitchard, 1963]. Other studies have considered estuaries to extend to the the head of the tide (e.g., Sherwood et al. [1990]), which may extend hundreds of kilometers beyond salinity intrusion and encompass most of the length of the riverestuary system. None of these definitions are entirely adequate for the large riverestuaries considered here - a distinction between the estuary proper and the tidal-river portion of the system is needed. Neither the upper limits of salinity intrusion nor the most landward point of current reversal are useful boundaries, because both are too variable. Jay et al. [2014] have proposed that the tidal river extends landward from the point where low-waters are lower on neap tides than on spring tides. More technically, this is the point landward of which tidal monthly variations in river stage (related to tidal-fluvial frictional interactions) are larger than tidal monthly variations in tidal amplitude. By this definition, the flow and sediment transport estimates derived herein apply to the tidalriver, though they may be made using one or more tide gauges in the saline part of the system. 
Estuaries are biologically diverse, and habitat for human beings and a variety of wildlife and species; thus estuaries are vulnerable to alteration of river flow, degradation of water quality, and availability of tidal fluvial habitats. They are also important ecosystems, as 22 of 32 largest cities in the world are located on river estuaries [Ross, 1995]. For socio-economic reasons, the effects of natural processes (e.g. climate variability) and human activities (e.g. navigational development, land reclamation, and water resources management) on the dynamics of such systems is a pressing issue.

Estuaries can be classified based on their geomorphology, water balance, stratification, and hydrodynamic characteristics. Pritchard [1952] classifies estuaries according to their geomorphology as coastal plain, fjord, bar-built, and tectonics. In term of water balance, in a positive estuary, the freshwater input (e.g. precipitation, and river flow) is greater than freshwater losses (e.g. evaporation, diversion, and infiltration), while in a negative one losses are dominant [Valle-Levinson, 2010]. The gravitational circulation induced by freshwater input is a primary component that describes the hydrodynamics of the system. Accordingly, based on estuarine stratification that is determined by the relative strength of buoyancy forcing from river discharge and mixing from tidal forcing, estuaries can be classified as salt wedge, strongly stratified, weakly stratified, or vertically mixed [Pritchard, 1955; Cameron and Pritchard, 1963].

Hansen and Rattray [1966] classified estuaries according to their hydrodynamic characteristics using two non-dimensional variables, stratification $\left(\partial S / S_{o}\right)$, and circulation $\left(U_{s} / U_{f}\right)$; where $\partial S$ and $S_{o}$ denote the vertical salinity gradient and cross- 
sectionally averaged salinity, respectively, and $U_{s} / U_{f}$ represents the ratio of nearsurface velocity to cross-sectionally averaged velocity. Note that all these variables are tidally-averaged. Their study describes the nature of salt transport in estuaries; however, not all the significant differences in the vertical distribution of properties can be described via these two non-dimensional parameters. Their results suggest that in highly stratified estuaries (e.g. $\partial S / S_{o}>>1$ ) mixing is weak, diffusive salt fraction is near zero and the advective component is dominant in salt transport. By contrast, during low flow periods when the circulation parameter is low (e.g. $U_{s} / U_{f}<2$ ) diffusive salt flux is dominant, regardless of stratification. Thus, according to their classification, four types of estuaries are present: Type 1, in which the net flows show no vertical structure; Type 2: in which net flows reverse with depth; Type 3: with strong gravitational circulation; and Type 4: salt wedge estuaries.

Jay et al. [1999] revised estuarine classification methods that use nondimensional hydrodynamic parameters, and geomorphology to describe a broader range of features and processes relevant to estuarine ecosystems. Their study suggested some relationships that help us estimate the residence time and particle trapping efficiency from bathymetric data and a few measurements. They also proposed a geomorphic classification schema with a hierarchical structure that identifies the major sediment transport mechanisms for a variety of estuarine types, identifies the types of reaches, and allows determination of transport capacity versus supply limitation separately for coarse and fine sediments. Their study provided a connection to hydrodynamic approaches via nondimensional parameters 
associated with each of six major types of estuarine forcing (i.e. river flow, tidal flow, density gradients, wind waves, atmospheric forcing, and sea ice cover).

\section{Motivation for this study}

The freshwater discharge to the oceans is an important component of the global water balance, and its quantification is necessary for climate analyses and efficient water resources management. Globally, changes in discharge affect chemical/fate/sediment input to the ocean, and on a smaller scale, accurate river discharge measurements are required to assess coastal inundation and plan navigation projects, as well as for analyses of coastal upwelling, beach sediment supply, habitat access and restoration, and salinity intrusion.

Sediment supplied to estuaries and the coastal zone impacts primary production, recreational and commercial fishing, nutrient supply, habitat restoration, human health, transport of pollutants, geomorphic evolution, and navigation. Climate change and watershed management practices modulate runoff and, therefore, the timing and magnitude of sediment delivery to estuaries. Processes such as tidal currents, the springneap cycle, coastal upwelling, wind waves, watershed inflow, and climatic variability cause suspended sediment concentration (SSC) to vary in time and space within estuaries. These processes act on multiple time scales, from seconds to years, and have diverse effects on SSC [Schoellhamer, 2002].

The lower reaches of a tidal river are, however, difficult locations in which to determine net freshwater discharge and sediment transport for methodological reasons. 
The difficulties include the reversing tidal flow, the compensation flow for the tidal Stokes drift, spring-neap water storage effects, lateral circulation, and the presence in some systems of multiple distributaries or separate ebb/flood channels. While recent studies have introduced methods to calculate discharge in tidal rivers far from the mouth, it remains difficult to estimate net discharge or transport near the mouth of an estuary with conventional technology [Jay et al., 1997]. Due to these difficulties inherent in measuring freshwater discharge at the mouth of the estuary discharge gauging stations are typically located above the head of the tide, where downstream inputs and losses are not included.

The need for more accurate estimates of freshwater and sediment supply to estuaries motivates this study. The proposed method moves the nexus of measurement away from the complexities of the delta without requiring flux measurements at the ocean entrance, integrates processes over the watershed, and extends our knowledge about the hydrologic characteristics of the estuaries using historic observations made along the channel.

\section{Background}

Previous studies have desribed the along-channel propagation of a long wave in an idealized estuary using cross-sectionally integrated equations for conservation of mass and along-channel momentum:

$$
\hat{b} \frac{\partial \hat{\zeta}}{\partial \hat{t}}+\frac{\partial \hat{Q}}{\partial \hat{x}}=0
$$




$$
\frac{\partial \hat{Q}}{\partial \hat{t}}+\frac{\partial}{\partial \hat{x}}\left(\frac{\hat{Q}^{2}}{\hat{A}}\right)+g \hat{A} \frac{\partial \hat{\zeta}}{\partial \hat{x}}+\beta \hat{b} \hat{T}=0
$$

where $x$ denotes longitudinal axis (positive landward), $Q$ is cross-sectionally integrated transport (that is decomposed to river flow $Q_{R}$, and tidal transport, $Q_{T}$ as $Q=Q_{R}+Q_{T}$ ), $A$ is channel cross-section, $g$ is acceleration due to gravity, $\xi$ is surface water variation, $\beta$ denotes the ratio between the momentum conveying width and the total width, and $T$ is the bed stress divided by water density. A circumflex indicates a dimensional variable. To obtain the equations above the following assumptions are made: i) the estuary is shallow, uniform in depth and narrow such that lateral variability is negligible (e.g. external Kelvin number $<<1$ ), ii) the tide consists only of a landward propagating wave with no reflected wave, iii) the freshwater only enters into the system at the upstream boundary, and iv) the only external forcing factors are ocean tides and river flow.

Equation (1.1) shows that along-channel variation in flow is balanced with temporal variation in water level, and equation (1.2) indicates that local acceleration ( $\partial \hat{Q} / \partial \hat{t})$ is balanced with convective acceleration $\left(\partial / \partial \hat{x}\left(\hat{Q}^{2} / \hat{A}\right)\right)$, water surface slope ( $g \hat{A} \partial \hat{\zeta} / \partial \hat{x})$, and friction $(\beta \hat{b} \hat{T})$ [Kukulka and Jay, 2003].

In estuaries and shallow water, non-linear terms in the long-wave equation can significantly modify wave shape, propagation and amplitude (Figure 1-1), adding many "shallow water" or "overtide" constituents at multiples or sums of the basic astronomical tidal frequencies [Doodson, 1957; LeBlond, 1978]. Figure 1-1 shows how nonlinearities in the Columbia River estuary modify the tidal wave propagating landward. Upstream 
gauges display lower energy content (i.e. smaller amplitude) and more asymmetry (i.e. higher energy content in over-tide frequencies). The spatial decay in tide amplitude shown in Figure 1-1 is a strong function of river flow, as I show in Chapter 3, due to nonlinear frictional affects. The most important nonlinearity in tidal rivers is quadratic bed stress, $\tau_{B}=\rho T=\rho C_{D}|U| U$, which alters wave amplitude and phase and exchanges energy between frequencies [Parker, 1991] (Here $\rho$ is water density; $U$ is dimensional total velocity, the sum of river flow plus tidal flow; and $C_{D}$ is the drag coefficient). Tidal theory indicates that tides and river discharge interact through this quadratic bed friction, which diminishes and distorts the tidal wave as discharge increases. This motivates the expression of $\tau_{B}$ using a Tschebyshev expansion [Dronkers, 1964]:

$$
\frac{\tau_{B}}{\rho}=C_{D}|U| U \approx C_{D} U_{0}^{2}\left[a_{1}\left(U_{T}+U_{R}\right)+a_{2}\left(U_{T}+U_{R}\right)^{2}+a_{3}\left(U_{T}+U_{R}\right)^{3}\right]
$$

where: $a_{i}$ are coefficients that depend on the ratio of river flow to total flow, $U_{0}$ is a velocity scale, $U_{\mathrm{R}}(<0$; i.e., flowing seaward) is non-dimensional river flow (sum of all flows at sub-tidal frequencies), and $U_{T}$ is non-dimensional total tidal velocity (sum of flow for all tidal frequencies); all variables are sectionally averaged. Kukulka and Jay [2003] and others have shown that an increase in discharge amplitude $\left|U_{\mathrm{R}}\right|$ increases $\tau_{B}$ and damps the tide.

\section{Aim and scope of this study}

Important unanswered questions are: i) How do tidal properties vary with flow and friction? ii) How can these variations be used as an estimator for river discharge 
and sediment transport?, and iii) How do climate change and human activities affect the flow and sediment regime? I intend to answer these questions through this study.

I first demonstrate the feasibility and utility of a tidal discharge estimate (TDE) based on analysis of tidal statistics from a single gauge, using known astronomical forcing (Chapter 2; published in 2013 [Moftakhar et al., 2013]). TDE is particularly useful for hindcasting discharge to the earliest days of tidal observations, a time that often precedes hydrologic measurement and when no more than one tide gauge was available in most harbors [Talke and Jay, 2013]. The physical basis of the TDE method is that nonlinear bed friction couples tides and river discharge (Figure 2-1) in a manner that can be modeled analytically [c.f. Godin 1999; Jay, 1991]. If discharge and astronomical (or coastal) tidal forcing are known, the tidal response may be predicted by a forward model [Jay and Flinchem, 1997; Kukulka and Jay, 2003a,b]. Conversely, if observed tides and the astronomical or coastal forcing are known, discharge may be estimated via an inverse model. To test and demonstrate the TDE method, an inflow record for San Francisco (SF) Bay is constructed for the $1858-2010$ period. One advantage of using TDE in SF Bay is that it moves the nexus of measurement away from the complexities of the Bay's landward delta, without requiring flux measurements at the ocean entrance. Because tide gauges are needed for safe navigation and tidal prediction, they were often installed well before the onset of systematic river gauging [Talke \& Jay, 2013], providing an opportunity to extend flow records back in time using TDE. The theoretical underpinning of this method assumes that the estuary is convergent and there is at least a rough balance between tides and discharge. Nonetheless, TDE can work well in more complex systems 
such as SF Bay. Due to limitations in tidal harmonic analysis, the TDE method resolves an $~ 18$ day averaged discharge, and cannot estimate shorter-term river flow variations such as rain-on-snow floods that may occur on time scales of <10days [Jay and Naik, 2011].

In Chapter 3 (to be submitted to Journal of Geophysical Research; Oceans), I demonstrate the feasibility of multiple-gauge tidal discharge estimate (MTDE) based on analysis of tidal constituents, using tidal observations made on multiple locations along a tidal reach. I first develop and calibrate MTDE to two real estuaries, to show the applicability of the model in prototype systems. Then, I develop an idealized twodimensional (2D), depth-averaged numerical model (Delft-3D Flow [Booij et al. 1999]) with a convergent cross-sectional profile. I next implement a sensitivity study in which the response of tides to a long (40 day) and short (10 day) hydrological event is simulated. The model is re-run using a range of non-dimensional numbers that characterize the relative effects of friction, river flow, tides, and convergence lengthscale. Finally, the effect of different non-dimensional forcing on the applicability of the proposed MTDE model is assessed. MTDE is shown to be more accurate over a broad range of estuarine types.

In Chapter 4 (manuscript in preparation, to be submitted to the Journal of Hydrology), I propose a method to hindcast flow and sediment input with higher resolution in time, to provide a better understanding of the changes in freshwater and sediment inputs to SF Bay over the last $\sim 160$ years. In this study I have recovered and digitized $\sim 80$ years of Sacramento River daily water level data between 1849 and 1946, 
from which daily river discharge is estimated after adjusting for changes to the river channel. This discharge measure, which we call the Sacramento Discharge Estimates (SDE), is combined with the Net Delta Outflow Index (NDOI) estimates (1930-2011) and TDE (1858-2011 described in Chapter 2; downscaled to daily) to provide a more accurate version of SF Bay historic inflows from 1849-2011. This Composite Discharge Estimate (CDE) is then used, with integral constraints from observed SF Bay bathymetric change, to provide estimates of daily sediment discharge. These discharge estimates describe how the timing and magnitude of sediment import into SF Bay has changed over time. Figure 1-2 provides an overview to the content and structure of this dissertation.

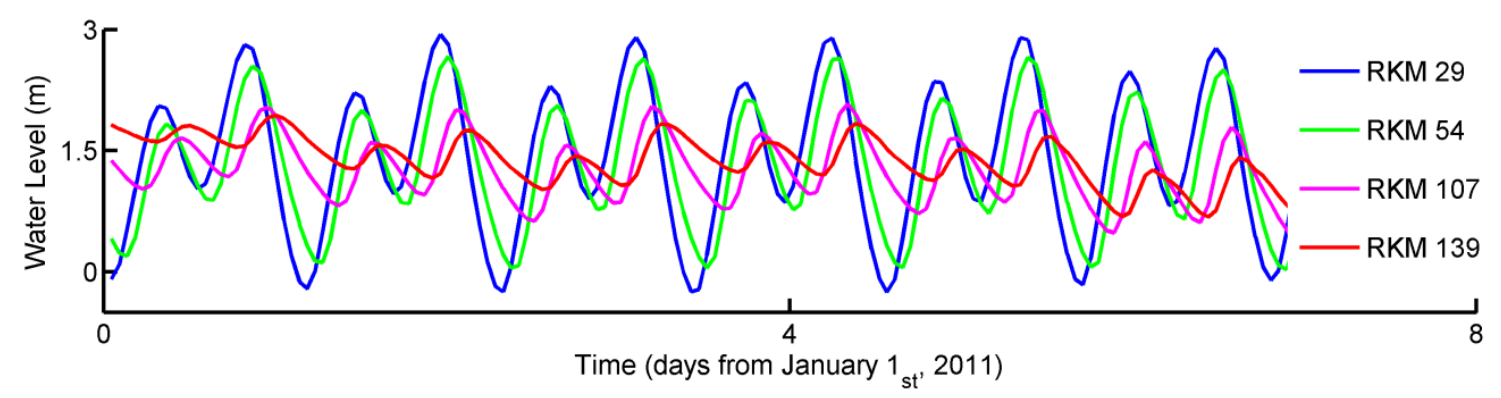

Figure 1-1 Modification of progressive tidal wave by nonlinearities in Columbia River estuary 


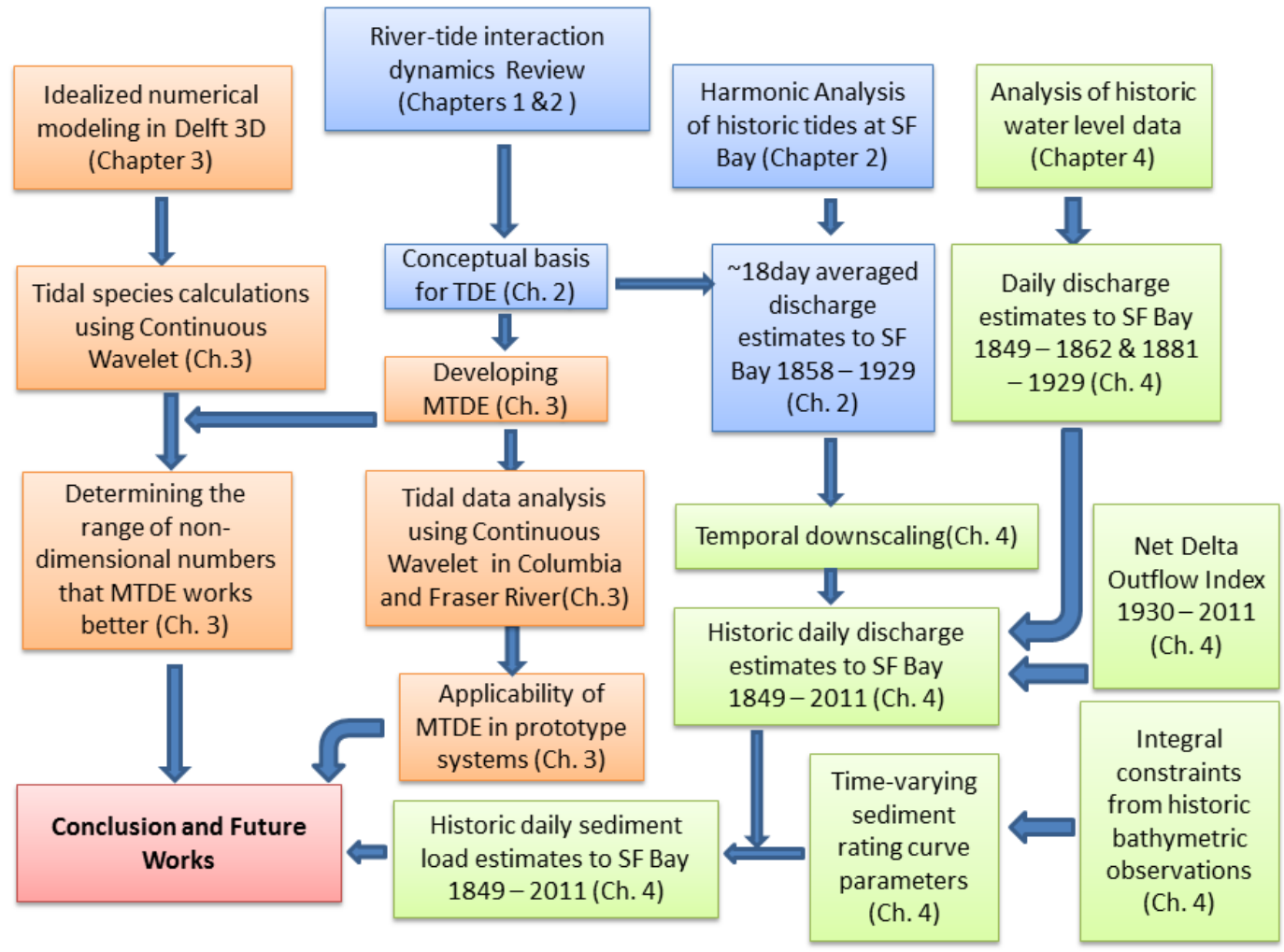

Figure 1-2 An overview of the structure of this dissertation 


\section{Chapter II: A Novel Approach to Flow Estimation in Tidal Rivers ${ }^{1}$}

Reliable estimation of river discharge to the ocean from large tidal rivers is vital for water resources management and climate analyses. Due to the difficulties inherent in measuring tidal-river discharge, flow records are often limited in length and/or quality and tidal records often predate discharge records. Tidal theory indicates that tides and river discharge interact through quadratic bed friction, which diminishes and distorts the tidal wave as discharge increases. We use this phenomenon to develop a method of estimating river discharge for time periods with tidal data but no flow record. Employing sequential 32-day harmonic analyses of tidal properties, we calibrate San Francisco (SF) tide data to the Sacramento River delta outflow index from 1930-1990, and use the resulting relationship to hindcast river flow from 1858-1929. The $\mathrm{M}_{2}$ admittance (a ratio of the observed $\mathrm{M}_{2}$ tidal constituent to its astronomical forcing) best reproduces high-flows, while low-flow periods are better represented by amplitude ratios based on higher harmonics (e.g., $M_{4} / M_{2}^{2}$ ). Results show that the annual inflow to SF Bay is now $30 \%$ less than before 1900 and confirm that the flood of January 1862 was the largest since 1858.

\section{Introduction}

Accurate freshwater discharge estimates for rivers that interact with ocean tide are needed for many purposes, e.g., flood management and reservoir operations [Madsen and

\footnotetext{
${ }^{1}$ Moftakhari, H. R., D. A. Jay, S. A. Talke, T. Kukulka, and P. D. Bromirski (2013a), A Novel approach to flow estimation in tidal rivers, Water Resour. Res., 49, doi:10.1002/wrcr.20363.
} 
Skotner, 2005; Kisi and Cimen, 2011; Wang et al., 2009]. The discharge of large tidal rivers to the ocean is an important component of the global water balance [Oki et al., 1995], and changes in discharge affect sediment input to the ocean [Syvitski et al., 2003]. Both are important for climate analyses [Laize and Hannah, 2010] and water resources management [Loitzenbauer and Mendes, 2012]. On a smaller scale, accurate river discharge measurements are required to assess coastal inundation and plan navigation projects [Peng et al., 2004, Prandle, 2000], as well as for analyses of coastal upwelling [Gan et al., 2009; Palma et al., 2006], beach sediment supply [Flick and Ewing, 2009; Inman and Jenkins, 1999], estuarine sediment supply and transport [Jay et al., 1990; Prandle, 2004; Schoellhamer 2007; Ganju et al. 2008], habitat access and restoration [Kimmerer, 2002; Kukulka and Jay, 2003a,b; Cloern et al., 1983], salinity intrusion [Prandle, 1985; Uncles and Peterson, 1996; Cloern et al., 1989; Monismith et al., 2002], and impacts of future climate change [Kukulka and Jay, 2003a,b].

The lower reach of a tidal river is, however, a difficult location to determine net flow for methodological reasons. Difficulties include the reversing tidal flow, the compensation flow for the tidal Stokes drift, spring-neap water storage effects, lateral circulation, and the presence in some systems of multiple distributaries or separate ebb/flood channels. Recent studies have introduced methods to calculate discharge in tidal rivers. While these studies were suited for cases far from the mouth [Hoitink et al., 2009; Sassi et al., 2011a; Kawanisi et al., 2010], it remains very difficult to determine a statistically significant discharge near the mouth of an estuary [Jay et al., 1997]. Thus, discharge gauging stations are typically located above the head of the tide, often hundreds 
of kilometers inland. At those locations, infiltration and inflows from coastal tributaries in areas of high precipitation and downstream losses from diversion and evaporation are not included in the measured flow.

The purpose of this paper is to demonstrate the feasibility and utility of a tidal discharge estimate (TDE) based on analysis of tidal statistics, using known astronomical forcing. The physical basis of the TDE is that nonlinear bed friction couples tides and river discharge (Figure 2-1) in a manner that can be modeled analytically [c.f. Godin 1999; Jay, 1991]. If discharge and astronomical (or coastal) tidal forcing are known, the tidal response may be predicted by a forward model [Jay and Flinchem, 1997; Kukulka and Jay, 2003a,b]. Conversely, if observed tides and the astronomical or coastal forcing are known, discharge may be estimated via an inverse model. While TDE has been outlined [Jay and Kukulka, 2003] and tested in a preliminary way [Jay et al., 2005], this contribution represents the first detailed test of the method, including a quantification of uncertainties. To test and demonstrate the TDE, an inflow record for San Francisco (SF) Bay is constructed for the $1858-2010$ period.

The SF Bay delta, through which most freshwater reaches the bay, is a good example of the difficulties inherent in flow estimates for tidal rivers. Uncertainty in the timing and magnitude of freshwater inflow into the bay exists because the delta is a network of channels with numerous connections, diversions, inputs and outputs [Kimmerer, 2002]. Also, estimates of groundwater recharge and losses from diversion, evaporation and infiltration are included in the flow index used to estimate flows into the bay [http://www.water.ca.gov/dayflow/output/] and may not always be available or 
accurate. While for many purposes the estimation of discharge to the ocean is desired, conditions at the ocean boundary are not conducive to long-term flow measurements. Decades of experience in estuarine flux measurement has established that net, non-tidal fluxes of water usually cannot be measured in estuaries, because they are small relative to tidal fluxes [Jay et al., 1997]; however, subtidal estuarine exchange flow can be estimated using numerical methods [MacCready, 2011].

One advantage of using TDE in SF Bay is that it moves the nexus of measurement away from the complexities of the delta, without requiring flux measurements at the ocean entrance. Because tide gauges are needed for safe navigation and tidal prediction, they were often installed well before the onset of systematic river gauging [Talke \& Jay, 2013], providing an opportunity to extend flow records back in time using TDE. Continuous tide measurements began in 1853 in the Eastern Pacific and in 1858 in the Western Pacific [Talke \& Jay, 2013], and a tide gauge has operated continuously in San Francisco since 1854 [Smith, 2002]. The hourly record has been digitized and is described in Bromirski et al. [2003]. While some stage measurements exist for the Sacramento River from as early as 1850 [Logan, 1864], subsequent levee construction and sedimentation due to hydraulic mining make early measurements difficult to interpret [Gilbert, 1917]. As a consequence, commonly accepted estimates of Sacramento Delta river-flow begin in 1930, with the California Department of Water Resources' Net Delta Outflow Index or NDOI [www.water.ca.gov/dayflow/output/]. Earlier flow measurements are available (e.g., daily flow at Red Bluff from 1891), but are far from the Golden Gate and do not adequately represent basin-scale processes. To avoid these 
problems, earlier studies have used precipitation data to estimate pre-1930 hydrographs of flow from the watershed to the estuary (e.g. Ganju et al. [2008]). However, such methods cannot easily take into account natural and anthropogenic changes to the system, including changing snow levels and snow-melt patterns, the channelization of river flow and the subsequent reduction in flood-plain area, and the effects of reservoir management. We argue that for estimating net flow from the estuary to the ocean, such problems can be reduced or eliminated by application of TDE to historic tide data at a location (the Golden Gate) which is much less altered than inland locations, and which integrates processes over a basin scale. TDE may therefore capture changes in reservoir management, climate cycles and long-term hydrological trends that cannot easily be ascertained from other data sources.

\section{Data and Methods}

\section{2-1- Setting}

SF Bay consists of two distinct sub-estuaries. The northern reach, the SF Bay delta, is a partially-mixed estuary dominated by seasonally varying fresh water inflows, while the southern part is a tidal lagoon estuary and typically well-mixed [Cheng and Gartner, 1985; Chua and Fringer, 2011]. Freshwater inflow occurs primarily from the Sacramento and San Joaquin rivers (Figure 2-2), with annual average flows of 558 and $126 \mathrm{~m}^{3} \mathrm{~s}^{-1}$, respectively [http://wdr.water.usgs.gov/ ]. Flows in both systems have been reduced and altered considerably by diversion [Kimmerer, 2002]. The tides in SF Bay have a mixed diurnal-semidiurnal character. Analyses (below) of data from the SF tide 
gauge at the Presidio (Figure 2-2) show that the present amplitude of the major semidiurnal constituent $\mathrm{M}_{2}$ is $0.57 \mathrm{~m}$, while the largest diurnal $\mathrm{K}_{1}$ constituent has an amplitude of $0.37 \mathrm{~m}$. The $\mathrm{M}_{2}$ and $\mathrm{K}_{1}$ amplitudes in SF Bay have increased since 1854, with the change in $\mathrm{M}_{2}\left(0.4 \mathrm{mmyr}^{-1}\right.$ or $7 \%$ century $\left.^{-1}\right)$ being particularly prominent [Jay, 2009]. This factor must be taken into account in our analyses.

\section{2-2- Data Sources}

\section{2-2-1- Tide Data}

Hourly San Francisco, CA, water level data from the National Oceanic and Atmospheric Administration (NOAA; station ID: 9414290) were used to implement TDE in SF Bay. This station has the longest continuous tidal record in the United States, but has been located in at least seven places since its installation in 1854 [Smith, 2002]. It is now located on southern side of the bay entrance channel (the "Golden Gate"), at $37^{\circ}$ $48.4^{\prime} \mathrm{N}$ and $122^{\circ} 27.9^{\prime} \mathrm{W}$ (Figure 2-2). The gauge was first installed 640m east of Fort Point on June 30, 1854. In 1877, decay of the Fort Point wharf necessitated moving the gauge. It was relocated to Sausalito, $3.2 \mathrm{~km}$ to the north and further from the entrance, from 1877 to 1897 . In 1897 , the gauge was moved back across the Golden Gate to the Presidio, about $1.2 \mathrm{~km}$ east of Fort Point. In 1927, it was moved to its present location at the Fort Point Coast Guard wharf at Crissy Field [Smith, 2002], 1.55km east of Fort Point. Although the official NOAA history [Smith, 2002] does not indicate this, our examination of the marigrams that serve as the basis for the hourly record indicates that the gauge was moved at least once in 1862 and perhaps more than once, due to damage caused by the extraordinary storms of that winter. Due to subsidence, the gauge was also 
moved in April 1858 and again in July 1859 to new locations adjacent to the original Fort Point wharf (see also [Talke \& Jay, 2013]). Before April 1858, comparisons show that the self-recording gauge was erratic, with water level errors of up to $0.5 \mathrm{~m}$ relative to a fixed staff during some months [Talke \& Jay, 2013]. Combined with the subsidence issue, the data until early 1858 are considered unreliable and are not used here (see also [Bromirski et al., 2003]). Nonetheless, the overall gauge record is relatively complete, with only $\sim 7838$ hourly data missing in the 157 year length of record.

\section{2-2-2- Discharge and Precipitation Data}

In this study we use the Net Delta Outflow Index (NDOI), an output of the California Department of Water Resources DAYFLOW program (http://www.water.ca.gov/dayflow/), as a proxy for tidally average daily river inflow to San Francisco Bay from the Sacramento River delta. NDOI accounts for about $90 \%$ of the inflow to SF Bay; about $10 \%$ comes from local tributaries [Conomos and Peterson, 1977]. NDOI accounts for river inflows, precipitation, agricultural consumptive demand, and California Water Project exports. Sixty-one years of NDOI measurements (from 1930 to 1990 ) are used to calibrate our TDE model, and twenty years (1991 to 2010) are used to validate it. Because fewer stream gauge sites were in place before 1956, NDOI estimates for 1930-1955 are less certain than those for later periods; personal communication [David Schoellhamer, USGS, Sacramento]. Also, NDOI does not account for tidal monthly increases in storage during periods of larger tides, an effect that is likely to be largest during low flow periods. 
We also use the daily discharge measured at Red Bluff, CA (USGS 11377100) from 1891-present, to check the accuracy of the model. For comparison with tidal properties, which are harmonically analyzed over 32-day window (see section 2-3-1), the daily discharge data were sampled with a 32 day moving average, calculated at 7 day intervals. Data were weighted with a Kaiser filter [Kaiser, 1974] with a side lobe attenuation factor of 4.5 .

Our estimates of inflow to SF Bay are also compared to two measures of unimpaired flow to the bay. The Eight-River Index (ERI), published by The California Department of Water Resources (http://cdec.water.ca.gov/), combines the flows into the Sacramento and San Joaquin Rivers from major tributaries, including the Feather, Yuba, American, Stanislaus, Tuolomne, and Merced Rivers, after removing the effect of diversions, storage, export, and import. It is available as monthly totals for the wet half of the water year (December - May) back to 1906 [Ganju et al., 2008]. The ERI provides a valuable check to pre-1930 hindcasts. The post-1930 ERI is useful for investigating the effect of water resources management measures.

Finally, TDE hindcasts were compared to precipitation data from San Francisco (1850-present) provided by Golden Gate Weather Services (http://ggweather.com/sf/monthly. html).

\section{2-3- Methods}




\section{2-3-1- Conceptual Basis}

Observed tides are the result of astronomical forcing and propagation/damping in the ocean and coastal waters. At open-ocean locations, tides can be approximately described in terms of five primary astronomical constituents $\left(\mathrm{M}_{2}, \mathrm{~S}_{2}, \mathrm{~N}_{2}, \mathrm{~K}_{1}\right.$, and $\left.\mathrm{O}_{1}\right)$ and several hundred smaller ones [Parker, 2007]. In estuaries and shallow water, however, non-linear terms in the long-wave equations that describe tidal motion can significantly modify wave propagation and amplitude, adding many "shallow water" or "overtide" constituents at multiples or sums of the basic astronomical tidal frequencies [Doodson, 1957; LeBlond, 1978]. The most important nonlinearity in tidal rivers is quadratic bedstress, $\tau_{\mathrm{B}}=\rho C_{D}|U| U$, which alters wave amplitude and phase and exchanges energy between frequencies [Parker, 1991]. (Here $\rho$ is water density; $U$ is dimensional total velocity, the sum of river flow plus tidal flow; and $C_{D}$ is the drag coefficient.) If the fluvial velocity is a significant fraction of the tidal current amplitude, the absolute velocity in $\tau_{\mathrm{B}}$ is a non-linearity that complicates analytical manipulation - the flow reverses, but not for half of the tidal cycle. This motivates expression of $\tau_{\mathrm{B}}$ using a Tschebyshev expansion [Dronkers, 1964]:

$$
\frac{\tau_{B}}{\rho}=C_{D}|U| U \approx C_{D} U_{0}^{2}\left[a_{1}\left(U_{T}+U_{R}\right)+a_{2}\left(U_{T}+U_{R}\right)^{2}+a_{3}\left(U_{T}+U_{R}\right)^{3}\right]
$$

where: $a_{i}$ are coefficients that depend on ratio of river flow to total flow, $U_{0}$ is a velocity scale, $U_{\mathrm{R}}(<0$; i.e., flowing seaward) is non-dimensional river flow (sum of all flows at sub-tidal frequencies), and $U_{T}$ is non-dimensional total tidal velocity (sum of flow for all tidal frequencies); all variables are sectionally averaged. To determine how tidal 
properties will vary with flow, (2.1) must still be embedded in a one-dimensional analysis of the wave equation in such a way that the influence of changes in flow can be traced.

Kukulka and Jay (2003) carried out such an analysis, assuming strong bed friction; time-invariant, exponential channel geometry; a single source of river flow far upriver; and negligible influence from wind stress and baroclinic forcing. They then employed a perturbation method to obtain the lowest order wave equation [see Kukulka and Jay, 2003, for more details]. In the case of high-river flow $\left(\left|U_{R}\right| \approx\left|U_{T}\right|\right)$, and taking only the component at the frequency of $U_{T}, a_{1}$ and $a_{3}$ are $\sim 0$, as expected from the quadratic drag law [Kukulka and Jay, 2003a,b]. Thus, (2.1) reduces to:

$$
\frac{\tau_{B}}{\rho} \approx 2 C_{D} U_{0}^{2} a_{2} U_{T} U_{R}=-2 C_{D} U_{0}^{2} U_{T}\left|U_{R}\right| \quad a_{2} \approx 1
$$

As suggested by (2.2a) and Figure 2-1, an increase in discharge amplitude $\left|U_{\mathrm{R}}\right|$ increases $\tau_{\mathrm{B}}$ and damps the tide. Tidal phase is also modified, because the ratio of the acceleration and friction in the wave equation is altered [Godin, 1985, 1999; Jay and Flinchem, 1997; Kukulka and Jay, 2003a; Buschman, 2009]. This damping of river tides suggests that it can be used to estimate river flow via an inverse model, at least for high flows. (More generally, $C_{D}$ in (2.1) may also be modified, due to changes in salinity intrusion and/or bedform characteristics. This does not affect the applicability of TDE, as long as the product $C_{D}\left|U_{\mathrm{R}}\right|$ varies in a consistent manner with flow, though it may influence the parameterization used for TDE.) 
Damping of the tide as suggested by (2.1) is only one possible type of tidal-fluvial interaction. Nonlinear friction also distorts the tide as it propagates, and appears in the tidal record as nonlinear "overtides", or higher harmonics of combinations of primary constituents [Parker, 2007]. For example, self-interaction of $\mathrm{M}_{2}$, a quadratic nonlinearity that rises rapidly in importance as river flow increases, generates the overtide $\mathrm{M}_{4}$, with half the period of $\mathrm{M}_{2}$. This possibility can be seen by rephrasing (2.1) for low river flow:

$$
\frac{\tau_{B}}{\rho} \approx 2 C_{D} U_{0}^{2}\left[a_{1} U_{T}+a_{3}\left(U_{T}^{3}+3 U_{R} U_{T}^{2}\right)\right]
$$

where $a_{2} \sim 0$ for low flows [Kukulka and Jay, 2003a,b]. While the cubic term in (2.2b) contains a mix of tidal and overtide terms, the overtide term containing $U_{\mathrm{T}}{ }^{2}$ is proportional to $U_{\mathrm{R}}$. We conclude from these asymptotic forms that frictional damping of the tides is quantitatively related to river flow, but that multiple mechanisms are present. Thus, there may be more than one tidal statistic that can be used to infer flow from tidal properties.

The bottom stress parameterizations (2.1) and (2.2) reveal the interaction of tides with river flow and can be incorporated in a cross-sectionally averaged tidal propagation model. In such a model, tidal wave propagation is described by a complex wave number $q=k+i r$ that is the eigenvalue of the wave equation. Here, $k=2 \pi / \lambda>0$ ( $\lambda$ is wavelength), and $r<0$ is the damping modulus. Based on tidal theory [Jay, 1991], wave amplitude and $r$ can be approximated [Kukulka and Jay, 2003a] at any distance from the ocean $x$ : 


$$
\begin{gathered}
\frac{\left|T P_{X}\right|}{\left|T P_{r e f}\right|}=e^{-r x} \\
-r x \approx \log \left(\frac{\left|T P_{X}\right|}{\left|T P_{r e f}\right|}\right) \cong c_{0}^{\prime}+c_{1 a}^{\prime} U_{R}^{\frac{1}{2}}+c_{1 b}^{\prime} U_{R}^{\frac{3}{2}}+c_{2}^{\prime} \frac{U_{T}^{2}}{\sqrt{U_{R}}} \\
r \approx c_{0}+c_{1} U_{R}^{n}+c_{2} \frac{T_{R r e f}^{2}}{\sqrt{U_{R}}} \quad 0.5 \leq n \leq 1.5
\end{gathered}
$$

where: $T P_{\text {ref }}$ is a reference tidal property (amplitude or range) in the astronomical potential or at a coastal reference station removed from the influence of river flow, $T P_{X}$ is a tidal property at point $x, x$ is taken as constant (and absorbed into the $c_{i}$ ), and $T_{R r e f}$ is tidal range at the reference station. Parameters $c_{i}$ and $c_{i}{ }^{\prime}$ vary with $x$, channel shape and $U_{R} / U_{T}$, and (2.3c) is a pragmatic simplification that reduces the number of free parameters. The last term in $(2.3 \mathrm{c})$ represents a tidal-monthly modulation of tidal properties, the amplitude of which is dependent on the inverse square root of the river flow. Eq. (2.3c) with $n=1$ is the basis of the forward model used by Kukulka and Jay [2003a] and Jay et al. [2011] for hindcasts of tidal properties.

The relative importance of the terms in (2.3c) depends on the characteristics of the system. Preliminary analyses showed that in SF Bay, tidal range deviates $<20 \%$ from its monthly mean over a typical month, and these deviations are largely averaged out over the $31.7 \mathrm{~d}$ analysis period used here. The last term in $(2.3 \mathrm{c})$ is therefore much smaller than the second term, which can vary by several orders of magnitude over a year. Thus, the 
last term has been neglected in our TDE inverse model. A further simplification is achieved using a Taylor expansion of $\log \left(T P_{X} / T P_{r e f}\right)$, recognizing that $T P_{X} / T P_{r e f} \approx 1$ :

$$
\begin{gathered}
\log \left(\frac{T P_{X}}{T P_{r e f}}\right)=\log (1-\delta)=\delta+\ldots \approx \delta \\
\delta=\frac{T P_{r e f}-T P_{X}}{T P_{r e f}}<<1
\end{gathered}
$$

where higher terms are neglected.

Together (2.1) to (2.4) suggest a relationship between the monthly averages of a tidal property ratio $\left(T P_{R}=T P_{X} / T P_{r e f}\right)$ and $U_{R}$ of the form:

$$
T P_{R} \approx \alpha_{1}+\beta_{1} U_{R}^{n_{1}}
$$

where: $\alpha_{1}, \beta_{1}$ and $n_{1}$ are coefficients to be determined from data, and $0.5 \leq n_{1} \leq 1.5$. Assuming a constant (over a tidal cycle) cross-sectional area $A, U_{R}$ can be replaced by river discharge $\left(Q_{R} \cong A \times U_{R}\right)$ :

$$
T P_{R} \approx \alpha_{2}+\beta_{2} Q_{R}^{n_{1}}
$$

Eq. (2.6) is perhaps the simplest form of a forward model for determining tidal properties (averaged over a tidal month), given astronomical or coastal tidal forcing and river flow. To obtain $Q_{R}$ from known tidal properties, TDE inverts (2.6) to reach a bionomial form, while the fact that $n_{1}$ is $O(1)$ allows truncation of the power series to two terms: 


$$
Q_{R} \approx \alpha+\beta T P_{R}^{\gamma} \quad \text { where } \quad \frac{2}{3} \leq \gamma \leq 2
$$

\section{2-3-2- Tidal Estimates}

Application of TDE based on (2.7) requires that tidal properties be determined as a time series with a resolution of a few days to weeks. One way to do this is through use of overlapping, short harmonic analyses. A harmonic analysis (HA) provides a leastsquares fit description of the changing elevation of the sea surface at a point as a sum of a finite number of sine and cosine waves of known frequency; the amplitudes and phases are the parameters determined by a least-squares fit [Parker, 2007]. The tidal analysis program T_Tide [Pawlowicz et al. 2002] is used here, in a modified form that employs a robust least-squares solution to determine the tidal parameters [Leffler and Jay, 2009].

Defining an analysis window length is an important concern in analysis of nonstationary data. Short HA analysis windows $(<15 \mathrm{~d})$ cause mixing of information between tidal frequencies [Jay and Flinchem, 1999], whereas long tidal windows will average out flow variability. In this study, sequential $761 \mathrm{hr}(31.7 \mathrm{~d})$ harmonic analyses were carried out at $7 \mathrm{~d}$ intervals over the length of record, with 59 constituents included in the analysis. Only data that were $>80 \%$ complete over a $761 \mathrm{hr}$ increment were analyzed.

A $31.7 \mathrm{~d}$ analysis window is long relative to river flow fluctuations associated with winter floods, and use of a normal 31.7d HA analysis window (which is effectively a boxcar filter) causes considerable averaging of flow-affected tidal properties and may, like any short harmonic analysis, report tidal properties that reflect some degree of aliasing [Jay and Flinchem, 1999]. To minimize these problems, the HA was 
implemented with a Kaiser filter window [Kaiser, 1974] with a side lobe attenuation factor of 4.5, rather than the boxcar window that is standard in $T_{-}$Tide. The Kaiser filter allows for an effective tidal analysis and better resolution of intermittent flood events, while avoiding aliasing [Jay and Flinchem, 1999]. More than $80 \%$ of the data-set energy is within the center 18 days; we therefore assign an effective resolution of 18 days to our analysis

Kukulka and Jay [2003a,b] implement (2.3c) to determine tidal properties (amplitudes, phases and daily tidal ranges) between a station of interest and a coastal reference station. Because there was only one tide station in SF Bay until recent decades, we use the astronomical tidal potential $V$ (defined in the next paragraph) instead of a coastal reference station. More specifically, we apply (2.7) with $T P_{R}=\mathrm{M}_{2}$ admittance ( $A D_{M_{2}}$, the ratio of observed to potential $\mathrm{M}_{2}$ ) to hindcast moderate and high-flow conditions, as suggested by (2.2a). Low-flow conditions are hindcast using a ratio involving the $\mathrm{M}_{4}$ overtide in (2.7), as suggested by (2.2b).

The tidal potential $V\left(\right.$ in $\mathrm{m}^{2} \mathrm{~s}^{-2}$ ) describes the effect of gravitational acceleration vector $(A)$ from the sun and moon in the form of a gradient [Pawlowicz, 2002]:

$$
A=-\nabla V
$$

The ratio $V / g$ has units of $\mathrm{m}$ ( $\mathrm{g}$ is gravitational acceleration in $\mathrm{ms}^{-2}$ ) and represents the tide that would occur if the ocean were in a frictionless equilibrium with gravitational forcing. Hourly values of $V$ are calculated using a program provided (Dr. R. Ray, 
personal communication) by the National Astronautics and Space Administration (NASA) that is based on Cartwright and Eden [1973]. In the Cartwright and Eden approach, $V$ contains $\sim 480$ frequencies in diurnal, semidiurnal, terdiurnal (thrice daily) and low-frequency bands. There is no significant astronomical forcing in the quarterdiurnal band ( $4 \times$ daily). Thus, the observed $\mathrm{M}_{4}$ tide arises entirely from nonlinear processes.

T_Tide was used to calculate amplitudes, phases and error estimates at 7 days intervals for tidal constituents (here $\mathrm{M}_{2}$ and $\mathrm{M}_{4}$ ) for both the observed tidal records and for the hourly time series of $V . \mathrm{M}_{2}$ admittance is expressed as:

$$
A D_{M_{2}}=\frac{A_{M_{2}} e^{i \theta_{M_{2}}}}{\hat{A} e^{i \hat{\theta}}}
$$

where: $A_{M_{2}}$ and $\theta_{M_{2}}$ are, respectively the amplitude and phase of observed $\mathrm{M}_{2}$, and $\hat{A}$ and $\hat{\theta}$ are with the same parameters for potential $V$. The $\mathrm{M}_{2}$ admittance amplitude ( $\left|A D_{M_{2}}\right|$, will vary with flow, because the observed tide is influenced by flow.

$\mathrm{M}_{4}$ arises from $\mathrm{M}_{2}$ via a quadratic nonlinearity and has no astronomical component. Thus, $\mathrm{M}_{4}$ admittance cannot be defined in the same way as $\left|A D_{M_{2}}\right|$. We use, therefore, $\mathrm{M}_{2}$ observations as the reference wave for $\mathrm{M}_{4}$ and calculate an amplitude ratio and a phase difference as follows:

$$
\frac{M_{4}}{M_{2}^{2}}=\frac{A_{M_{4}} e^{i \theta_{M_{4}}}}{A_{M_{2}}^{2} e^{2 i \theta_{M_{2}}}} \Rightarrow A_{\frac{M_{4}}{M_{2}^{2}}}=\frac{A_{M_{4}}}{A_{M_{2}}^{2}} \quad, \quad \theta_{\frac{M_{4}}{M_{2}^{2}}}=\theta_{M_{4}}-2 \theta_{M_{2}}
$$




\section{2-3-3- Detrending}

Harmonic analyses indicate that the SF admittance ratio $\left|A D_{M_{2}}\right|$ increased from roughly 1858 to 1987 , but has slightly decreased thereafter (Figure 2-3). Increasing tidal amplitudes are seen at most Northeast Pacific stations, likely due to a combination of large-scale and coastal oceanic processes, and harbor development [Jay, 2009; Woodworth, 2010]. Because TDE requires estimating flow-induced anomalies in tidal properties, trends in tidal constituents unrelated to river flow could significantly bias flow hindcasts, and long-term alterations in river flow due to multiple and increasing flow diversions over time (Nichols et al., 1986) could produce a secular (century scale) increase in tidal constituents. Even though there are no sharp increases in $\left|A D_{M_{2}}\right|$ associated with the completion of water projects, removal of secular $\left|A D_{M_{2}}\right|$ trends in a non-biased way is a key component in hindcasting SF Bay inflow. We assume, to lowest order, that the century-scale trends in tidal properties is unrelated to flow and validate this assumption ex post facto by analyses of the 1858-2011 TDE hindcast.

For simplicity, we use a piece-wise linear function to remove the trend from the $\left|A D_{M_{2}}\right|$ time series. To investigate possible bias introduced by trend removal, TDE hindcasts were evaluated for five different physically plausible detrending scenarios and tested against 11 major $20^{\text {th }}$ Century floods. These scenarios are based on alternative hypotheses regarding the causes of the long-term trend. In scenario \#1, $\left|A D_{M_{2}}\right|$ is not detrended, which corresponds to the assumption that all the long-term trend in admittance 
is due to changes in river flow. In scenario $\# 2$, a single linear trend over the entire $150 \mathrm{yr}$ record is removed, assuming that tidal evolution has been uniform in time and independent of discharge. In scenario \#3, high discharge periods are removed from the $\left|A D_{M_{2}}\right|$ time series, before removing a linear trend from the $150 \mathrm{yr}$ record, to reduce any possible bias introduced by an uneven distribution of freshet events and their regulation. In scenarios \#4 and \#5, variability in tidal evolution (e.g., as might be caused by changing gauge position or historical sedimentation/erosion interacting with changes in coastal tides) is allowed. Thus, a piecewise removal of trends is made using natural breaks in the time series. Four time periods are used: 1858 to 1877 (Fort Point period), 1877 to 1897 (Sausalito period), 1897 to 1987 (Crissy Field period), and 1987 to 2010 (modern period); the reason for change in trend ca. 1987 is unclear, though the break is obvious. In scenario \#4, the full time series is used for detrending, whereas in scenario \#5, high flow periods are excluded, as in scenario \#3.

Table 2-1 lists TDE hindcast flows for each detrending scenario using (2.7), with $\left|T P R=A D_{M_{2}}\right|$. TDE hidcasts based on $\frac{M_{4}}{M_{2}^{2}}$ are also given for reference (though this method is only realistic for low flows), because $\frac{M_{4}}{M_{2}^{2}}$ shows no trend and does not need to be detrended. Scenario \#5, with the lowest root mean square (RMS) error between hindcast and measured floods, was used for detrending the $\left|A D_{M_{2}}\right|$ time series (Figure 23). Although $A_{M_{4} / M_{2}^{2}}$ poorly represents historical floods (Table 2-1), a scatter plot of $A_{M_{4} / M_{2}^{2}}$ vs river discharge (Figure 2-4) shows that it exhibits a stronger sensitivity (larger 
slope) than $\left|A D_{M_{2}}\right|$ at low flows. We hindcast, therefore, low inflow periods using $A_{M_{4} / M_{2}^{2}}$, for which detrending is not needed. This lack of trend suggests that the factors affecting overtide generation have not changed greatly over time.

Trend removal interacts, however, with another issue - tides are smaller at Sausalito than at Fort Point, and the mean and variance of $\left|A D_{M_{2}}\right|$ are systematically smaller during the 1877-1897 period that the gauge was in Sausalito. The admittances were corrected using two degrees of freedom, such that the mean and variance for the 1877-1897 Sausalito $\left|A D_{M_{2}}\right|$ values were equal to the average of those for 1868-1877 and 1898-1907, when the gauge was at Fort Point.

\section{2-3-4-Regression Analysis and Flow Hindcasts}

The parameters $\alpha, \beta$ and $\gamma$ in (2.7) are determined by non-linear regression analysis of the 1930-1990 NDOI estimates against tidal properties, using the Matlab function (nlinfit). For use in the regression analysis, the weekly $T_{-}$Tide outputs (and the similarly averaged flows) were bin-averaged in 100 bins, evenly spaced in terms of the tidal property $\left(\left|A D_{M_{2}}\right|\right.$ or $\left.A_{M_{4} / M_{2}^{2}}\right)$. Before bin-averaging, points associated with noisy or incomplete data were removed from the time series of tidal properties. Specifically, we used only $\mathrm{M}_{2}$ and $\mathrm{M}_{4}$ amplitudes with a signal to noise ratio (SNR) >10; the SNR statistic is a standard T_Tide output [Pawlowicz et al., 2002].

As shown in Figure 2-4, the relation between tidal properties and flow is nonlinear, and no single tidal property provided optimal hindcasts through the full range 
of observed flows. Thus, separate non-linear regressions were carried out for low (NDOI $<\sim 1000 \mathrm{~m}^{3} \mathrm{~s}^{-1}$ ) and high flows (NDOI $>\sim 1000 \mathrm{~m}^{3} \mathrm{~s}^{-1}$ ). The ratio $A_{M_{4} / M_{2}^{2}}$ was used for low flows (Figure 2-4b), with $A_{M_{4} / M_{2}^{2}}<0.09$, while $\left|A D_{M_{2}}\right|$ was used for high flows ( $\left|A D_{M_{2}}\right|<0.36$; Figure 2-4a). This approach to the regression models is justified below in terms of the RMS (root mean square) errors of the 1930-1990 hindcasts, after definition of an error criterion.

A uniform time series of flows was hindcast for 1858-2010 using (2.7), with the regression parameters specified in Table 2-2. One modification of these hindcast flows was made. During low river flow periods, neap-spring variations in tidal range [neglected in (2.7)] affect flows hindcasts, causing artificial neap-spring variability. A SaviztkyGolay filter was used to remove these fluctuations [Savitzky and Golay, 1964]. The Saviztky-Golay filtering method is better than a moving average filter because it tends to preserve data features such as peak height and width, which are usually attenuated by the moving average filter [Guinon et al., 2007].

\section{2-3-5- Error Propagation}

There are uncertainties associated with river flow hindcasts that must be quantified by statistical methods. A Monte Carlo analysis is used here to define the $95 \%$ confidence intervals of the estimates. In a Monte Carlo simulation, the behavior of a statistic in random samples is assessed by the empirical process of drawing many random samples and observing their behavior [Mooney, 1997]. For estimating confidence intervals by Monte Carlo analysis, it is necessary to determine the standard deviation ( $\sigma$ ) 
of each parameter, determined by T-Tide for each component for each analysis window [Pawlowicz et al., 2002], and then propagate the individual parameter errors to determine errors in regression variables. For the standard deviation of $\left|A D_{M_{2}}\right|\left(\sigma_{A D_{M_{2}}}\right)$ we have:

$$
\sigma_{A D_{M_{2}}}=\frac{\sqrt{\sigma_{A_{M_{2}}}^{2}+A_{M_{2}}^{2} \sigma_{\theta_{M_{2}}}^{2}}}{\hat{A}}
$$

where $\sigma_{A_{M_{2}}}$ is the standard deviation of $A_{M_{2}}$, and $\sigma_{\theta_{M_{2}}}$ is the standard deviation of $\theta_{M_{2}}$.

The standard deviation of $M_{4} / M_{2}^{2}$ is:

$$
\sigma_{\frac{A_{M_{4}}}{M_{2}^{2}}}=A_{\frac{M_{4}}{M_{2}^{2}}} \times \sqrt{\left(\frac{\sigma_{A_{M_{4}}}}{A_{M_{4}}}\right)^{2}+2 \times\left(\frac{\sigma_{A_{M_{2}}}}{A_{M_{2}}}\right)^{2}}
$$

For comparison to the uncertainties derived for our TDE estimates below, we note that any river instrumental discharge measurement can be assumed to have a $95 \%$ confidence limit of $\pm 5 \%$ [Di Baldassarre and Montanari, 2009].

Monte Carlo simulations were carried out based on 5000 ensembles. Using nonlinear regression, $\alpha, \beta$ and $\gamma$ in (2.7) were calculated for each ensemble. As Figure 25a shows, the distribution of coefficients is approximately Gaussian, and the $95 \%$ confidence interval limits can be estimated from the 2.5 and $97.5 \%$ quantiles. While somewhat more than $95 \%$ of the observed data fall within the $95 \%$ confidence interval, errors are dependent on flow and the method is more reliable for high flows than during dry periods (Figure 2-5b). 


\section{2-3-6- Model Selection}

As described above, $\left|A D_{M_{2}}\right|$ and $A_{M_{4} / M_{2}^{2}}$ models were used for NDOI $>1000 \mathrm{~m}^{3} \mathrm{~s}^{-1}$ and $\mathrm{NDOI}<1000 \mathrm{~m}^{3} \mathrm{~s}^{-1}$, respectively. This choice can be justified ex post facto in terms of RMS errors for the 1930 - 1990 calibration period (Figure 2-6). For SF Bay at least, use of statistics related to quadratic overtide $\mathrm{M}_{4}$ appears to provide the best hindcasts during low river-flow periods. RMS errors for low-flow events estimated using the $\left|A D_{M_{2}}\right|$ model are $\sim 1000 \mathrm{~m}^{3} \mathrm{~s}^{-1}$, larger than the flows. In contrast, the RMS errors for the $A_{M_{4} / M_{2}^{2}}$ model are $\leq 500 \mathrm{~m}^{3} \mathrm{~s}^{-1}$.

\section{Results and Discussion}

\section{3-1- Validation of the TDE Model}

Hindcast flows were validated using four series of data: (a) NDOI for 1930 to 2010 (Figure 2-7), (b) the daily flow at Red Bluff (1891-1944; Figure 2-8), (c) the monthly averaged eight-river flow index (1906 - 2010; Figure 2-9) and (d) monthly precipitation data at SF (1850-2010; Figure 2-10).

\section{3-1-1-Comparison to NDOI}

The efficacy of the hindcasts for the calibration period (1930-1990) can be seen in Figures 2-7a,b and Table 2-3. The TDE time series for 1980-1984 (Figure 2-7b) shows that the major flood of 1983, the moderate freshets in 1980, 1982, and 1984, and the lowflow period of 1981 are all reproduced by the hindcast. Some details of the hindcast flow differ from the measured flow, and account for some of the scatter in Figure 2-7a; in 
particular, the hindcast discharge sometimes lags the measured NDOI by several days (see section 3.2 for discussion).

Another way to test the model is to compare hindcasts with observations for a validation period not used for calibration. The result shows good agreement between TDE estimated flows and calculated NDOI (Nash-Sutcliffe coefficient equal to 0.902; Table 2-3). In addition, 1991-2010 NDOI is compared with the TDE hindcast (Figure 27c). TDE hindcasts generally exhibit errors $\leq 20 \%$; the rms error is $343 \mathrm{~m}^{3} \mathrm{~s}^{-1}$. They are especially successful during high river flows (errors usually $\leq 10 \%$ rms error $=551 \mathrm{~m}^{3} \mathrm{~s}^{-1}$ ), when the alteration of tidal properties is large. Figure 2-7d shows TDE modeled flows with estimated 95\% confidence intervals from 1996 to 2000. As in Figure 2-7b, the overall pattern and major peaks are captured, but the hindcast and observed flows in Figure $2-7 \mathrm{~b}$ and $2-7 \mathrm{~d}$ do not always rise or fall at the same rate. TDE hindcasts also underestimate some peaks, but the differences fall within the estimated $95 \%$ confidence interval for most high flow periods and most periods of nearly steady flow. One possible reason for differences in timing and magnitude of peaks between observations and TDE hindcasts is that tidal properties are likely affected to some degree by salinity intrusion, and the adjustment time for the salt distribution in SF Bay due to changes in river flow is several weeks [Monismith at al., 2002].

\section{3-1-2- Comparison to flow at Red Bluff}

Measured flows at Red Bluff (USGS 11377100), available daily from 1891 present, can also be used to assess TDE hindcasts. While this gage measures the flow from only $14 \%$ of the basin, it provides a valuable check before 1930, when NDOI is not 
available. To compare Red Bluff flows with our hindcast, we plot observed Red Bluff flows against bin-averaged NDOI over the period 1930-1944 (i.e., using data from before the Shasta Dam came online; Figure 2-9). Red Bluff flows are similarly plotted against bin-averaged TDE hindcast flows for 1891-1944 (Figure 2-8); regression lines were fitted in both cases. The slopes of the two flow estimates $(0.156 \pm 0.025$ and $0.171 \pm 0.016)$ agree within their mutual $95 \%$ confidence limits, the adjusted $\mathrm{R}^{2}$ are very similar $(0.536$ for the NDOI line vs. 0.561 for the TDE line), and there is a zero offset of 125 to $176 \mathrm{~m}^{3} \mathrm{~s}^{-1}$ (again similar within $95 \%$ confidence limits, \pm 59 and $\pm 82 \mathrm{~m}^{3} \mathrm{~s}^{-1}$, respectively). These results suggest that there is no systematic error within the TDE before 1930, and random errors may cause the slight difference in slope, offset and $\mathrm{R}^{2}$ values [Taylor, 1996].

\section{3-1-3-Comparison to the Eight-River Flow Index}

Another way to assess the robustness of TDE is to compare our hindcast flows to measures of unimpaired SF Bay inflow. Figure 2-9 shows the yearly averaged TDE flow estimates vs. the Eight-River Index or ERI (both averaged over December to May) for the periods 1906 - 1929 and 1930 - 2010. The TDE and ERI measures are well correlated in both time periods ( $\mathrm{R}^{2}$ is 0.848 and 0.813 before and after 1930 , respectively), but the slope of the fitted line is different before (0.0917) and after (0.0565) 1930. Several flow management factors may contribute to this decrease in slope, including diversion and reservoir storage beyond May.

\section{3-1-4- Comparison with precipitation data}

Precipitation data can also be used to check the accuracy of TDE hindcasts. Figure 2-10 shows annual San Francisco precipitation and TDE modeled annual average 
flows, 1858-2010. In general, the precipitation record agrees with the estimated river flow, with large rainfall years producing correspondingly large annual flows. Precipitation data also strongly support the peak TDE flow measured in January 1862 (Figure 2-11), as the two-month rainfall total of $861 \mathrm{~mm}$ measured from December 1861January 1862 is $25 \%$ greater than the next largest total $(685 \mathrm{~mm}$ in January-February 1998). The San Francisco precipitation data are consistent with monthly data for Sacramento for 1852-1862 [Logan, 1864], which indicate that 219, 382, and 108mm of rainfall fell in the three months from December 1861 to February 1862, respectively. Moreover, the rain-on-snow events of December 1861 and January 1862 removed the snow-pack in the Sierra mountains [e.g., Hunsacker \& Curran, 2005], significantly increasing the flood intensity.

Interestingly, the TDE hindcast suggests that the annual flow from the 1861-1862 winter was smaller than the next two largest rainfall years in 1889-1890 and 1997-1998. Examination of the precipitation data shows that rainfall in 1861-1862 was concentrated over a shorter period than in 1889-1890 and 1997-1998, and led to a larger flood but, apparently, a smaller annual flow. The different annual flows also could be caused by differences in evapotranspiration, storage, diversion, and infiltration between the water years [see e.g., Hamlet et al., 2007]. Indeed, the spring-freshet in 1862 was small, while the relatively large spring freshet in 1890 shows that there was significant snowpack storage (Figure 2-11). It is also possible that missing data in May-June 1862 caused an underestimate of the 1862 freshet (see Talke \& Jay, 2013). Finally, because rainfall is spatially variable, the local rainfall data in Figure 2-10 are only an approximate indication 
for precipitation over the watershed. Nonetheless, the qualitative agreement between precipitation and estimated flow in Figure 2-10 support the validity of TDE.

\section{3-2- TDE Hindcasts}

\section{3-2-1- Magnitude of the Great 1862 Flood}

The above results suggest that TDE successfully captures trends and magnitude of observed river flow, 1930-2010. Tidal data for 1858-1929 allow us to provide novel discharge hindcasts for the years prior to 1930, for which NDOI estimates are not available. A plot of the TDE hindcast for 1858 to 2010 shows that the 1862 flood is the largest flow event of the last 150 years (Figure 2-11). Specifically, the TDE hindcast for January 1862 shows a peak 18 -day flow of $9850 \mathrm{~m}^{3} \mathrm{~s}^{-1}, 25 \pm 20 \%$ larger than the peak flood in January 1997 (similarly averaged), which is the largest flow in the NDOI record. Precipitation data 1858-2010 (Figure 2-10) supports this conclusion-winter 1862 is the wettest season in the entire precipitation record. Hunsaker and Curran [2005], modifying a method developed by the Corps of Engineers, argued that the instantaneous peak flow for the 1862 was the largest in the last 150yrs and 32\% greater than in 1997; this estimate is based, however, on only $\sim 8 \%$ of the total Sacramento River basin area. While monthly SF precipitation similar to that in January 1862 occurred in 1853, 1867, 1881, 1986 and 1997, the heavy rains of January 1862 were preceded by very high precipitation in December 1861. The duration of heavy rainfall, the antecedent snowpack, and the rapid snowmelt together make the flooding in January 1862 the dominant flood event of the last 150 years. Accordingly, this series of storms served as the historic basis for the 
USGS ARkStorm study [http://wdr.water.usgs.gov/], a recent attempt to estimate the consequences of a truly catastrophic, California-wide flood.

\section{3-2-2- Changes in the Annual hydrograph}

The TDE hindcasts also allow evaluation of long-term changes in the annual hydrograph. Figure 2-12a compares 40-year TDE hindcasts averaged by year day for the late $19^{\text {th }}$ century $(1858-1898)$ and modern era (1968-2008). Both the timing and magnitude of the annual peak flow has changed considerably over time, which is consistent with the results of other studies [Ganju etal., 2008; Aguado et al., 1992]. Before 1900 , the snowmelt-driven peak flow of $\sim 1850 \mathrm{~m}^{3} \mathrm{~s}^{-1}$ typically occurred in early May. The contemporary peak $\left(\sim 1700 \mathrm{~m}^{3} \mathrm{~s}^{-1}\right.$ is $\sim 10 \%$ smaller and normally occurs between January and March, roughly coincident with peak precipitation. Historic summer flows were $100-300 \mathrm{~m}^{3} \mathrm{~s}^{-1}$ larger than at present, and the minimum flow of $400 \mathrm{~m}^{3} \mathrm{~s}^{-1}$ occurred on average in November. The present minimum flow of $\sim 300 \mathrm{~m}^{3} \mathrm{~s}^{-1}$ occurs about one month earlier. Dominant reasons for these changes are:

Flow control and diversion: In the $19^{\text {th }}$ century, before construction of storage reservoirs, most peak flows occurred due to a spring snowmelt. During the $20^{\text {th }}$ century, flood control and diversion for irrigation and human consumption reduced total flows and contributed to the movement of peak flows to winter or early spring [Nichols et al., 1986; Knowles, 2002].

Climate Change: Change in of the amount and timing of precipitation and the seasonal temperature cycle may also have affected the magnitude and timing of 
runoff, though temperature increases have greatly outweighed changes in precipitation. A dominant fraction of river flow in the watershed originates from melting snow packs, and increasing temperature results in increased winter runoff and earlier peak spring river flows [Hamlet et al., 2005; Cayan et al., 2001; Hamlet and Lettenmaier, 2007]. Climate scenarios suggest further decreases in precipitation and earlier snowmelt [Hamlet et al., 2005; Leung et al., 2004].

TDE hindcasts suggest that the above changes have resulted in a $~ 30 \%$ decrease in annual average discharge after $1900\left(\sim 2.1 \mathrm{~km}^{3}\right)$, compared to the $19^{\text {th }}$ century ( $2.7 \mathrm{~km}^{3}$ ), a decrease of $\sim 29 \%$. Nichols et al. [1986] suggests that modern inflow to the bay is $\sim 40 \%$ below historic levels ca. 1850 . Given uncertainties in both estimates, they are in approximate agreement.

The timing of high flow periods and flood has also changed. This is demonstrated for $1858-1898$ and $1968-2008$ by plotting against year-day the $97.5 \%$ exceedance values (the flow exceeded only $2.5 \%$ of the time for any given year-day) (Figure 2-12b). Before 1900, high flow events occurred primarily in winter (January and February) and late spring (May and June). During the $20^{\text {th }}$ century, large flows have most often occurred in March and April. The hindcast flows for 1858-2010 also support this conclusion (Figure 2-11) and emphasize that spring freshets, common in the late $19^{\text {th }}$ century, were much less frequent after 1900 (even before significant flow regulation) and essentially vanished after Shasta Dam was completed in 1944. The large event in autumn 1904 (evident in Figure 2-11) is unique in the record, which suggests that it might be an anomaly due to faulty tide data. In fact, gauge comparisons from 1904 indicate that some clogging 
occurred due to sedimentation on September 7th (probably from a storm), and resulted in water level errors of 0.1-0.3m over the next month (see also Talke \& Jay, 2013). Hence, the reduced admittance may be in part due to gauge issues. However, precipitation records indicate that 129mm of precipitation fell in September 1904 in San Francisco,

more than in any other September between 1849 and 2011 (http://ggweather.com/sf/ monthly.html). Thus, the event appears to be real, though perhaps the peak flow has been overestimated. The fact that the event cannot be traced in any of the USGS fluvial flow/elevation records available for this time period emphasizes the importance of estimating flows closer to the ocean. Finally, while there are a few early winter (December) events before 1900, these become much more prominent after about 1940; this may be due in part to flow regulation after 1944; i.e., emptying of reservoirs in early winter during wet years.

\section{3-3- Error Analysis}

Evaluating the significance of the TDE hindcast flows requires understanding the magnitude of likely errors, which may be systematic (due to bias) or random. Random errors associated with estimates are reflected in the confidence intervals (e.g., Figure 27), but systematic errors are not. We consider here the likely importance of both kinds of errors.

\section{3-3-1- Systematic Errors}

TDE estimates are sensitive to the method used to detrend tidal admittances, and this is the most likely source of systematic error. As discussed in section 2-3-3, there has 
been a secular (century scale) increase in $\left|A D_{M_{2}}\right|$ at SF that reflects in part changes in ocean tides, but may also reflect changes SF Bay bathymetry and shorelines. This must be removed to avoid aliasing of discharge estimates. We have used the simplest reasonable approach to de-trending, piecewise linear removal, which adequately accounts for the exogenous factors (e.g., bathymetric changes). Comparing different possible scenarios (Table 2-1), we chose a scenario that minimized errors associated with TDE hindcasts of selected $20^{\text {th }}$ Century flood events. As shown in Table 2-1, choosing a different detrending approach can considerably alter the estimates for some $19^{\text {th }}$ Century floods. For example, the five detrending scenarios described in Table 2-1 lead to a peak flow in January 1862 that ranges from 9500 to $14,550 \mathrm{~m}^{3} \mathrm{~s}^{-1}$ (Table 2-1). Our adopted TDE hindcast $18 \mathrm{~d}$ average flow, $9850 \mathrm{~m}^{3} \mathrm{~s}^{-1}$, is near the low end of the estimate. The wide range of possible flows for this event reflects both its real magnitude and its position near the beginning of the time series, which produces a large difference between scenario 1 (no trend removal) and other scenarios. On the other hand, our adopted estimate for the $1881 \mathrm{flood}, 8400 \mathrm{~m}^{3} \mathrm{~s}^{-1}$, is above the average for the five scenarios, and the range for this event is smaller (6850 to $9750 \mathrm{~m}^{3} \mathrm{~s}^{-1}$; Table 2-1) than for the 1862 flood. Clearly, the choice of the detrending scenario affects the TDE hindcast flows before 1900. In general, if detrending had not been used (which we regard as quite unrealistic, given that tidal amplitudes are increasing throughout the Northeast Pacific [Jay, 2009]), predicted flows would have been much higher for this time period.

The treatment of the 1877-1897 period when the tide gauge was in Sausalito is also important, because the $\mathrm{M}_{2}$ tide was systematically smaller by $\sim 10 \%$ at this location, 
relative to Fort Point. We have used the simplest reasonable correction, adjustment of the mean and standard deviation of $\left|A D_{M_{2}}\right|$ for this time period.

Imperfect conceptual modeling of the tidal-fluvial interactions by (2.7) is also a possible problem. TDE is based on an approximate inversion of a tidal wavenumber model for a single, incident tidal wave. Given that the SF tide gauge is located at the estuary mouth, the incident wave is unlikely, at that location, to reflect the state of the friction in the estuary. It is likely that the gauge is responding to modification of both the incident and reflected wave; fortunately, the wavenumbers for both waves scale with discharge in the same manner. Tidal properties may also respond to other factors correlated with river flow. A change in salinity intrusion length may change the friction on a tidal wave [Giese and Jay, 1989]. Thus, the tidal admittance variations used here to gauge discharge may in part be a response to changes in salinity intrusion length driven by river discharge. While this is an issue of theoretical interest, it is of little practical importance. Finally, high flows in SF Bay from winter storms are correlated with high water levels [Bromirski and Flick, 2008]. Elevated water levels may also affect tides by changing friction and/or residence time. This does not appear to be a major issue-high flows are more accurately modeled than low flows - but it may contribute to scatter in the results.

Systematic errors in the 1930-1990 NDOI estimates used for TDE calibration must also be considered, particularly before 1956, when fewer data were available for DAYFLOW calculations, and these might distort TDE hindcasts. DAYFLOW routing is particularly difficult during low flows when tidal current reversals extend far up into 
delta channels. Indeed, the lowest flows during the calibration period occurred before 1956, and TDE hindcast errors are largest and most variables for low flows. Still, the errors in low-flow TDE hindcasts during the calibration period are not strongly biased. Thus, systematic errors seem unlikely or would affect all TDE hindcasts uniformly, and have, therefore, little impact on historic comparisons.

\section{3-3-2- Random Errors}

Random errors associated with tidal measurements can arise from various difficulties with the gauge and data reduction. Our examination of a selection of the original marigrams from which the hourly tidal data were compiled does not suggest any systematic errors, and random errors ("data noise") are quantified in the T_Tide estimates and were used to determine overall TDE uncertainties as per (2.11) and (2.12). The completeness of the tidal data and overall high quality of the record minimize this source of error. Net inflow to the Bay cannot be measured directly and is routed (as NDOI) using the data gathered at upstream stations. Random errors related to infiltration and evaporation estimates likely contribute to the divergence of TDE and NDOI estimates, as may errors in the assumed lags used in compiling NDOI. The latter may contribute to differences in both the timing and absolute values of peak flows, as well as the shape of the hydrograph associated with high flow events. Non-stationarity in river flow over the period of harmonic analysis may also contribute to TDE errors.

\section{3-4- Future Improvements}


NDOI includes the $90 \%$ of the total freshwater discharge to SF Bay that comes from the Sacramento River delta, as noted above. Because we have calibrated our TDE estimates to NDOI, our present calculation also includes only the input to SF Bay from the delta, not the total flow to the ocean. While the estimates presented here could be scaled up by a uniform $10 \%$ to account for local creeks and rivers, local inflow is likely distributed differently in time than delta inflow. Thus, a more sophisticated procedure, perhaps based on correlation of local precipitation data with local stream flow records should be used, an effort we will not attempt here (but see Ganju et al. 2008).

Our TDE estimates are also imperfect because they average over tidal monthly variations in delta storage, due to the $761 \mathrm{hr}$ tidal analysis window. A future analysis based on short, continuous wavelet transform windows (ala Jay and Kukulka [2003]) would provide flow estimates with a higher inherent time resolution. Moreover, TDE could be improved by using two stations. In a two-station analysis, the amplitude admittance ratio is formed using the fluctuations in tidal constituents at a more landward station. The more seaward gauge is then used to eliminate fluctuations in ocean conditions in (2.3), rather than the astronomic tidal potential $V$. Finally, it would be useful to determine whether tidal properties could be used as a proxy for historic salinity intrusion, presently quantified by the $\mathrm{X} 2$ metric (the distance to the salinity $=2$ isopycnal; www. water.ca.gov/ dayflow/).

Recent studies suggest that, within a deltaic channel network, flow division at tidal junctions is affected by neap-spring variations in tidal range [Buschman et al., 2010; 
Sassi et al., 2011b]. Use of TDE to examine this division between distributaries would be an interesting and important challenge.

\section{3-5- Broad Utility}

The actual value of any indirect flow estimation method like TDE can only be determined by experience - can its success in SF Bay be replicated elsewhere? Preliminary results suggest that it can also be used in the Columbia [Jay and Kukulka, 2003] and Fraser Rivers. The choice of hindcast parameters and other details are, however, system specific. Also, it may be advantageous to substitute a coastal (or nearcoastal) tide gauge for the astronomical potential, if a second gauge is available. A second gauge is unlikely to be available, however, for hindcasting, as here, historical flows. To the degree that tide gauges are located seaward of typical river gauges and often have longer records, the method presented here should be applicable on a global basis.

\section{Summary and Conclusions}

The discharge of large tidal rivers to the ocean is an important issue for the global water balance, sediment input to the ocean, climate analyses and characterization of natural variability, and water resources management. However, this discharge is often difficult to determine, as illustrated by the case of San Francisco (SF) Bay. Uncertainty in the timing and magnitude of freshwater inflow to SF Bay exists because the delta through which most freshwater reaches the bay is a network of channels with numerous connections, inputs and outputs. Because of these issues, the presently used NDOI is an 
imperfect measure. In this study, tidal constituents, astronomical forcing and a model of the frictional interaction of flow and tides were used to hindcast monthly averaged river flows into SF Bay via a tidal discharge estimation method (TDE). Results show that the $\mathrm{M}_{2}$ admittance provides the best TDE estimates during periods of high river flow. In dry periods, tidal wave distortion becomes more dominant and higher harmonics are best used for the TDE hindcast. The TDE model was calibrated with 1931-1990 NDOI data, and validated using: (a) NDOI for 1991-2011; (b) the gauged discharge 1891-1944 at Red Bluff, CA; (c) the Eight River Index (1906-2011); and (d) the 1858-2010 SF precipitation record. The annual hydrograph of inflow to SF Bay has changed considerably over time, due to both human alteration and climate change. Before 1900 peak flows were in spring (May and June) but now they occur in winter. However, our hindcast indicates that the largest flood on record occurred in Jan. 1862 (as measured by an 18 day average) and was about $25 \%$ larger than the 1997 flood. 
Table 2-1: TDE Hindcasts for different scenarios vs. observed

\begin{tabular}{|c|c|c|c|c|c|c|c|c|c|c|c|c|c|}
\hline \multirow{2}{*}{ Scenario } & \multicolumn{10}{|c|}{ Year } \\
\cline { 2 - 15 } & 1938 & 1942 & 1956 & 1958 & 1970 & 1983 & 1986 & 1995 & 1997 & 1998 & 2006 & 1862 & 1881 \\
\hline Observed & 5550 & 6100 & 5700 & 5800 & 7550 & 8200 & 6250 & 7200 & 6300 & 6900 & 5700 & - & - \\
\hline$\# 1$ & 6000 & 6000 & 6300 & 5800 & 5600 & 6500 & 5800 & 6500 & 5500 & 5550 & 4700 & 14550 & 9750 \\
\hline$\# 2$ & 5350 & 5700 & 6500 & 5750 & 6350 & 7800 & 7300 & 8400 & 7400 & 7500 & 6900 & 10800 & 6850 \\
\hline$\# 3$ & 5500 & 5800 & 6600 & 5850 & 6400 & 780 & 7300 & 8400 & 7400 & 7450 & 6900 & 11025 & 7100 \\
\hline$\# 4$ & 5450 & 5700 & 6550 & 5800 & 6350 & 7800 & 7300 & 8350 & 7200 & 7200 & 6000 & 9500 & 8600 \\
\hline$\# 5$ & 5500 & 5800 & 6600 & 5800 & 6450 & 7900 & 7300 & 8200 & 7000 & 7050 & 5800 & 9850 & 8400 \\
\hline$M_{4}$ & $M_{2}^{2}$ \\
\hline
\end{tabular}

Table 2-2: Estimated coefficients in Equation 2.7

\begin{tabular}{|c|c|c|c|c|}
\hline \multirow{2}{*}{$\sqrt{\mid}$} & \multicolumn{2}{|c|}{$\left|A D_{M_{2}}\right|$} & \multicolumn{2}{c|}{$A_{\frac{M_{4}}{M_{2}^{2}}}$} \\
\cline { 2 - 5 } & Low Flows & High Flows & Low Flows & High Flows \\
\hline$\alpha$ & $4.8398 \mathrm{E}+05$ & $1.0555 \mathrm{E}+05$ & 205.8077 & $-4.2415 \mathrm{E}+04$ \\
\hline$\beta$ & $-4.8758 \mathrm{E}+05$ & $-1.6505 \mathrm{E}+05$ & $1.8903 \mathrm{E}+09$ & $6.0315 \mathrm{E}+04$ \\
\hline$\gamma$ & 0.0083 & 0.4454 & 6.1302 & 0.1379 \\
\hline
\end{tabular}

Table 2-3: Model efficiency coefficients

\begin{tabular}{c|c}
\hline Time span & Nash-Sutcliffe coefficient \\
\hline $1930-1990$ & 0.727 \\
$1991-2010$ & 0.902 \\
\hline
\end{tabular}




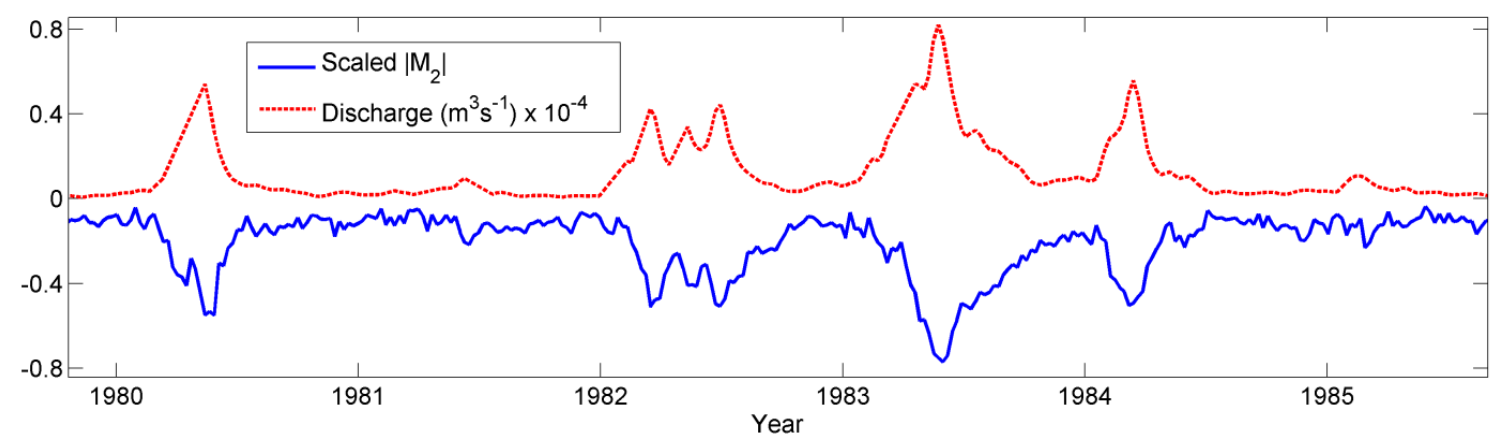

Figure 2-1: Example of the interaction of tides with river flow in San Francisco Bay; |M2| has been scaled relative to the difference between the minimum and maximum M2 (change in $|\mathrm{M} 2| /[$ maximum change in $|\mathrm{M} 2|]$ ); flow is the NDOI (Net Delta Outflow Index). The mean $\left|\mathrm{M}_{2}\right|$ amplitude is $0.57 \mathrm{~m}$, while the maximum change in $\left|\mathrm{M}_{2}\right|$ is $\sim 0.12 \mathrm{~m}$. 


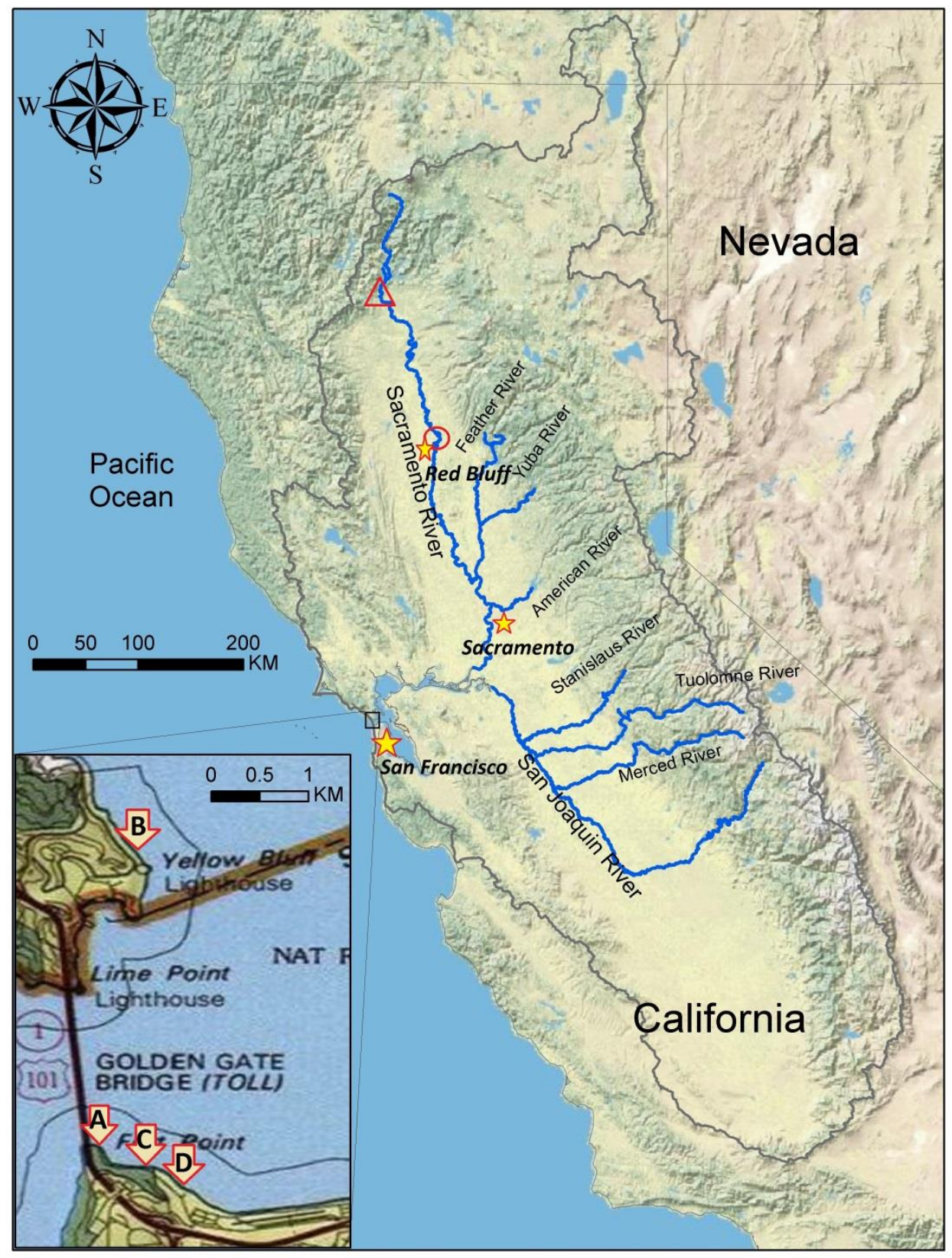

Figure 2-2: San Francisco Bay delta watershed boundaries and tributaries (USGS, HUC, http://www.nationalatlas.gov/); points A, B, C and D show tide gage locations (NOAA Station ID: 9414290$)$ at Fort Point (1854 - 1877), Sausalito (1877 - 1897), Presidio (1897 - 1927) and Presidio (1927 - present), respectively. The red circle shows the stream gauge site for Sacramento River near Red Bluff (USGS 11377100); the red triangle indicates the Shasta Dam (OESRI). 


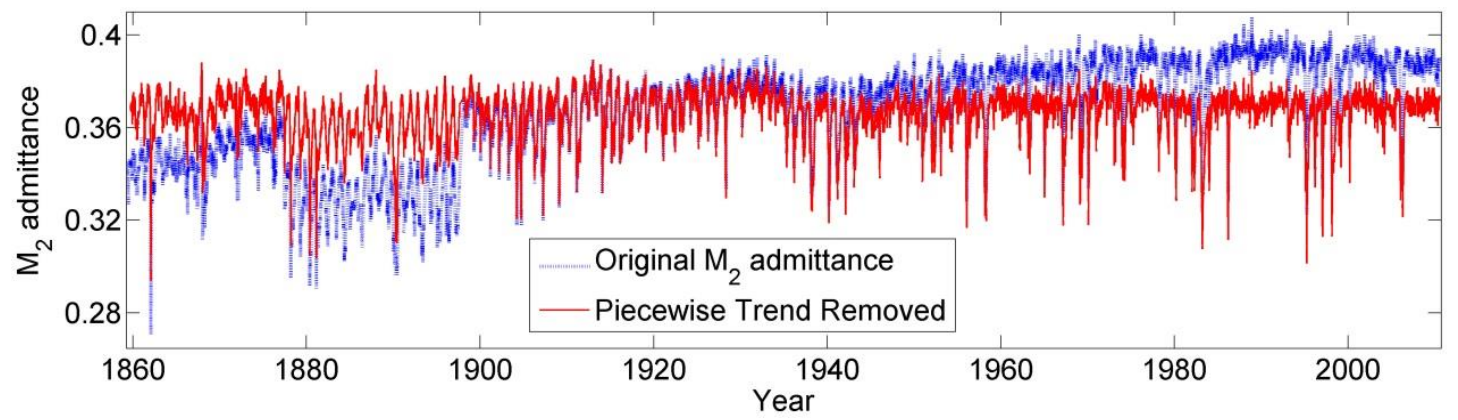

Figure 2-3: $\left|A D_{M_{2}}\right|$ with and without piecewise detrending.
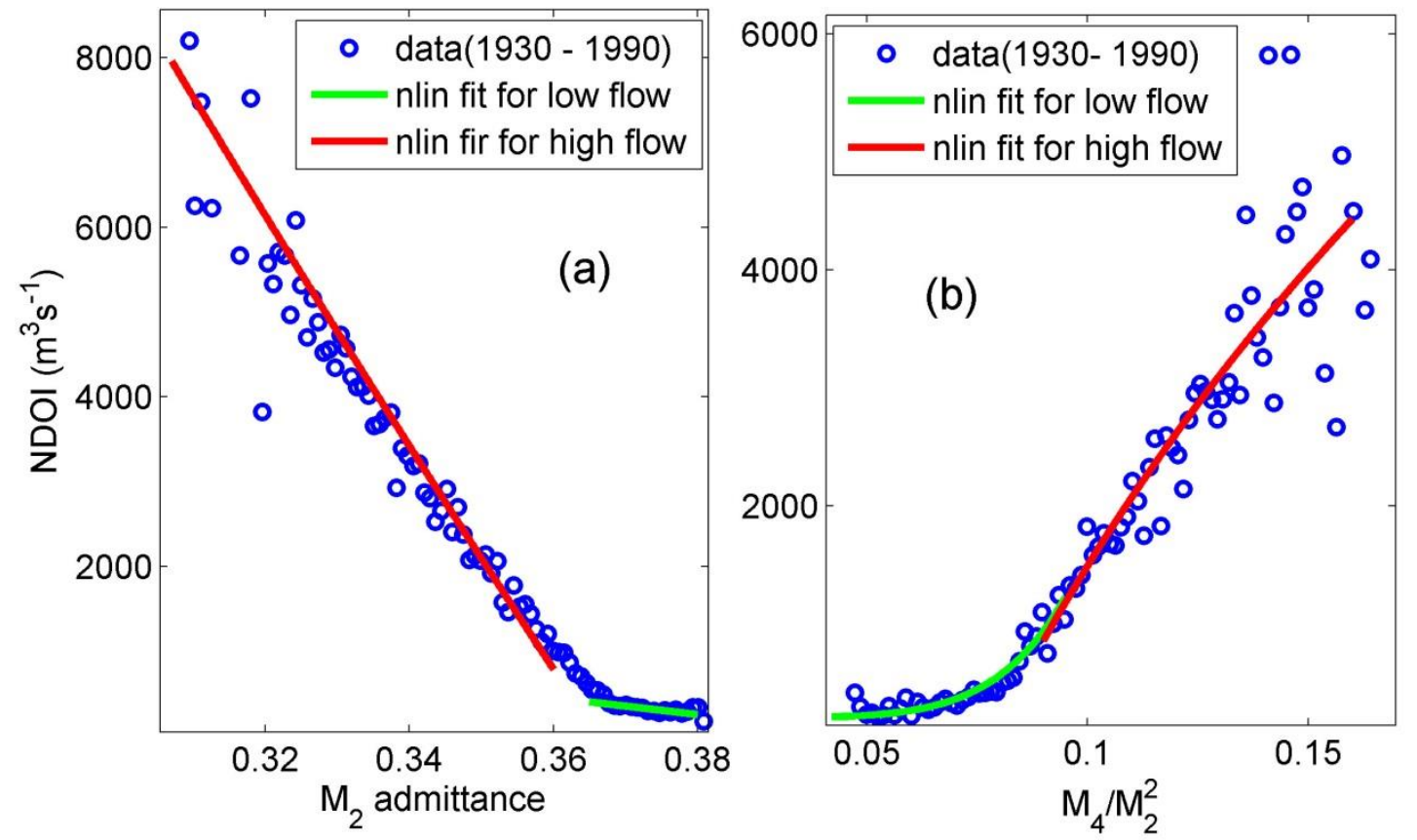

Figure 2-4: Nonlinear regression, (a) $\mathrm{M}_{4} / \mathrm{M}_{2}^{2}$ versus NDOI (Net Delta Outflow Index, (b) $\mathrm{M}_{2}$ admit. versus NDOI. 

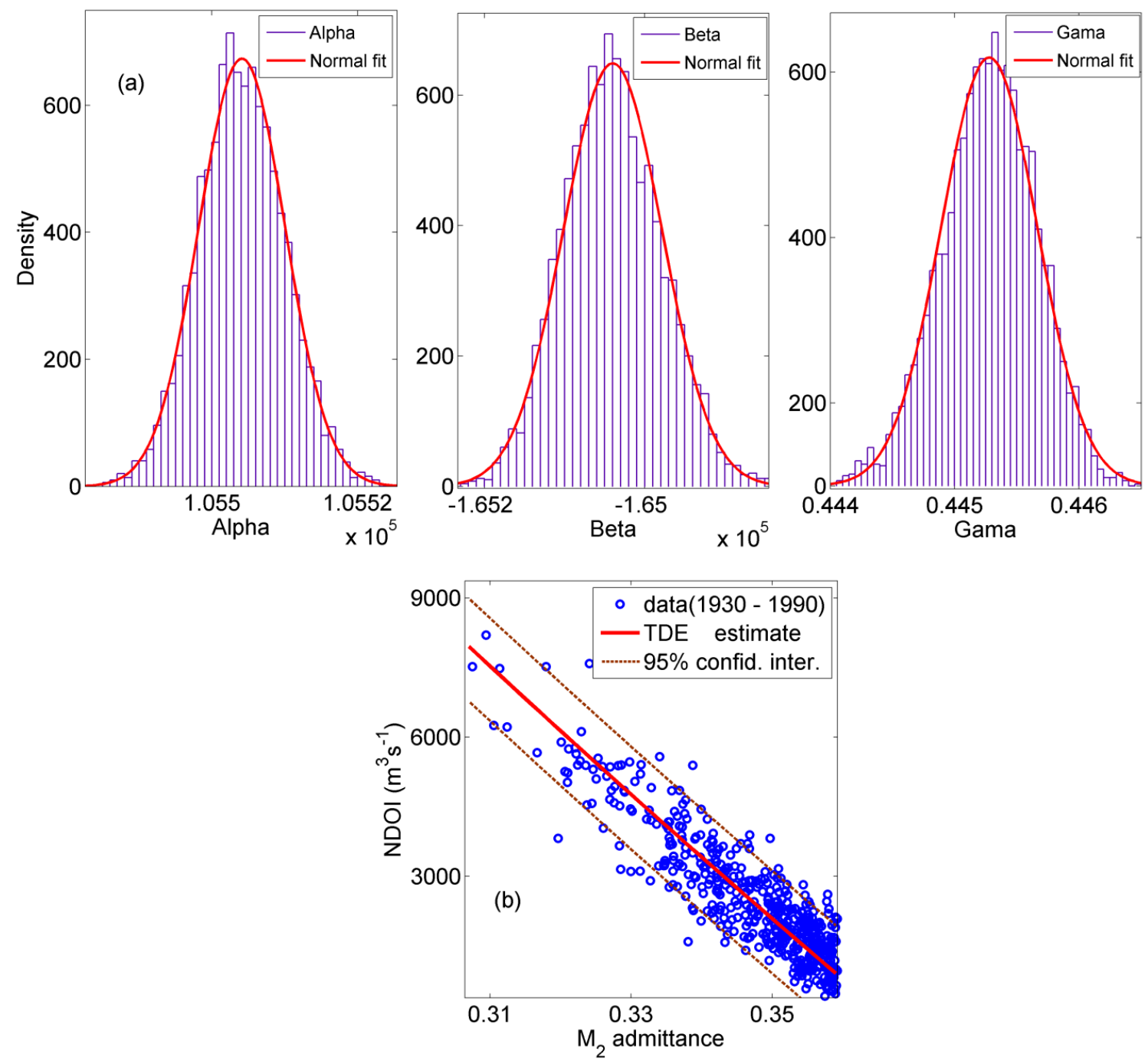

Figure 2-5: a) Distribution of coefficients $\alpha, \beta$ and $\gamma$ in (7) for high river flow estimation using $\left|A D_{M_{2}}\right|$; b) estimated NDOI for high-flow periods and $95 \%$ confidence interval limits vs. $\left|A D_{M_{2}}\right|$ based on Monte Carlo analysis. 

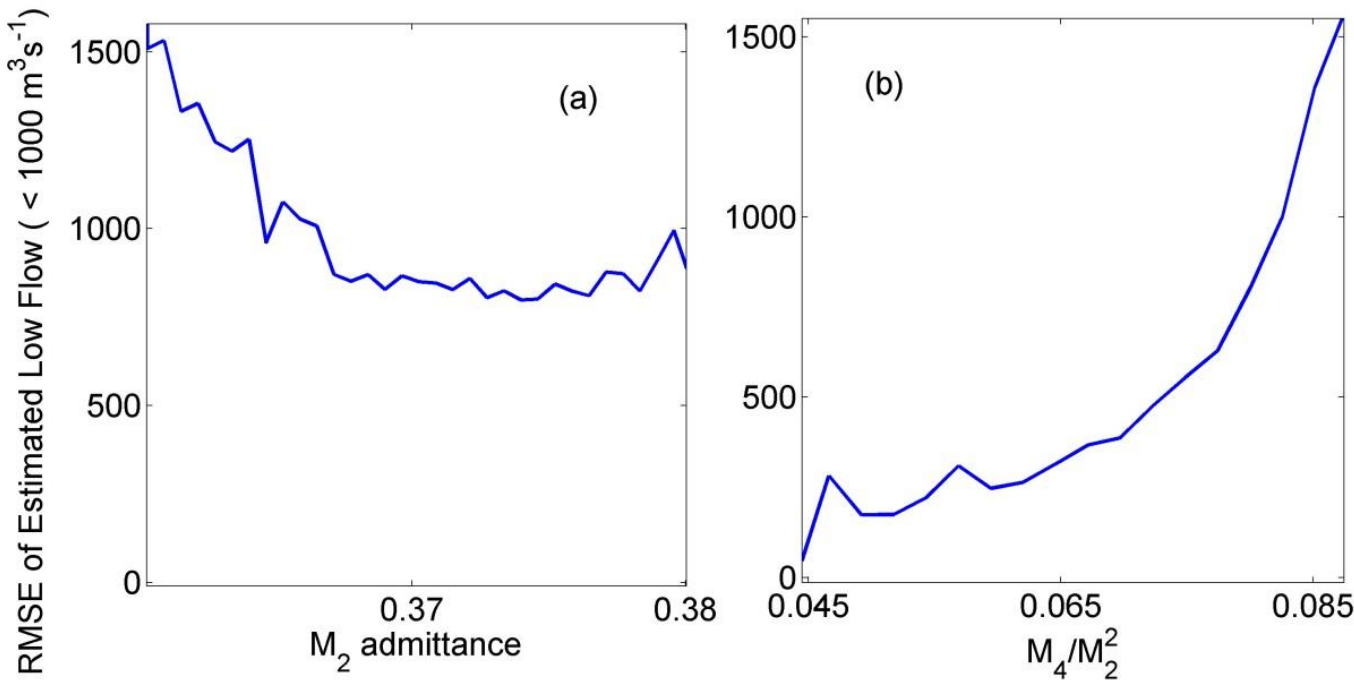

Figure 2-6: Root mean square error (RMSE) during low flow periods, for: (a) $A D_{M_{2}}>0.36$ and (b) $A_{\frac{M_{4}}{M_{2}^{2}}}<0.09$ 

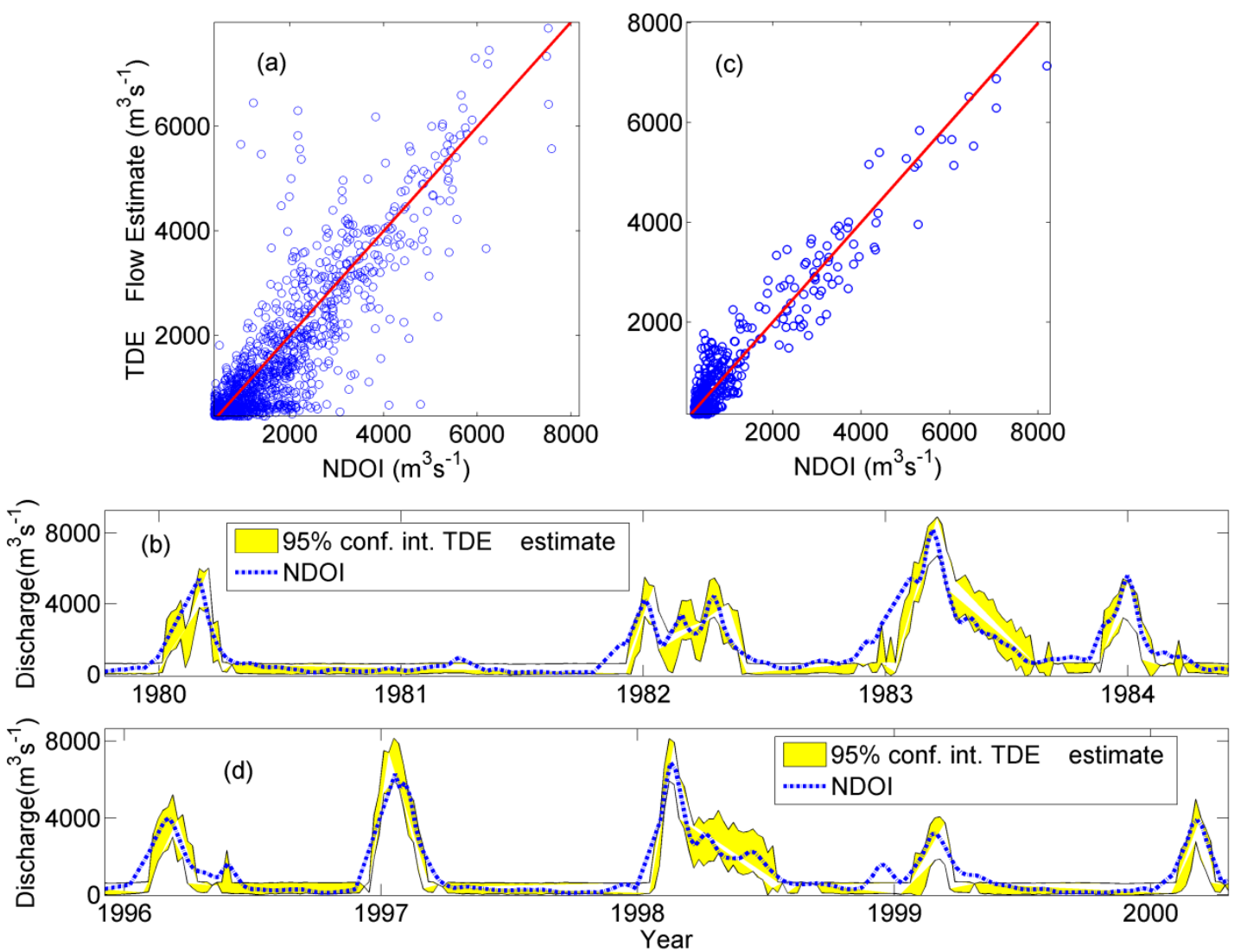

Figure 2-7: Comparison of estimated flows with observations: (a) scatterplot of TDE hindcast vs. NDOI flows for the calibration period 1930 to 1990, (b) time series of hindcast TDE flows (with 95\% confidence limits) and NDOI for 1980 to 1984, (c) scatterplot of TDE hindcast vs. NDOI for 1991 to 2010, (d) time series of hindcast TDE flows (with 95\% confidence intervals) and NDOI for 1996 to 2000.

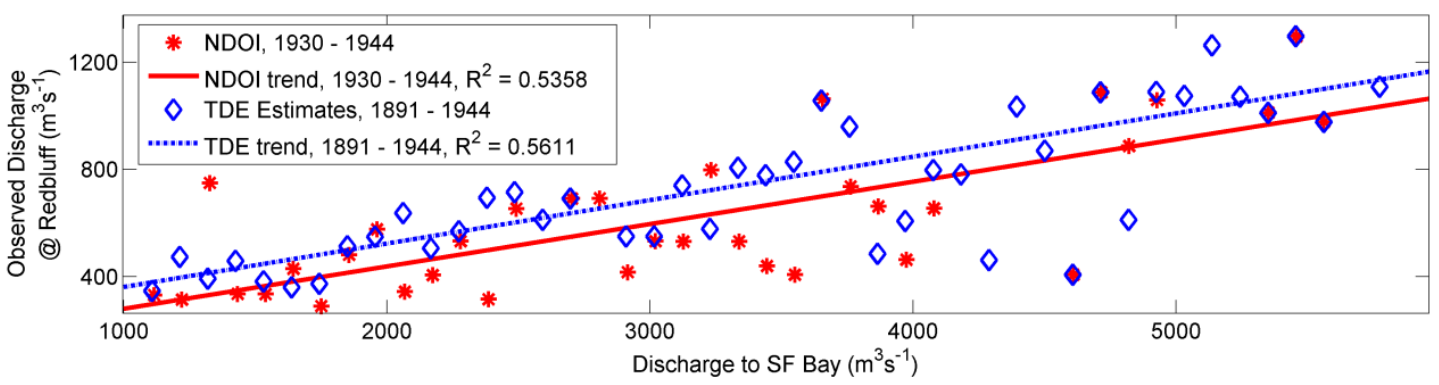

Figure 2-8: Red Bluff flow vs. bin-averaged NDOI (bin size, $200 \mathrm{~m}^{3} \mathrm{~s}^{-1}$ ) for the period 1930-1944 (red stars and fitted red line) and TDE estimates for the period of 1891-1944 (blue diamonds and fitted blue dotted dash-line) 


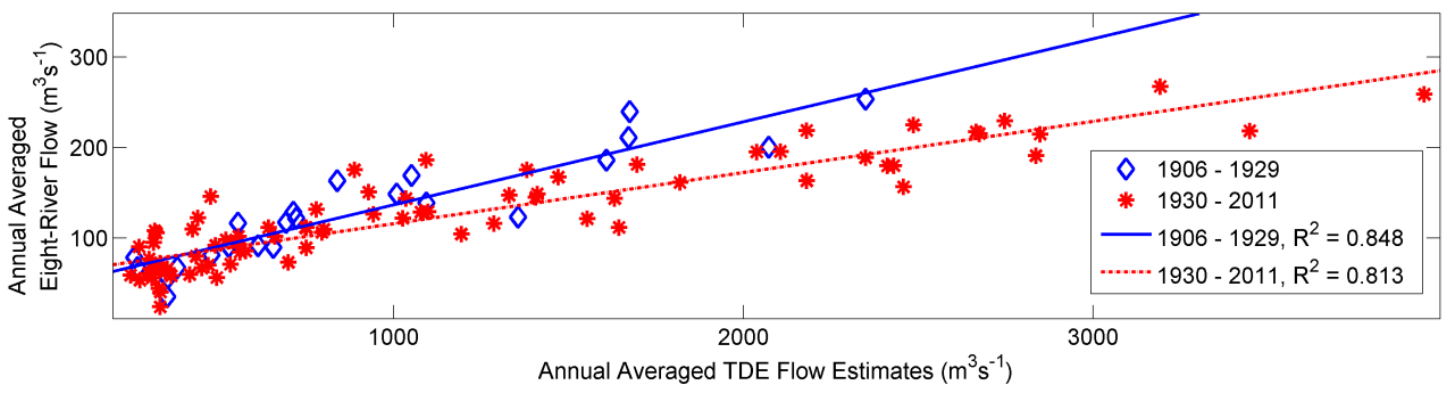

Figure 2-9: Annual averaged TDE flow estimates vs. annual averaged Eight-River flow index.

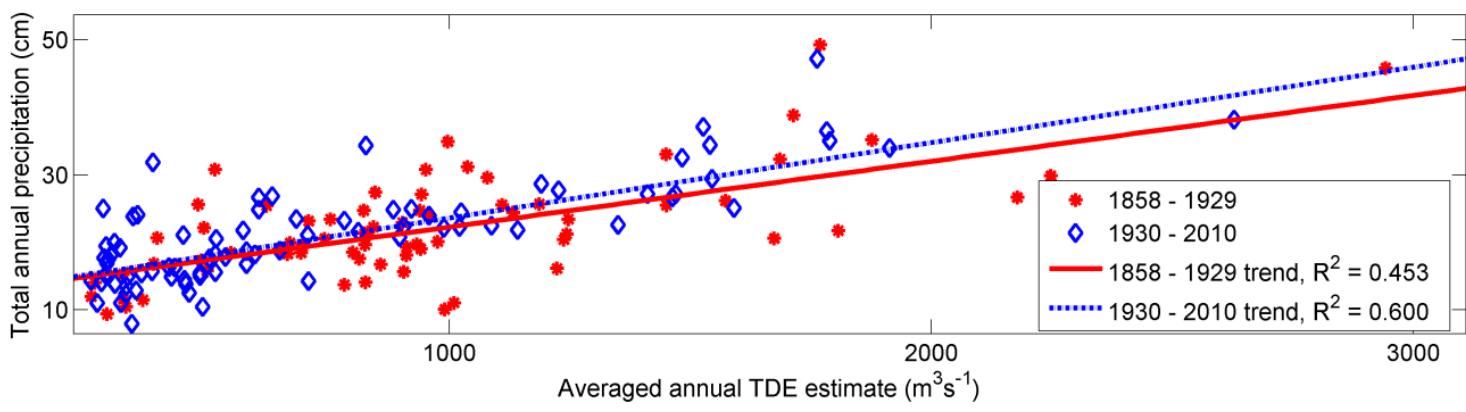

Figure 2-10: Annual precipitation at San Francisco vs. hindcast annual average TDE for 1858-2010.

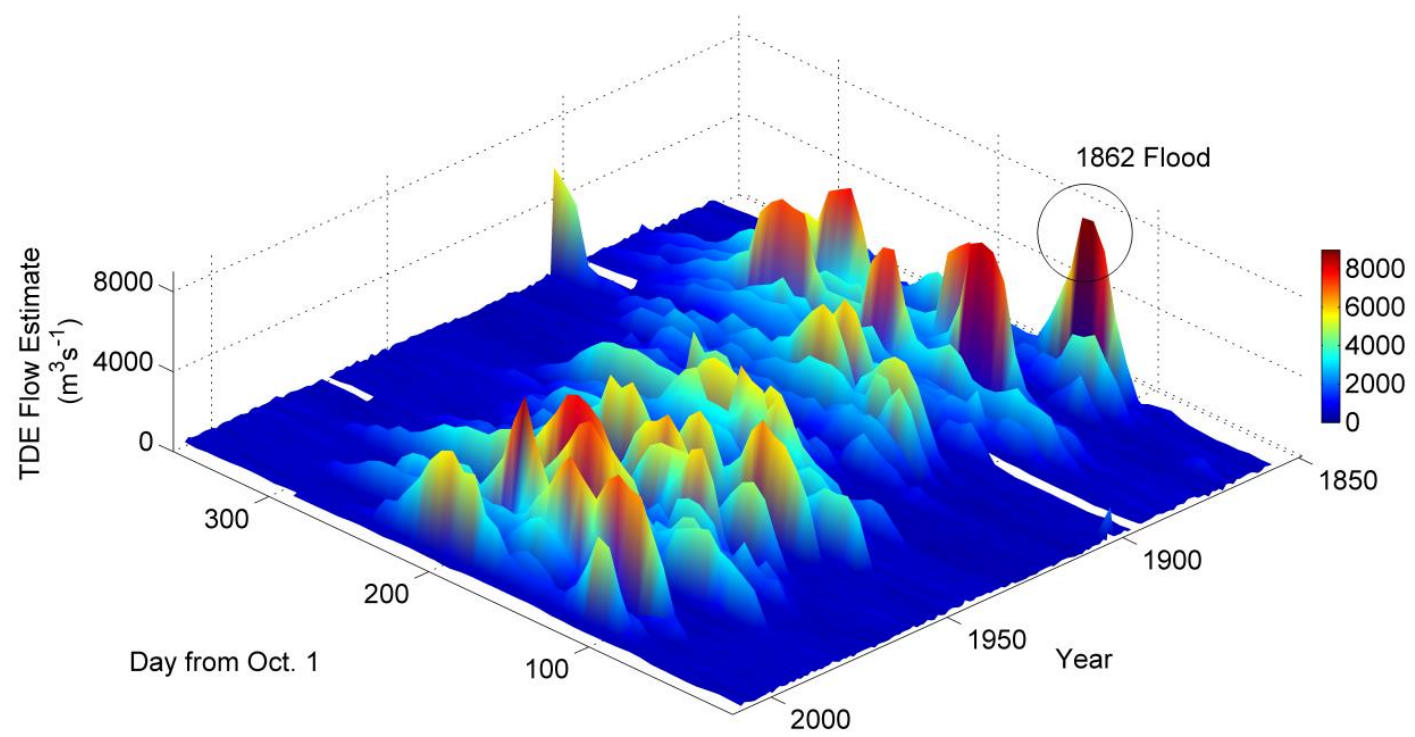

Figure 2-11: TDE hindcasts of annual hydrographs, 1858-2010. 

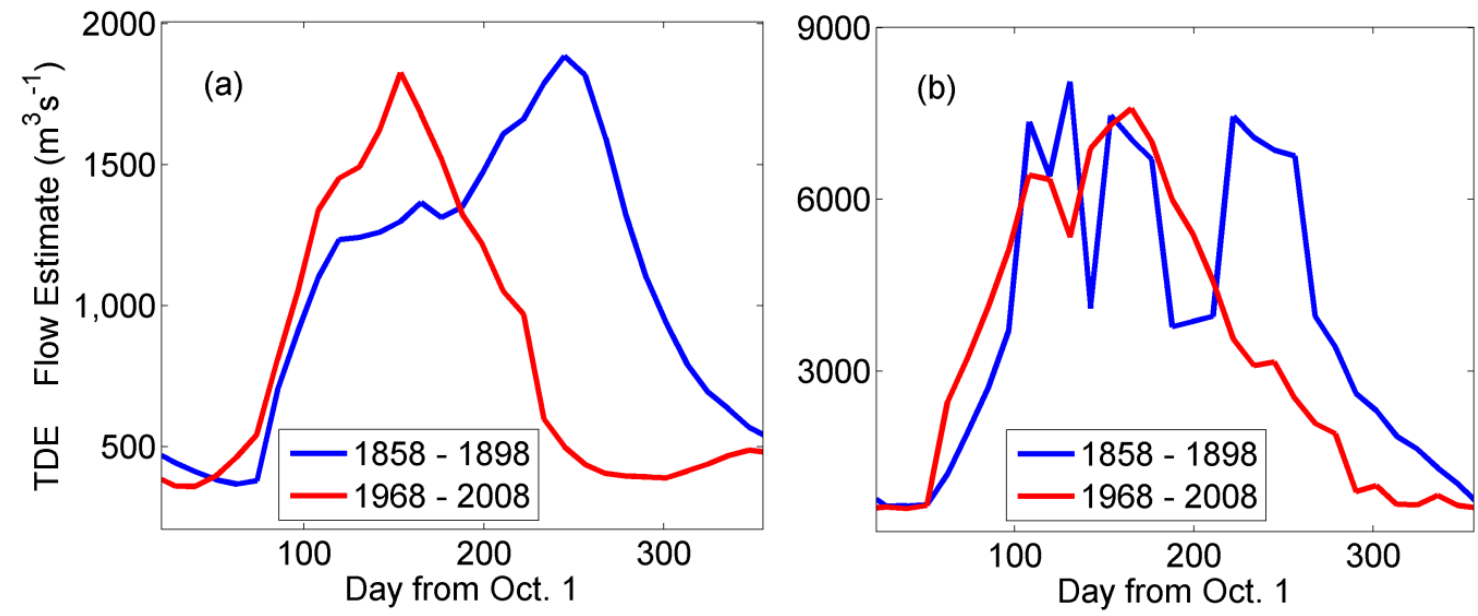

Figure 2-12: a) TDE hindcasts of flow by year-day averaged over 40yrs for 1858-1898 and 1968-2008, b) TDE hindcasts of $97.5 \%$ flow exceedance by year day, for the same periods. 


\section{Chapter III: River Flow Estimation in Estuaries Using Multiple-Tide Gages Distributed Along a Channel}

Reliable estimation of river discharge to the ocean from large tidal rivers is vital for water resources management and climate analyses. Due to difficulties inherent in measuring freshwater discharge at the mouth of an estuary, discharge gauging stations are typically located above the head of the tide, where downstream inputs and losses are not included. The distortion of the tidal wave through quadratic bed friction between tides and river discharge has been used to estimate river flow entering bays/estuaries using a single tide gauge (Chapter II). In this study, employing continuous wavelet analysis of tidal properties, I develop a method of estimating river discharge using tides measured at multiple gages along tidal rivers. First we develop and calibrate a Multiple-gauge Discharge Estimate (MTDE) model to two of the largest estuaries in the Pacific NorthWest, Columbia River and Fraser River estuaries, to show the applicability of the model in real fluvial systems. Next, we run the numerical model of an idealized estuary under different hydrologic and morphologic scenarios to evaluate the effect of different tidal/hydrodynamic mechanisms on the applicability of the MTDE. The proposed model improves on previous efforts in time resolution and methodology, and enables us to predict discharges during low-flow periods more accurately. MTDE performance is evaluated in terms of three non-dimensional numbers; non-dimensional friction, nondimensional river flow, and convergence length scale. Results suggest that MTDE should be applicable to a variety of tidal systems, but that the gauge locations must be carefully 
chosen so that at least one is located in a reach where tides vary strongly with river flow, for all relevant flow conditions. Gauges located farther from the mouth are more successful during low flow periods. Because the tidal wave may not reach upstream locations during high flow periods, gauges closer to the mouth are more useful under these conditions. Thus, MTDE is best implemented using at least three gauges: a reference station near the river mouth, and two upstream gauges that together, respond strongly to river flow variations over the expected dynamic range of flow. Favorable gauge locations are determined by the characteristics of each system, and are a function of governing nondimensional numbers.

\section{Introduction}

The discharge of large tidal rivers to the ocean is an important component of the global water balance [Oki et al., 1995; Alsdorf and Lettenmaier, 2003], and its measurement is necessary for climate analyses and water resources management [Laize and Hannah, 2010; Loitzenbauer and Mendes, 2012]. Globally, changes in discharge affect chemical, fate, and sediment input to the ocean [Martin and Whitfiled, 1983; Syvitski et al., 2003, Syvitski, 2003]. On a smaller scale, accurate river discharge measurements are required to assess coastal inundation and plan navigation projects [Peng et al., 2004, Prandle, 2000], as well as for analyses of coastal upwelling [Gan et al., 2009; Palma et al., 2006], beach sediment supply [Flick and Ewing, 2009; Inman and Jenkins, 1999], habitat access and restoration [Kimmerer, 2002; Kukulka and Jay, 2003a,b; Cloern et al., 1983], salinity intrusion [Prandle, 1985; Uncles and Peterson, 
1996; Cloern et al., 1989; Monismith et al., 2002], and impacts of future climate change [Kukulka and Jay, 2003a,b; Moftakhari et al., 2013].

The lower reaches of a tidal river are difficult locations to determine net freshwater discharge for methodological reasons, and it remains difficult to estimate discharge near the mouth of an estuary with conventional technology [Jay et al., 1997; Fram et al., 2007]. The difficulties include the reversing tidal flow, the compensation flow for the tidal Stokes drift, spring-neap water storage effects, lateral circulation, and the presence in some systems of multiple distributaries or separate ebb/flood channels [Moftakhari et al., 2013]. However, recent studies have introduced methods to calculate discharge in tidal rivers far from the mouth [Hoitink et al., 2009; Sassi et al., 2011; Kawanisi et al., 2010; Chen et al., 2014], but the losses due to infiltration, evaporations, and water diversion that does not let the mass to be conserved in the system increases the uncertainty of discharge estimates at the mouth based o observations made far upstream.

Tidal range decays upriver due to the effects of friction and the river flow. Godin [1999] and Kukulka and Jay [2003a,b] suggested that the damping coefficient depends nonlinearly on river flow velocity. Sassi and Hoitink [2013] explained the mechanism of river-tide interactions, as mutual feedbacks between river stage and tidal motion. Their study suggests that even for high river flow and low tidal velocity amplitudes, river-tide interaction contributes significantly to subtidal friction, and the additional friction, due to river-tide interaction, is directly proportional to the tidal amplitude squared. 
Moftakhari et al. [2013] developed a tidal discharge estimate (TDE) approach to estimate discharge at the mouth using the frictional perturbations that river flow imposes on tidal constituents (see Kulkuka \& Jay [2003a,b]). The physical basis of TDE is nonlinear friction between river flow and tides. If observed tides and the astronomical or coastal forcing are known, discharge may be estimated via an inverse model. The advantage of using TDE is that it moves the nexus of measurement away from the complexities of the delta, without direct requiring flux measurements at the ocean entrance. It also estimates net flow from the estuary to the ocean right at the mouth, which is much less altered than inland locations, and integrates processes over a basin scale; it may therefore capture changes in reservoir management, climate cycles and long-term hydrological trends that cannot easily be ascertained from other data sources. TDE, however useful, is based on very simple dynamical ideas that do not include a number of factors (e.g. the return flow due to upstream Stokes drift and variations in channel cross-section with river flow). TDE also assumes a convergent estuary, and at least a rough balance between tides and discharge.

Cai et al. [2014] investigate the influence of river discharge on tidal wave propagation with specific attention to residual water level (WL) slope, using a onedimensional analytical model for tidal hydrodynamics. Their study improved the prediction of the tidal propagation in estuaries (i.e. tidal damping, velocity amplitude, wave celerity and phase lag), and proposed an alternative analytical approach for estimating freshwater discharge on the basis of tidal WL observations along the estuary. Like TDE, the Cai et al. [2014] approach requires exponential convergence of the cross- 
sectional area, and that the influence of river discharge and tidal discharge are of similar magnitude. Further, the tides must be predominantly semidiurnal.

The purpose of this paper is to demonstrate the feasibility and utility of a multiple-gauge tidal discharge estimate (MTDE) based on analysis of tidal constituents, using tidal observations made on multiple locations along a tidal reach. We first develop and calibrate our MTDE model to two real estuaries, to show the applicability of the model in prototype systems. Then, we implement in Delft-3D Flow [Booij et al. 1999] an idealized two-dimensional (2D) numerical grid, with a convergent cross-sectional profile that resembles many estuaries. Boundary forcing is described in terms of nondimensional numbers for friction, river flow, and convergence length scale. We run Delft3D under for a variety of representative hydrologic and morphologic scenarios to evaluate the effect of different mechanisms on the applicability of the proposed model.

\section{Calibration and Case studies}

\subsection{Settings}

In this study we calibrate our model to the estuaries of Columbia River and Fraser River (Figure 3-1a); two of the largest estuaries in the Pacific Northwest. Together, they drain about $888,000 \mathrm{~km}^{2}$ of North America, and deliver an annual average of about 273,000 million cubic-meter $\left(\mathrm{Mm}^{3}\right)$ of freshwater to the Pacific Ocean, $2003-2013$. 
The Fraser River (FR), with an average flow of $2700 \mathrm{~m}^{3} \mathrm{~s}^{-1}$, is the largest river reaching the west coast of Canada and one of the largest undammed rivers in North America. The watershed above the river gauge at Hope (Figure 3-1b) provides about $72 \%$ of the fresh flow to the Ocean, while the rest of the flow comes from the local tributaries adjacent to the Delta. The river flow is strongly seasonal and most of the discharge comes from melting snow from May to mid-July [Milliman, 1980]. Tidal range at the mouth is $4 \mathrm{~m}$ and in winter (e.g. during low flow periods) decreases landward to about $1 \mathrm{~m}$ at Port Mann (Figure 3-1b); while during Spring freshets it is about 10-20 $\mathrm{cm}$ at Port Mann [Milliman, 1980]. Tides are mixed diurnal/semidiurnal in this system, but mainly semidiurnal [Kustaschuk \& Best, 2005]. The total length of estuary is $108 \mathrm{~km}$ [Le Blond, 1978].

The Columbia River (CR) with the average flow of $7500 \mathrm{~m}^{3} \mathrm{~s}^{-1}$ is the fourth largest river in North America. Climate change, flow regulation, and irrigation diversion have reduced the mean and peak flows, and altered the shape its annual hydrograph over the last century. The tide has a mixed character with a ratio of semidiurnal to diurnal amplitude of 1.5 at the estuary mouth. The diurnal tidal range in the lower CR varies from $\sim 1.7$ to $3.6 \mathrm{~m}$ at the ocean entrance and increases to a maximum of 2.0 to $4.0 \mathrm{~m}$, at Astoria (river-kilometer (RKM) 29; Figure 3-1c). The tidal range then decreases in the landward direction [Jay et al., 2011; Jay et al., 2014]. CR tides are non-stationary landward of RKM 30, so that a description of mean properties in terms of tidal constituents is an approximation [Kukulka and Jay, 2003a]. The total length of estuary to the most seaward dam is $234 \mathrm{~km}$ [Jay et al., 2013]. 


\subsection{Data Sources}

\subsubsection{Tide data}

Hourly tide data from 2002 - 2012 for tide gauges located at Astoria, Skamokawa, Wauna, Long view, St Helens, and Vancouver along CR estuary (Figure 31b, and 3-1c) were downloaded from the National Oceanic and Atmospheric Administration (NOAA) website (http://tidesandcurrents.noaa.gov/). This period was chosen because data collected before March 2002 exhibit gaps, irregularities in timing, and datum shifts at some stations. Hourly data for tide gauges located on Steveston, New Westminister, Port Mann and Mission along FR estuary were recorded by the Environment Canada (http://wateroffice.ec.gc.ca/), from 2000 - 2012 (Figure 3-1b). For both systems, the water level data are relatively (>96\%) complete for all the gauges over the analysis period, and the chosen period is long enough to capture a large dynamic range of river flow conditions, from relatively low, to moderate and high flow events.

\subsubsection{Discharge data}

Environment Canada provides the daily discharge estimates for the FR at Hope (ID: 08MF005; Figure 3-1b) starting in 1912; a continuous recorded flow of more than 104 years is available. The watershed area above this gauge is about $217,000 \mathrm{~km}^{2}$. We use the daily observed flow at this gauge as a representative of freshwater entering lower FR estuary.

The daily discharge values observed for CR at Beaver Army Terminal, near Quincy, OR (USGS 14246900) best represents the freshwater inflow to the lower CR 
estuary. The watershed area above this gauge is $\sim 665,000 \mathrm{~km}^{2}$; it drains $\sim 99 \%$ of the CR watershed, and captures $\sim 97 \%$ of the total discharge [Orem, 1968]. We use the daily observed flow at this gauge as a representative of freshwater entering lower CR estuary.

\section{Methods}

\subsection{Conceptual basis}

Moftakhari et al. [2013] developed TDE based on the idea that tides and river discharge interact through quadratic bed friction; the tidal wave diminishes and distorts as discharge increases. TDE suggests that river flow $\left(Q_{R}\right)$ is related to tidal property ratio ( $\left.T P_{R}\right)$ as:

$$
Q_{R}=\alpha+\beta \times T P_{R}^{\gamma}
$$

where $T P_{R}$ is the ratio of a tidal property (amplitude or range) at a given point along channel to a reference tidal property in the astronomical potential or at a coastal reference station. Moftakhari et al. [2013] used $\mathbf{M}_{2}$ admittance (a ratio of the observed $\mathbf{M}_{2}$ tidal constituent to its astronomical forcing) as $T P_{R}$ to validate TDE at San Francisco (SF) Bay for high flows, and $M_{4} / M_{2}^{2}$ for low flows. They hindcast the historic inflows to SF Bay from 1858 - 1929, the period during which hourly tide data are available, but no flow measurements are available. Since the historic tide data (e.g. the $19^{\text {th }}$ century and the early $20^{\text {th }}$ century) are available for only one gauge in SF Bay, astronomical tidal potential had to be used as the reference tidal property for $M_{2}$. However, tidal admittance based on astronomical tidal forcing does not reflect the physical processes (e.g. nonlinear 
continental shelf processes) that might affect tides near/at the coast. The use of observed tide at a reference gauge to calculate tidal admittance has the advantage of accounting for these physical processes and better represents the nonlinearities over low flow periods.

Elimination of the influence of coastal processes is one of the motivations behind use of multiple gauges. However, using a reference gauge (rather than the tidal potential) as a reference also facilitates improving the time-resolution of tidal discharge estimates. The Harmonic Analysis (HA)-based estimates used for SF Bay had an inherent time scale of $\sim 18 \mathrm{~d}$, due to the limitations of HA. Better time resolution can be achieved by Continuous Wavelet Transform (CWT) tidal analyses, but only at the cost of giving up frequency resolution. CWT analyses resolve tidal species, not tidal constituents, and the tidal admittance may vary across a tidal species, an affect that is more easily accounted for using a reference gauge than the astronomical potential.

Along-channel variations in tidal properties are an important consideration in using tide gauges for MTDE. The energy budget for the lower CR exhibits three reaches: (i) a tidally dominated lower estuary from the ocean entrance up to $\sim \mathrm{RKM} 15$, (ii) an intermediate, dissipation-minimum between about RKM 15 and 50, and (iii) a tidalfluvial reach landward of RKM 50 [Jay et al., 1990]. In FR, however the salt-wedge position is a function of discharge and tidal height, a salt-wedge extends into the lower main channel only [Kostaschuk \& Best, 2005]. In this study we use the Astoria in OR, located in the tidally dominated lower estuary, as the reference station, and use data from stations landward of RKM 30 to calibrate and validate the MTDE model. Also, we chose Steveston in the FR as a reference gauge. Both of these gauges are landward of salinity 
intrusion for part or much of the year, but near the upstream edge of salinity intrusion during low flow periods.

\subsection{Numerical modeling}

To determine how measured variations in river flow, friction and other factors altering tidal properties affect discharge estimates based on MTDE, an idealized, depthintegrated numerical 2D tidal-river model was developed using the open-source numerical model Delft3D Flow [Booij et al. 1999]. The grid is specified parametrically, so that properties such as the lateral depth profiles and the convergence of channel crosssectional in the along-channel direction. An example of the idealized bathymetry and numerical grid is shown in Figure 3-2. Given that salinity intrusion is negligible upstream of the reference gauge in both FR and CR systems, a vertically integrated approach appropriately describes the hydrodynamics of the system.

The width of the CR estuary decreases almost exponentially in the lower estuary (e.g. from $\sim$ RKM-30 to RKM-140), as observed in many estuaries and often assumed in idealized estuary models [Jay, 1991; Friedrichs \& Aubrey, 1994; Talke et al., 2009; Cai et al., 2014]. However, the landward $\sim 90 \mathrm{~km}$ of the estuary (i.e., landward of RKM 140) is relatively constant in width, in part due to dredging and modification of the banks. Although the tide reaches the Bonneville Dam at RKM-234 during low flow periods, it is very small there; thus there is effectively no reflection. The dominant tidal process affecting water levels landward of RKM-170 is daily hydropower management ("power peaking”), but this does not much affect $\mathrm{D}_{2}$ wave property, when estimated by a multi- 
day wavelet filter, so this process is not modeled. To eliminate reflections in the numerical model, we have extended the numerical grid to RKM-300. Each cross-section contains a Gaussian channel (e.g. Huijts et al. [2006]) and is flanked by an intertidal area with a constant slope (Figure 3-2). Smooth grid lines for any assumed convergence rate are produced parametrically, such that the channel cross-section contains 50 grid partitions and the intertidal areas contain 40. The estuary is divided into 750 alongchannel cells. The automatic Delft3D ‘orthogonalisation' software is used, and the grid is checked to ensure smoothness. The prototype bathymetry in the idealized tidal-river model is described in terms of parameters that can be systematically varied to produce a family of grids; the parameters are length $L$, channel depth $H$, channel width $W_{c}$, total width $W_{e}$, convergence length scale $L_{b}$. Here, the parameters $H=15 \mathrm{~m}, L=300 \mathrm{Km}$, and the ratio $W_{c} / W_{e}=0.5$ are held constant along-channel with $W_{e}=10 \mathrm{Km}$ at the mouth; and we have used three different values of convergence length scales for the lower reach of the estuary to test the effects of geometry (Table 1). The ratio and tidal to river flow and the strength of bed friction are also varied systematically, as described below.

The model is forced by a time-varying hydrograph of river flow $Q_{R}$ at the landward end and by $\mathrm{K}_{1}, \mathrm{O}_{1}, \mathrm{~N}_{2}, \mathrm{M}_{2}$ and $\mathrm{S}_{2}$ tidal constituents at the seaward boundary (Table 2), overtides are considered negligible at the seaward boundary; an appropriate assumption in both systems. A spatially constant bottom friction coefficient is used in each scenario (Table 1). To allow start-up time and include entire neap-spring and $\mathrm{K}_{1} / \mathrm{M}_{2}$ cycles, we run the model for 40 days. 
We control estuarine "type" by altering three non-dimensional master variables that control tides, on the grid described above; an example is shown in Figure 3-2. Thus, each new combination of master variables (Table 1) yields a new scenario. While additional variables could be added, these three were chosen based on the results from previous idealized studies [e.g., Ianiello 1979; Jay 1991; Lanzoni \& Seminara 1998] to produce the smallest parameter space sufficient to realistically test MTDE. These nondimensional parameters are also relevant, that changes in them are associated with secular change in estuaries and tidal rivers. Our choices for non-dimensional variables are:

i) Friction, parameterized as $\psi=C_{d} L_{b} \eta / H^{2}$ (the inverse of the Strouhal number), where $C_{d}$ is bottom friction, $L_{b}$ is the convergence length scale, $\eta$ is the tidal amplitude and $H$ is the total depth, for unstratified flow [Ianniello, 1979]. Parameter $\psi$ represents the effect of change in bed friction (e.g. change in bed material or bedforms) but also reflects the effect of mean sea level rise (via $H)$.

ii) River Discharge, parameterized as $\Omega=U_{R} / U_{T}$ (the ratio of freshwater velocity to tidal velocity). To compare $U_{R}$ and $U_{T}$, and estimate $\Omega$ we compare the peak river flow to the peak tidal discharge. The flow might occur on different time scales ranging from days (e.g. storm-driven freshets) to months (e.g. snowmelt driven freshets). Thus, for each magnitude of $\Omega$ we develop two hydrographs that have the same peak flows but differ in the time-scale of the high-flow event (i.e. "slow" freshets lasting almost a month and "fast" 
floods with a time scale of $\sim 10 \mathrm{~d}$ ). The slow hydrographs are long enough to cover the dynamic range of tidal variability. To study the sensitivity of model to spring-neap tidal effects we run the fast flood cases under two different scenarios, with the peak flow occurring during neap, and spring tides, respectively (Figure 3-3).

iii) Convergence length scale $\left(\omega L_{\underline{b}} \underline{c_{o}}\right)$, where $\omega$ and $c_{o}=(g h)^{1 / 2}$ denote the tidal frequency, and inviscid wave celerity, respectively. Given constant depth and constant $c_{o}$, we study the effect of funneling on tide propagation and applicability of MTDE, by varying different $L_{b}$.

The non-dimensional variables and their range of values are presented in Table 1. Using three different values for each of $L_{b}, \psi$ and $\Omega$, each with three sub-scenarios of different river flow hydrographs, implies $3 \times 3 \times 3 \times 3=81$ model runs in total. For each scenario we store water level for six gauges along the channel (at RKM 29, 53, 68, 107, 138 , and 172). The choice of these locations in the idealized model is compatible with the gauges located in the lower CR. Next, using the approach described in section 3.2.2 we analyze the tide data to obtain the amplitude of tidal constituents at each station. Then ratio of the $\mathrm{D}_{2}$ constituent at different locations to the reference station is calculated (i.e. the $\mathrm{D}_{2}$ admittance $\Gamma$, a complex number). $\Gamma$ can be resolved into an amplitude and phase and describes $\mathrm{D}_{2}$ tidal evolution along the channel. Finally, equation (3.1) can be used to estimate river flow from the $\mathrm{D}_{2}$ admittance amplitude $|\Gamma|$. Kukulka and Jay [2003a] showed that the admittance phase could also be used, but phases are more strongly 
affected by timing errors than amplitudes, so $|\Gamma|$ is more useful, at least for typical tidegauge records.

\subsection{Water level analysis}

The WL regime of tidal rivers is complex and statistically nonstationary, and like any other nonstationary signal, it is useful to employ more than one analysis tool to determine the energy content of different frequencies, ranging from tidal to interaannual time scales [Jay and Flinchem, 1997; Jay et al. 2014]. Power spectra and Continuous Wavelet Transform (CWT) analyses are often used together, because the former provides a high-resolution (in frequency) view of the average frequency content of a signal, while the latter resolves time variations in frequency content, but at a lower frequency resolution [Jay et al. 2014].

\subsubsection{Frequency domain analysis}

A power spectrum defines the time-average of the frequency content of water level time series at narrowly spaced frequencies [Jay et al., 2014]. At the tidal time-scale spectral analysis defines the major tidal constituents that should be included tidal analysis.

Figure 3-4b presents the power spectra of the WL data from $2002-2012$ for the gauges in the CR. The results suggest diurnal $\left(D_{1}\right)$ and semidiurnal $\left(D_{2}\right)$ bands contain most of the energy, however there are energies in biweekly, seasonal, semi-annual and annual bands as well. A peak at 7 days is seen in the discharge and at the Vancouver gauge; this represents the weekly "power peaking" [Kukulka and Jay, 2003a]. Figure 3- 
4a represents the spectral analysis of the WL data from 2000 - 2012 observed on the gauges in FR estuary. The results suggest that the energy content in diurnal and semidiurnal bands are of the same order of magnitude, and similar to the CR; there is also energy in seasonal, semi-annual and annual bands (3 - 12 months).

\subsubsection{Tidal analysis using CWT}

Moftakhari et al. [2013] determined tidal properties as a time series using a sequential 32-day harmonic analyses (HA), carried out at 7-day intervals over the length of record. To minimize the effect of averaging over the 32-day calculating window they implemented HA with a Kaiser filter, which allowed an effective resolution of 18 days to their tidal analysis. HA assumes a stationary system, which is a good assumption for oceanic tides. In tidal rivers aperiodic processes (i.e. storms and river discharge) may cause the measured wave to be non-stationary. Moreover, river flow energy may occur on timescales of a week or less (Figure 3-4). HA for window lengths less than 15 days of data may cause mixing of information amongst tidal frequencies and between tidal frequencies and frequencies not included in HA [Flinchem and Jay, 2000]. Wavelet analysis provides a valuable tool for analysis of tidal processes that deviates from the assumption of periodicity inherent in HA [Jay and Flinchem, 1997]. Properties of CWT such as linearity, reversibility guarantee that results in one frequency band are independent of those in other bands, so that the frequency responses are well-defined functions [Flinchem and Jay, 2000]. CWT filters banks can also achieve nearly optimal recovery of information (as defined by the Heisenberg principle), thus we use CWT to calculate $\mathrm{D}_{2}$ amplitude over a desired calculating window. 
The first step in use of the CWT method is choosing an oscillatory prototype function $\left(\Phi_{0}(t)\right)$, which satisfies the following criteria:

$$
\begin{aligned}
& \text { i) } \int \Phi_{0}(t) \Phi_{0}^{*}(t) d t>\infty \text {; where } \Phi_{0}^{*}(t) \text { is the complex conjugate of } \Phi_{0}(t), \\
& \text { ii) } \int \Phi_{0}(t) d t=0 \\
& \text { iii) } \quad \lim _{|t| \rightarrow \infty} \Phi_{0}(t)=0
\end{aligned}
$$

The prototype function guarantees that the prototype wavelet is wavelike and localized in time-frequency space. Figure 3-5 depicts the prototype function that has been used in this study, a Gaussian filter with 7 extrema (gaus8); this function helps us to accurately distinguish between $\mathrm{D}_{2}$ tide and higher frequencies (e.g. $\mathrm{D}_{4}$ tides). CWT properties guarantee that for $0>a>\infty$ and $-\infty>b>\infty, \Phi_{a, b}(t)$ forms a complete basis similar to the Fourier transform basis set over $[-\infty, \infty]$ :

$$
\Phi_{a, b}(t)=a^{-p} \Phi_{0}\left(\frac{t-b}{a}\right)
$$

In this study we apply the CWT over a moving calculating window of length of $49 \mathrm{hr}$ and the step size of $25 \mathrm{hr}$. Thus tidal variations are modeled on a time-scale much shorter than the high-flow events (e.g. a week or a month), and can accurately capture the river-flow induced variations in tides.

\subsection{Regression analyses}


In this study we use $\mathrm{D}_{2}$ admittance amplitude (the amplitude of the complex ratio of the observed $D_{2}$ tidal species at the gauge to the observed $D_{2}$ at reference gauge) to describe the variation of tidal properties with river flow using equations (3.1) and (3.2). In the prototype systems, the parameters $\alpha, \beta$, and $\gamma$ in equation (3.1) are determined by nonlinear regression analysis of observed discharge before 2010 against $\mathrm{D}_{2}$ admittance, using the Matlab function (nlinfit). For use in the regression analysis, the $\mathrm{D}_{2}$ admittance values were bin-averaged into 100 bins, evenly spaced along the admittance axis (Figures 3-6 and 3-7). Before bin-averaging, points associated with noisy or incomplete data were removed from the time series of tidal properties. As Moftakhari et al. [2013a] suggest and Figures 3-6 and 3-7 show, the relationship between $\mathrm{D}_{2}$ admittance and discharge is nonlinear and different between low and high flow periods. Thus separate nonlinear regressions were carried out for low $\left(<1,800 \mathrm{~m}^{3} \mathrm{~s}^{-1}\right.$ in FR) and high flows $\left(>1,800 \mathrm{~m}^{3} \mathrm{~s}^{-1}\right)$. However, for the three upstream gauges on CR, Longview, St Helens and Vancouver, a single curve adequately describes the relationship during both low and flow periods. Table 3 presents the regression parameters for each gauge in CR and FR. Next, the calibrated models (e.g. estimated regression parameters) are used to estimate the freshwater discharge to the lower estuary in both CR and FR post-2010.

The 40day modeled tides at each RKM in the idealized system (described in 3.2) were determined using CWT (described in 3.3.2) and the calculated admittance (with reference to the tide observed at the mouth) was analyzed versus freshwater discharge to determine how tidal properties vary with flow. The parameters $\alpha, \beta$, and $\gamma$ in equation 
(3.1) are determined by nonlinear regression analysis for each RKM, as for the observed time series.

\subsection{Addressing neap-spring effects}

The discharge estimated by MTDE is affected by neap-spring variations in frictional properties, mean depth, and Stokes drift, factors which are not addressed in equation (3.1). To account for neap-spring variations in admittance for any given discharge, we generalize equation (3.1) based on the analysis of Kukulka and Jay [2003a] to iteratively estimate discharge as:

$$
Q_{(n)}=a+b A D^{c}+d \frac{T R^{2}}{Q_{(n-1)}^{e}}
$$

where $T R$ is greater diurnal tidal range observed at the mouth $(T R)$, and $Q_{(n)}$, and $Q_{(n-1)}$ denote the estimated discharges at steps $n$ and $n-1$ of the iteration, respectively. Here, $A D$ denotes the tidal admittance, and parameters $a, b, c, d$, and $e$ are determined by nonlinear regression at each iteration step. To begin the iterative process, $d$ is assume to be zero for step $n=1$.

\section{Results and discussion}

The fitted non-linear curves that describe the relationship between the $D_{2}$ admittance and river flow were used to estimate river flow from equation (3.2), and to validate MTDE. In the prototype systems (the FR and CR) the models calibrated from data prior to 2010 were used to estimate flow after 2010. This comparison generally validates MTDE, but also indicates situations in which MTDE is not successful in 
predicting river flow. For the $2 \mathrm{D}$ numerical model, the calibrated curve to the $40 \mathrm{day}$ observation is used to estimate the freshwater discharge over the same 40day period and check the accuracy of the prediction. However, first two days of the data were neglected because of startup issues and the effective length of the observations is 38 days.

\subsection{Prototype systems}

The efficacy of the river flow predictions in FR from 2010 - 2012, the period that is not used for calibration, is shown in Figure 3-8. Figures 3-8a, 3-8b, and 3-8c show the scatter plot of estimated river flows based on tides observed at New Westminster, Port Mann, and Mission, respectively, versus observed freshwater discharge at Hope (Figure 3-1b); while Figure 3-8d compares the estimated river flow time series to the observed flow. For low to moderate river flow $\left(<6,000 \mathrm{~m}^{3} \mathrm{~s}^{-1}\right)$ periods, $\mathrm{D}_{2}$ admittance at the gauge located farthest upstream, Mission (RKM-82), best describes the variation in river flow; the Nash-Sutcliffe efficiency coefficient (NSEC) [Nash and Sutcliffe, 1970] for flow prediction over low to moderate flow rates is 0.93 . However, because the tidal wave did not reach this point during high flow events, this gauge could not predict flows greater than $6,000 \mathrm{~m}^{3} \mathrm{~s}^{-1}$. New Westminster and Port Mann, with NSEC equal to 0.87 and 0.89 respectively, work relatively well in estimating discharge over a wide range of flow rates; however both somehow underestimate low flows. Port Mann is more successful in term of high river flow prediction, relative to New Westminster. The likely reason that MTDE works well in the FR is: i) it is a weakly convergent river-flow dominated system, where tides are mostly affected by river-flow induced friction rather than tidal constituent interactions; thus, any change in river flow is appropriately reflected in tidal properties, 
and ii) large seasonal changes in $\mathrm{D}_{2}$ admittance allows MTDE to be readily calibrated. However, all stations show large changes in admittance over the annual flow range. Also, FR flows are essentially unregulated, and flows vary from $600 \mathrm{~m}^{3} \mathrm{~s}^{-1}$ to $11,700 \mathrm{~m}^{3} \mathrm{~s}^{-1}$. Thus, the relatively successful results for the FR suggest that: a) MTDE can be used for the wide flow range of an unregulated river, even with only four tide gauges; and b) that the large dynamic range in flow of such a system makes calibration easier.

The five CR gauges that we employ for tidal discharge estimate in this study are located in tidal-fluvial part of CR, where the tidal flow and river flow are at the same order of magnitude [Jay et al., 1990]. Figure 3-9 compares the measured freshwater inflow to the lower estuary with the estimated flow via MTDE at Skamokawa, Wauna, Longview, St Helens, and Vancouver, respectively, from 2010 - 2013, the period that is not used for calibration purposes. The results suggest the gauges farthest from the mouth better predict flows for both low and high flow periods; Overall NSEC for flow predictions scatter-plotted in the panels of Figure 3-9 are 0.32, 0.67, 0.82, 0.92, and 0.94, respectively. However, Skamokawa predicts the very high flow event in 2011 better than the rest. The reason that the two most landward gauges do not work well during the 2011 high flow event (e.g. $>15,000 \mathrm{~m}^{3} \mathrm{~s}^{-1}$ ) is that the tide do not reach these two locations for flows of this magnitude. While flows in the CR are mostly regulated so that flows rarely exceed $15,000 \mathrm{~m}^{3} \mathrm{~s}^{-1}$, flows of 20,000 to $30,000 \mathrm{~m}^{3} \mathrm{~s}^{-1}$ have occurred during brief winter floods on several occasions since 1964 . While MTDE adequately represent CR for flow prediction purposes for most purposes, we cannot confirm that it would work for rare high flows, because of a lack of data. For the last such event in February 1996 all of the 
tide gauges employed here were out of commission due to power failures, except the reference gauge at Astoria. The reason for relative success of the various gauges will be discussed in terms of non-dimensional parameters; below.

These results validate the MTDE over a wide range of flow regimes in two different river estuaries. Though the results suggest that there is a trade-off between river flow and optimal prediction position. Stations farther from the mouth are more sensitive to variations in river flow, and change in river flow is dominant over other factors contributing in tidal wave adjustment; but a station too far from the mouth will not have an observable tide during periods of very high discharge. Figure 3-10a conceptually depicts the along-channel variation of tidal amplitude during low and high flow events. The change in tidal amplitude due to variation in river flow is small at the gauges located close to the mouth. Thus, during low-flow periods. the strongest variations in admittance occur in the landward half of the system (e.g. $x / l>0.5$; where $x$ is along-channel distance from the mouth and $l$ is the total length of the estuary). During high-discharge periods, In contrast, variations in admittance are larger close to the mouth (for $x / l<0.5$ ), and the tide loses most of its energy before reaching the upriver gauges. Figure $3-10 \mathrm{~b}$ shows the variation of semidiurnal tidal amplitude (e.g. $\mathrm{D}_{2}$ amplitude) along channel during low and high flow periods in both CR and FR. The results suggest that a decrease in freshwater discharge from high flows in May $2011\left(\sim 15,000 \mathrm{~m}^{3} \mathrm{~s}^{-1}\right)$ to low flows $\left(\sim 4,000 \mathrm{~m}^{3} \mathrm{~s}^{-1}\right)$ in December 2011 only cause the $\mathrm{D}_{2}$ amplitude near the mouth to rise by $\sim 9 \%$. In contrast, the same change in river flow cause the $\mathrm{D}_{2}$ amplitude at St Helens $(x / l \sim 0.58)$ to increase from $0.19 \mathrm{~m}$ to $1.25 \mathrm{~m}(\sim 6.5 \mathrm{x}$ larger $)$. Similarly, an increase in river flow in the FR from 
$1,000 \mathrm{~m}^{3} \mathrm{~s}^{-1}$ in February 2012 up to $11,500 \mathrm{~m}^{3} \mathrm{~s}^{-1}$ in June 2012 causes the $\mathrm{D}_{2}$ amplitude to decrease by $\sim 10 \%$ at the mouth; while the same increase in river flow rate cause the $D_{2}$ amplitude at Mission to decrease from $1.65 \mathrm{~m}$ to $0.1 \mathrm{~m}$.

These results can be interpreted as follows. In lower reaches of an estuary where cross-sectional area is large, changes in river flow have only a limited influence on tidal properties relative to neap-spring adjustments and fluctuation in sea level. In systems in which salinity intrusion is present at their reference stations, variation in salinity intrusion might also influence bed friction and tidal properties. Upriver where cross-sectional area is smaller, salinity intrusion is not present, flow is uni-directional, and tidal-fluvial frictional interactions are the primary factor that modulate tides. However, under some circumstances (e.g. extremely high flow events when tidal waves could not reach far upstream) a downstream gauge may work better than upstream gauges, because the tide is nearly extinguished upriver. Figure 3-10 shows how the $\mathrm{D}_{2}$ amplitude at Mission (in FR) and Vancouver (in CR) tends to zero during the extremely high flow events. Thus, MTDE is best implemented with at least three gauges, a reference gauge and two gauges strategically located along the tidal-river in a manner that is adapted to the geometry and discharge regime of the system. We next study the effect of variation in physical parameters and tidal characteristics on the applicability of MTDE through numerical modeling on an idealized estuarine system.

\subsection{Idealized system}




\subsubsection{Applicability of MTDE}

We ran the idealized model described in section 3.2 under the 81 scenarios of variable morphologic/hydrologic characteristics defined in Table 1 and Figure 3-3a. The modeled WL data for the locations noted in Section 2.2.1 were analyzed via MTDE, and then MTDE estimates were compared with actual flow input to the model for each of the 81 scenarios to understand MTDE performance in terms of nondimensional variables. The analysis procedure was the same as for the observed tidal records.

The contour plots in Figure 3-11 show NSEC values for MTDE models for each of the 81 hydrologic/morphologic scenarios, described in section 3.2. Figures 3-11a, 3$11 \mathrm{~b}$, and 3-11c show the results under the three flow scenarios: slow freshet, fast flood during a neap tide, and fast flood during a spring tide, respectively. As the results show, the time scale that the high flow event occurs (e.g. gradually varying hydrographs vs. rapid varying flows) definitely affects the applicability of MTDE for a given set of nondimensional numbers. MTDE is more successful in flow prediction when the high flow event occurs over a longer time span (the slow freshet), than for the fast floods. This is likely the case, because flow variations can be substantial over the 49hr CWT filter length. Also, there are likely lags in the system between the forcing by discharge and the tidal response; these were not accounted for here. Jay et al. (2014) found these lags to be short, however.

The contour plots of Figure 3-11 help us determine the range of nondimensional variables that MTDE gives better predictions. The CR and FR systems are characterized as strongly convergent (closest to the case $L_{b}=100 \mathrm{~km}$ ), and weakly convergent (closest 
to the case $L_{b}=200 \mathrm{~km}$ ) tidal rivers, respectively [Lanzoni \& Seminara, 1998], with nondimensional friction numbers of $\Psi_{C R}=\frac{C_{d} L_{b} \eta}{H^{2}}=\frac{3 \times 10^{-3} \times 8.5 \times 10^{4} \times 1}{13.1^{2}} \approx 1.49$ [Kukulka \& Jay, 2003b; Jay et al., 2011], and $\Psi_{F R}=\frac{C_{d} L_{b} \eta}{H^{2}}=\frac{3 \times 10^{-3} \times 1.7 \times 10^{5} \times 1.5}{13.7^{2}} \approx 4.07 \quad[$ McDonald \& Geyer, 2004; Kustaschuk \& Best, 2005].

High flow events occur in the CR on both the fast (winter rain-on-snow events) and slow (spring snowmelt freshets) times scales [Jay and Naik, 2011] (Figures 3-11a). I suggest that MTDE should be able to successfully predict (NSEC $>0.5$ ) low to moderate discharges $(\Omega<0.5)$ in $\mathrm{CR}$ the (with nondimensional convergence of $\lambda L_{b}^{-1} \approx 1.14$ ) using the observed tides at gauges located at relative distance (e.g. $x / l$ ) greater than 0.4 , if the high flow event occurs on the fast time-scale. However, for relatively high flow events ( $\Omega$ $=0.9)$ gauges located at $0.3<x / l<0.5$ would be the best locations for MTDE. Because the tidal wave is weak beyond $x / l=0.5$ during extremely high flow events, gauges beyond this point cannot successfully predict river flow. For moderate to high flow events occurring on a monthly time scale (e.g. snowmelt driven flows) MTDE best predicts flow; using the tides observed at $0.4<x / l<0.7$. Figure 3-9 supports this analysis and shows how MTDE successfully estimates flows over a wide range of rates except the spring freshet in 2011 that gauges located in mid-estuary $(x / l \sim 0.5)$ work best.

The highest inflows in the FR (with nondimensional convergence of $\lambda L_{b}^{-1} \approx 2.18$ ), occur during snowmelt freshets [Milliman, 1980; Kustaschuk \& Best, 2005] that cause 
moderate to high flow events with a monthly time-scale. Thus, Figures $3-11 \mathrm{j}-3-111$ best describe the range of nondimensional numbers that MTDE would be able to predict river flow in FR; however the range of nondimensional friction ( $\Psi=0.5$ to 3$)$ covered in these panels does not quite match the value for FR $\left(\Psi_{F R} \approx 4.07\right)$. Figures $3-11 \mathrm{j}-3-111$ suggest that during moderate to high flow periods $(\Omega=0.6-0.9)$ in systems with somewhat lower friction (e.g. $\Psi<3$ ) compared with FR, MTDE best describes the variation in river flow based on observed tide at gauges located farthest from the mouth. In the Fraser, however, the high friction nearly extinguishes the tide at landward stations during high flow, and more seaward stations must be used for MTDE.

In summary, the range of nondimensional numbers used in our numerical modeling provides a tool to describe the hydrodynamic characteristics of a variety of prototype systems. Figure 3-11 provides an overview that describes conditions under which MTDE is able to accurately predict river flow in a given system with certain hydrologic and morphologic characteristics.

\subsubsection{Discussion}

Numerical model results (Figure 3-11) show that MTDE discharge estimates are associated with considerable uncertainty when the tide gauge employed is in lower reaches of a system, near the mouth of the estuary. The likely reason is that the WL at such gauge is more affected by lateral variability, and tidal-constituent interactions that cause the energy to deliver from one frequency to another than by river flow. Stokes drift compensation flow might be an important factor that produces error in flow estimates 
using tides observed close to the mouth. To the first order, the Stokes drift transport is [Longuet-Higgins, 1969]:

$$
Q_{s t}=\frac{1}{2}\left\{U_{(t)}\left(H_{(t)}-\bar{H}\right)\right\} W_{e}
$$

where $Q_{s t}, U, H$, and $W_{e}$ denote the Lagrangian Stokes drift (which must be compensated by an Eulerian return flow), cross-sectionally averaged velocity, water depth, total width of the estuary, and \{\} a tidal average, respectively. Figures 3-12a and b show the alongchannel variation of the ratio between Stokes drift flow and the freshwater inflow during low and high flow periods, respectively, for idealized tidal-river with $\Psi \approx 2$. The Eulerian Stokes drift compensation flow represents an addition to the net outflow that is not part of the river discharge, and which varies over the tidal month, approximately with the square of the tidal amplitude, as equation (3.4) suggests. The existence of the Stokes drift is one reason that the neap-spring term in equation (3.3) is needed. As the Figure 312 suggests, the Stokes drift is strongest in the lower reach of the system (e.g. $x / l<0.4$ ), and far from the mouth it tends to zero. For high flows, it never exceeds $\sim 6 \%$ of the river discharge and should not have a large effect on MTDE estimates. During low-discharge periods, the Stokes drift compensation flow reaches higher values, up to $35 \%$. The competing effects of river flow and Stokes drift are, accordingly, one of the reasons that MTDE is less successful during low flow periods. Nonetheless, Figures 3-8 and 3-9 suggest that MTDE can be used during low-discharge periods, if the gauge employed is properly located and calibrated. 


\section{Conclusions}

This study demonstrates the feasibility of the MTDE method for estimating freshwater discharge through a variety of estuaries and tidal-rivers using tidal observations made at multiple locations along the estuary. Farther from the mouth, where there is a balance between cross-sectional funneling and damping of the tide by friction, MTDE works better. During low to moderate flow periods, the WL observed on gauges located far upstream best reflect variations in river discharge, and MTDE best predicts river flow. However, the tide may not reach these upriver stations with sufficient amplitude during high-flow periods to allow MTDE to predict flow. During high-flow periods, MTDE based on gauges closer to the upstream limits of salinity intrusion is more effective. This suggests that practical use of MTDE in estuaries with high variability in river flow will require three tide gauges, a reference gauge near the ocean and two gauges further upriver.

The distribution of NSEC in the Delft3D results provides an overview of the response of the MTDE method to variations in three nondimensional numbers and identifies the ranges for which MTDE best predicts river discharge. Numerical model runs suggest that MTDE is most effective using gauges where there is strong variability in tidal properties with flow. Close to the estuary entrance tidal admittance variations (at least in the $\mathrm{CR}$ and FR) are small, and the tidal variability induced by fluctuating river discharge may be masked by the influences of coastal processes. Far upriver, the tides are always small, and again the dynamic range in tidal variability is too small to allow accurate discharge estimates from tidal properties, especially for high flows. A 
convergent estuary will, it appears from numerical model results, exhibit a "sweet spot" that maximizes tidal variability with flow. If, however, the river discharge range is sufficiently large, a single tidal-fluvial station may not adequately cover the full range of observed river discharge, leading to a need to employ three gauges, as noted above. Finally, Delft3D results suggest that the contribution of the Stokes drift compensation flow to the total outflow of the system may interfere with MTDE estimates during lowdischarge periods, at least for gauges located near the estuary mouth. 
Table 3-1: Nondimensional master variables used in modeling, and their ranges

\begin{tabular}{|l|l|l|l|}
\hline Variable & Value 1 & Value 2 & Value 3 \\
\hline Convergence length-scale $\left(L_{b} / \lambda\right)$ & 1.5 & 2.25 & 3 \\
\hline River flow/tidal flow $\Omega=U_{R} / U_{T}$ & 0.3 & 0.6 & 0.9 \\
\hline Friction $\psi=\left(C_{d} L \eta / H^{2}\right)$ & 1 & 2 & 5 \\
\hline
\end{tabular}

Table 3-2: Tidal constituent properties at the ocean boundary

\begin{tabular}{c|cc}
\hline Tidal Constituent & Amplitude $(m)$ & Phase (degree) \\
\hline $\mathrm{M}_{2}$ & 0.886 & 227.02 \\
$\mathrm{~K}_{1}$ & 0.413 & 241.42 \\
$\mathrm{~S}_{2}$ & 0.303 & 251.29 \\
$\mathrm{O}_{1}$ & 0.226 & 220.87 \\
$\mathrm{~N}_{2}$ & 0.168 & 204.22 \\
\hline
\end{tabular}

Table 3-3: MTDE regression model parameters

\begin{tabular}{c|c|c|c|c|c|c|c}
\multicolumn{2}{c|}{} & \multicolumn{3}{c}{ Low Flows } & \multicolumn{3}{c}{ High Flows } \\
\cline { 3 - 8 } \multicolumn{2}{c|}{} & $\alpha$ & $\beta$ & $\gamma$ & $\alpha$ & $\beta$ & $\gamma$ \\
\hline \multirow{4}{*}{$\begin{array}{c}\text { New } \\
\text { Westminster }\end{array}$} & $1.28 \times 10^{5}$ & $-1.26 \times 10^{5}$ & 0.017 & $1.04 \times 10^{6}$ & $-1.04 \times 10^{6}$ & 0.017 \\
\cline { 2 - 8 } & Port Mann & $1.74 \times 10^{5}$ & $-1.73 \times 10^{5}$ & 0.009 & $7.13 \times 10^{5}$ & $-7.16 \times 10^{5}$ & 0.016 \\
\cline { 2 - 8 } & Mission & $1.17 \times 10^{5}$ & $-1.16 \times 10^{5}$ & 0.010 & $9.49 \times 10^{3}$ & $-1.08 \times 10^{4}$ & 0.362 \\
\hline \multirow{4}{*}{$\begin{array}{c}\text { Columbia } \\
\text { River }\end{array}$} & Skamokawa & $5.36 \times 10^{5}$ & $-5.32 \times 10^{5}$ & 0.015 & $4.28 \times 10^{5}$ & $-4.30 \times 10^{5}$ & 0.123 \\
\cline { 2 - 8 } & Wauna & $1.31 \times 10^{5}$ & $-1.26 \times 10^{5}$ & 0.001 & $2.92 \times 10^{4}$ & $-3.08 \times 10^{4}$ & 1.301 \\
\cline { 2 - 8 } & Longview & $2.36 \times 10^{4}$ & $-2.80 \times 10^{4}$ & 0.622 & $2.36 \times 10^{4}$ & $-2.80 \times 10^{4}$ & 0.622 \\
\cline { 2 - 8 } & St Helens & $2.22 \times 10^{4}$ & $-2.63 \times 10^{4}$ & 0.363 & $2.22 \times 10^{4}$ & $-2.63 \times 10^{4}$ & 0.363 \\
\cline { 2 - 8 } & Vancouver & $2.36 \times 10^{4}$ & $-2.50 \times 10^{4}$ & 0.223 & $2.36 \times 10^{4}$ & $-2.50 \times 10^{4}$ & 0.223
\end{tabular}




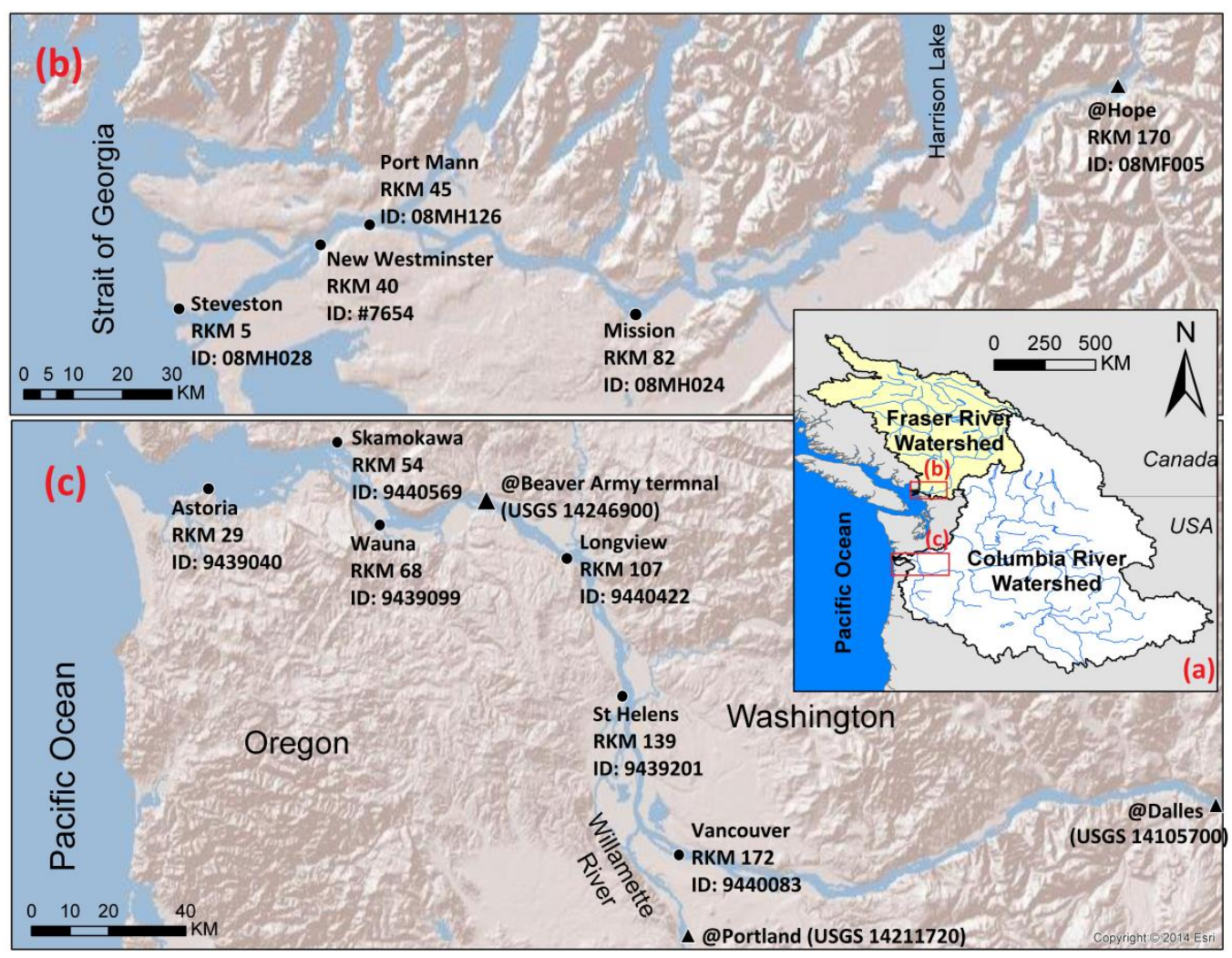

Figure 3-1: Map of the study area; Panel(a): The watershed boundaries for Fraser river and Columbia River, and location of panels (b) and (c); Panel (b): Fraser river lower estuary; Panel (c): Columbia river lower estuary. Black dots represent the tide gauges, and black traingles represent the river flow observatories. The IDs mentioned beside each gauge in the FR are based on Canada Environment database, and in the CR are on the NOAA database. Copyright for ESRI and http://www.cec.org/.
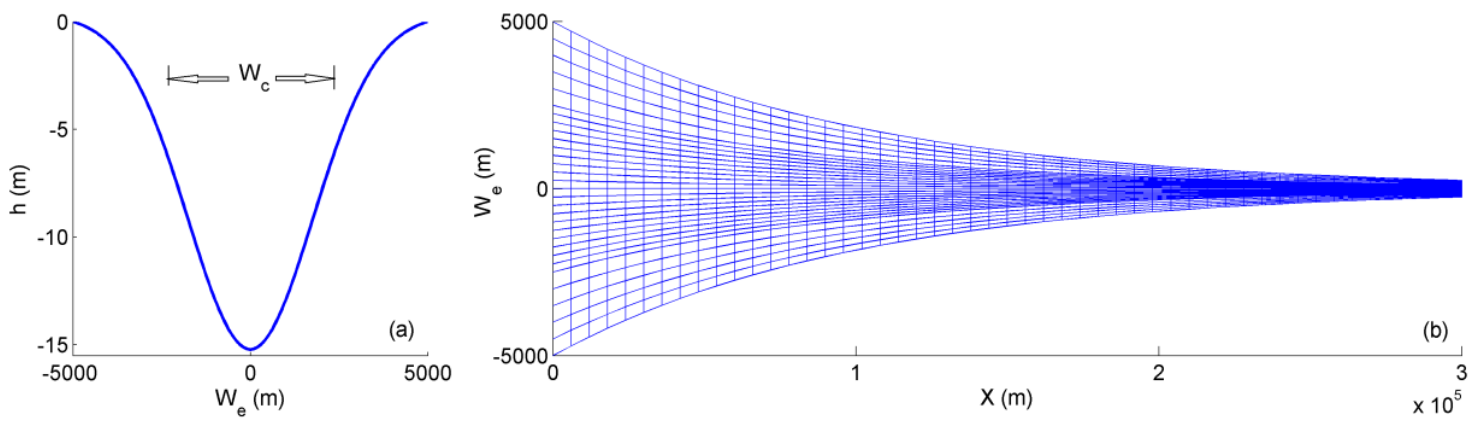

Figure 3-2: (a) Idealized bathymetry and (b) the plan view of the grid 

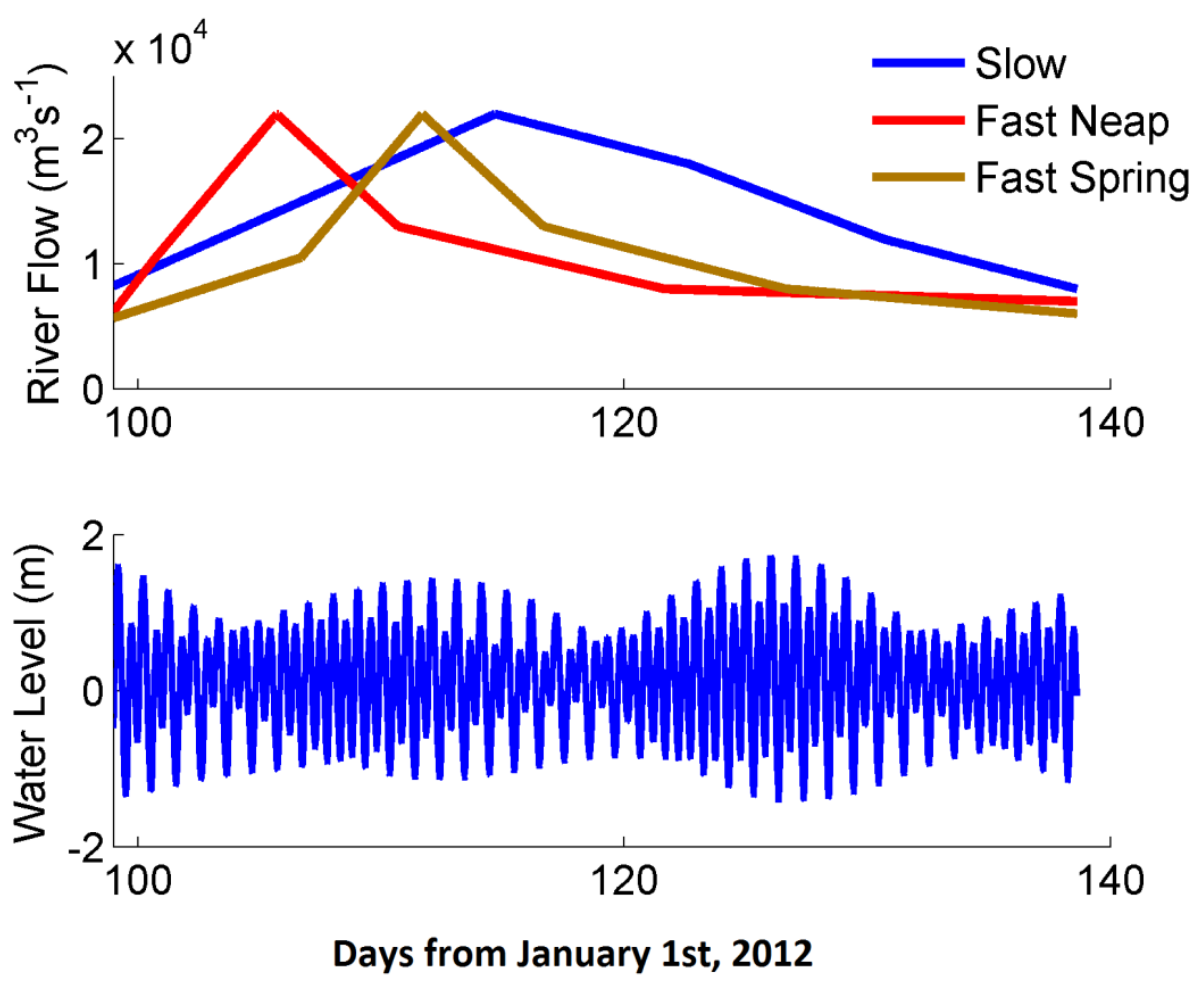

Figure 3-3: Panel (a) measured river flow at the upstream boundary under different scenarios of gradually varying high flow event (e.g. "slow" freshet and "fast" floods); Panel (b) measured water-level at the ocean boundary.

(a)

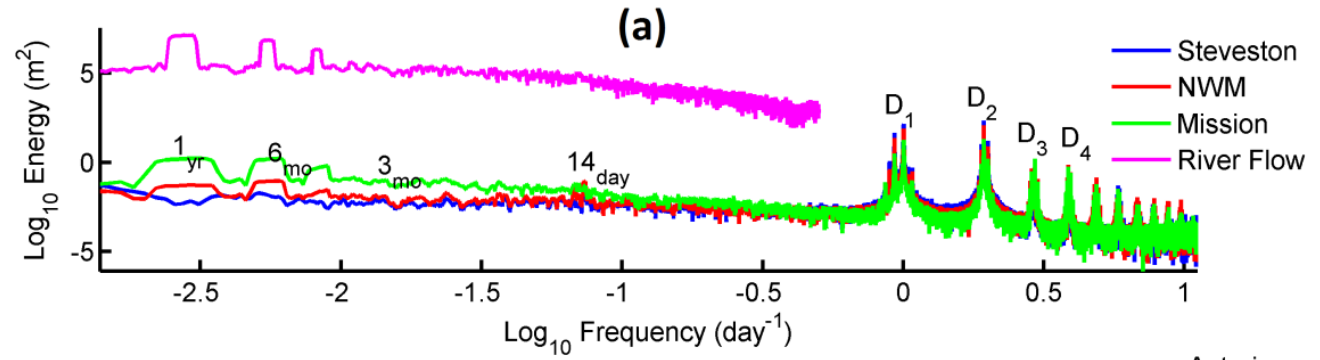

(b)

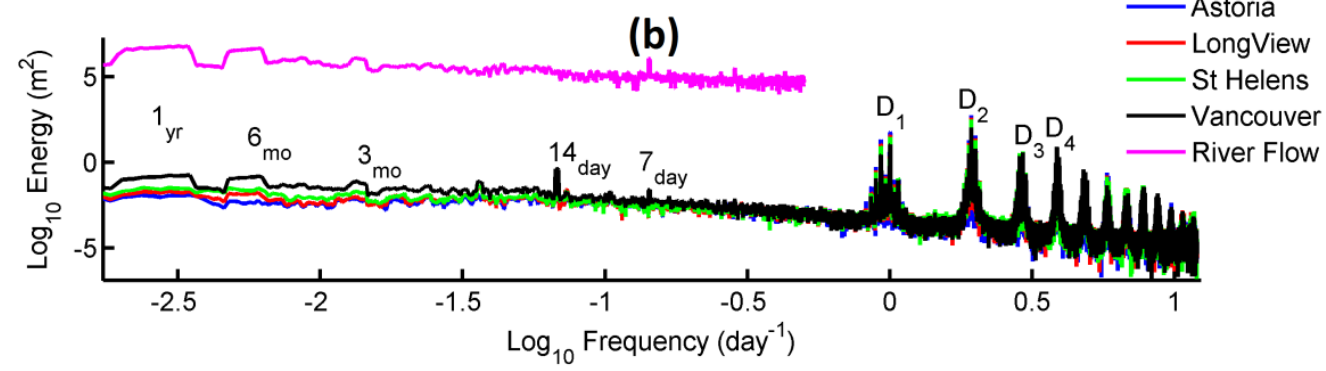

Figure 3-4: Spectral analysis results; Panel (a): Fraser River; Panel (b): Columbia River 


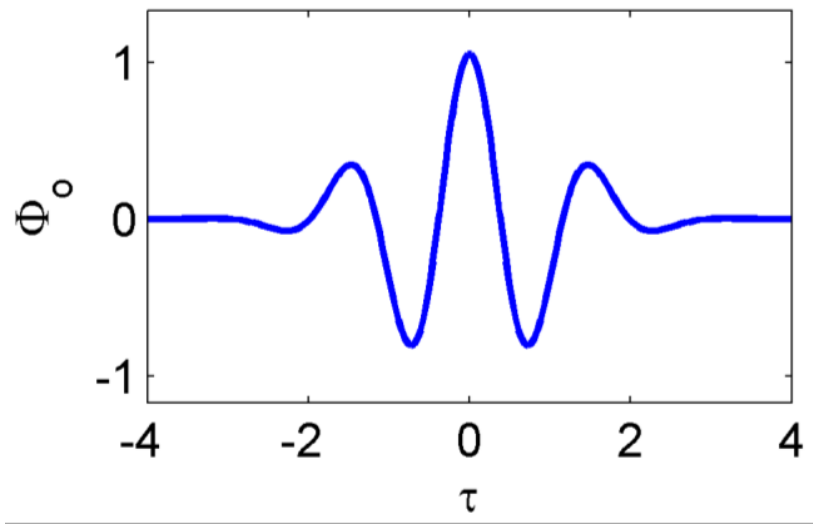

Figure 3-5: Prototype function in CWT
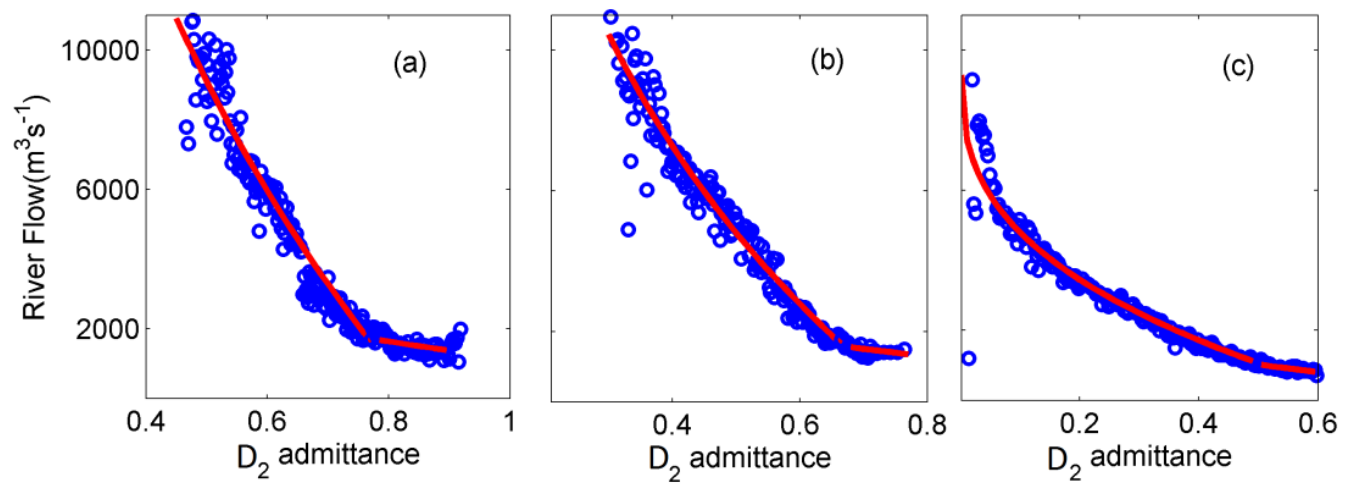

Figure 3-6: Regression analysis results, Fraser; (a) New Westminster (RKM 40), (b) Port Mann (RKM 45), (c) Mission (RKM 65).
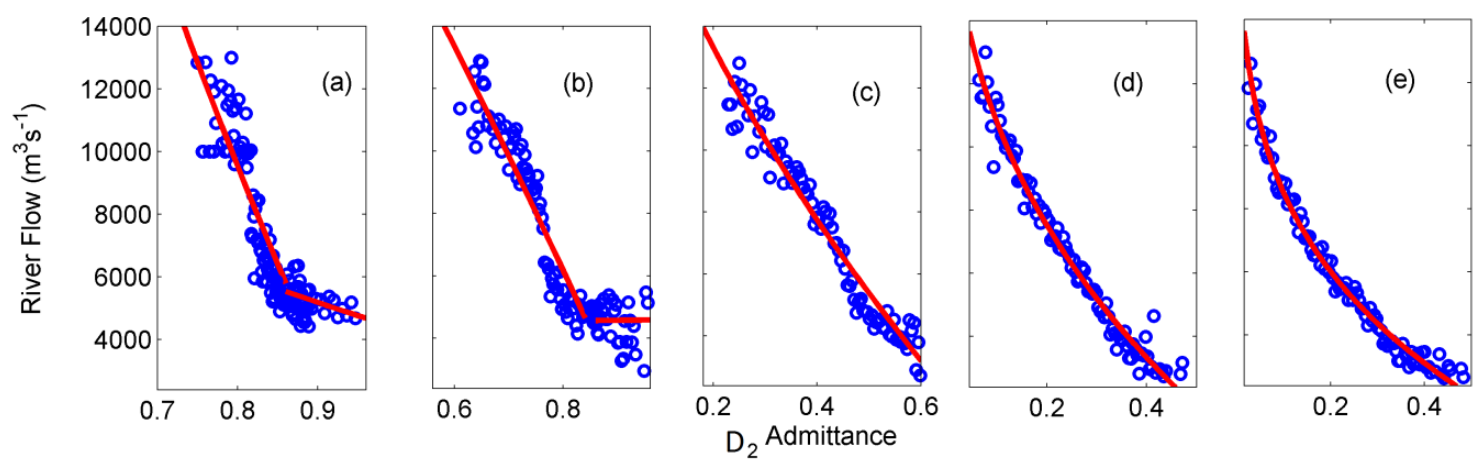
Figure 3-7: Regression analysis results, Columbia River; (a) Skamokawa (RKM 53), (b) Wauna (RKM 68), (c) Longview (RKM 107), (d) St Helens (RKM 138), (e) Vancouver (RKM 172).
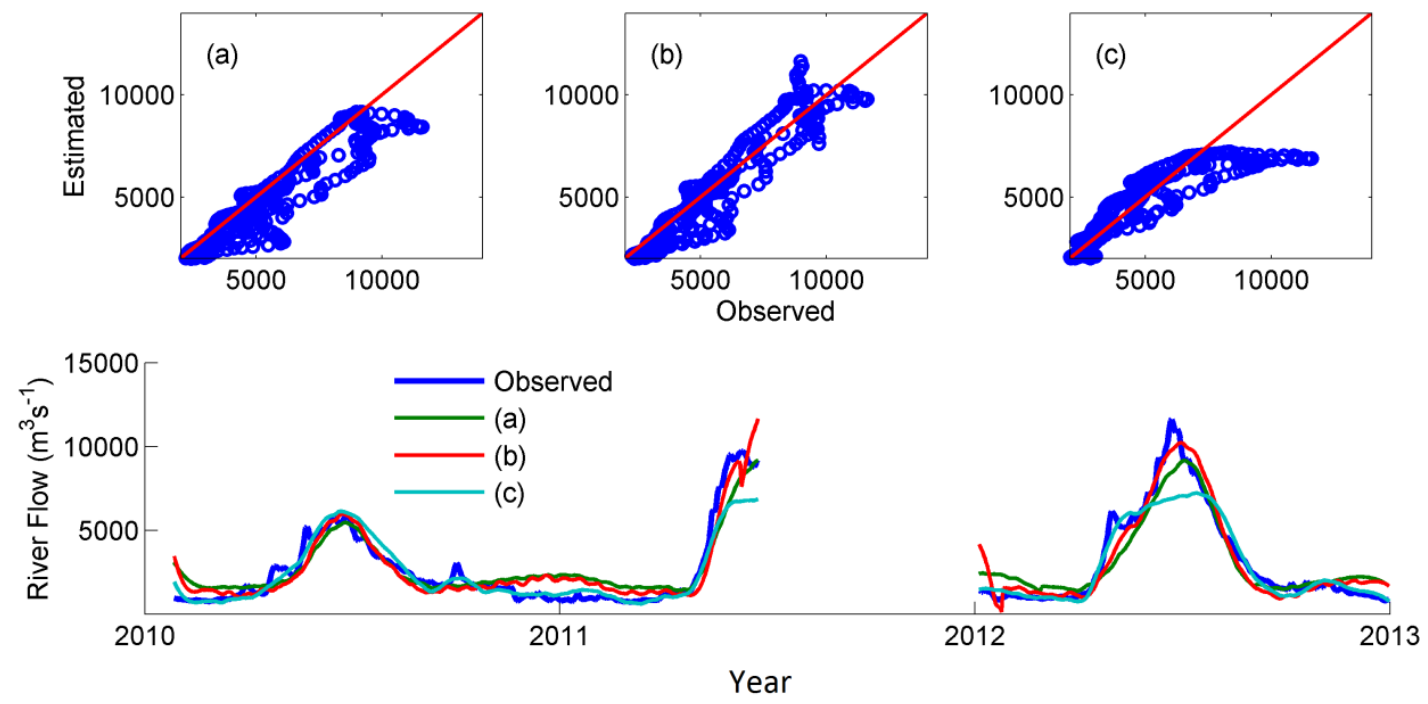

Figure 3-8: Fraser River validation; (a) New Westminster (RKM 38), (b) Port Mann (RKM 45), (c) Mission (RKM 60). The observed WL at the refrence gauge (Steveston) is not available from June to December 2011, so the MTDE could not predict flow during this period.
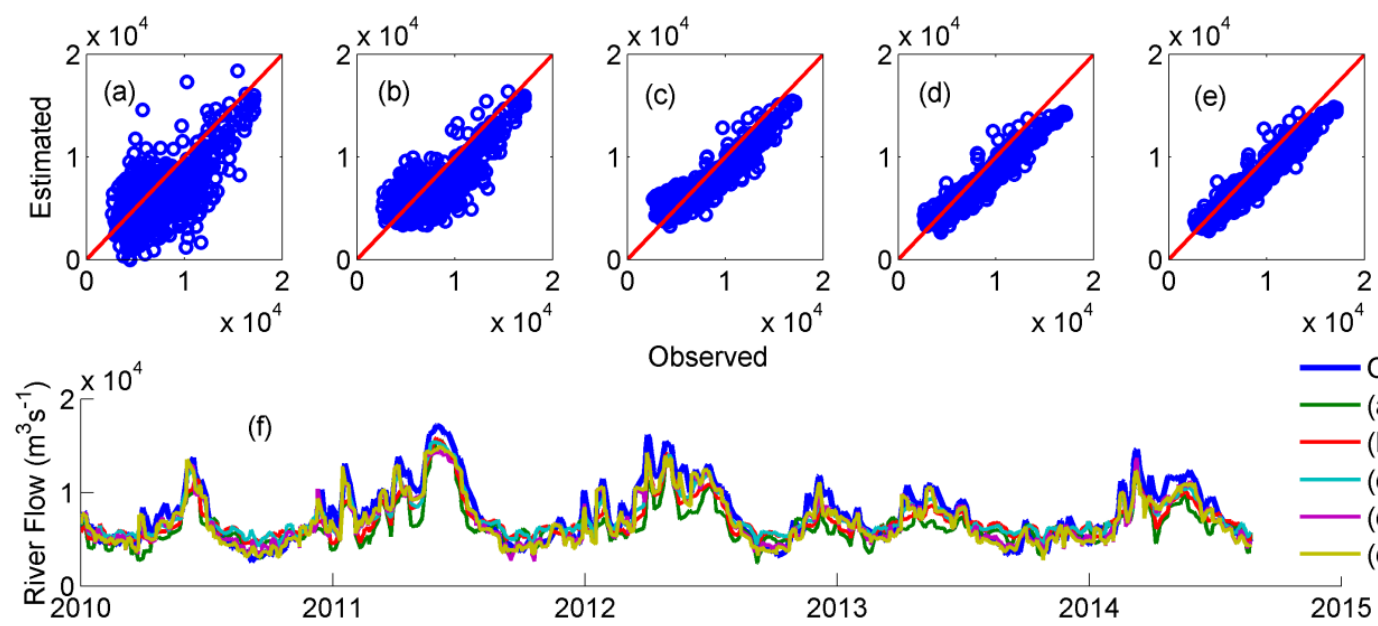

Observed

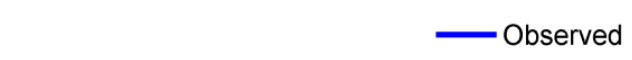



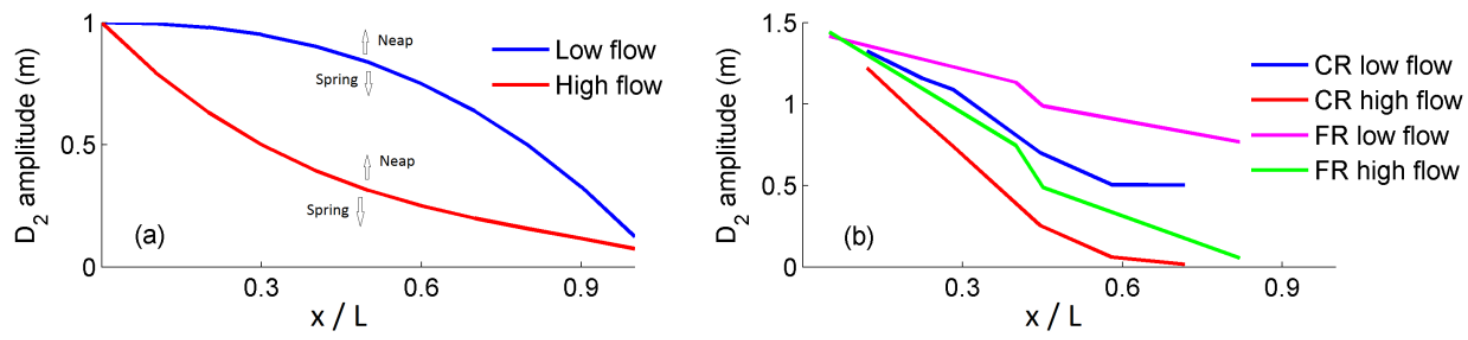

Figure 3-10: a) conceptual along-channel variation of tidal amplitude; b) variation of semidiurnal tidal amplitude (e.g. $\mathrm{D}_{2}$ amplitude) along channel; FR low flow in February 2012 $\left(\sim 1,000 \mathrm{~m}^{3} \mathrm{~s}^{-1}\right)$, and FR high flow $\left(\sim 11,500 \mathrm{~m}^{3} \mathrm{~s}^{-1}\right)$ in June 2012; CR low flow $\left(\sim 4,000 \mathrm{~m}^{3} \mathrm{~s}^{-1}\right)$ in December 2011, and CR high flow in May $2011\left(\sim 15,000 \mathrm{~m}^{3} \mathrm{~s}^{-1}\right)$.

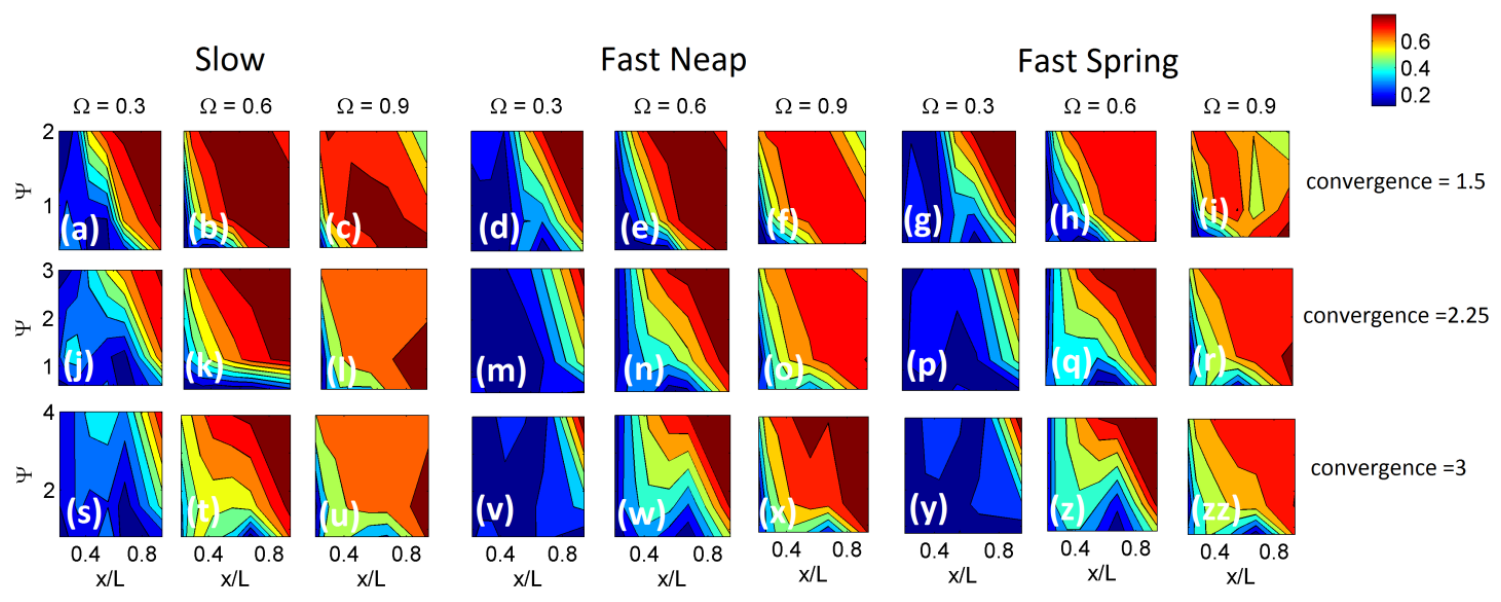

Figure 3-11: Idealized numerical modeling results; colorbar shows the Nash-Sutcliffe efficiency coefficient 

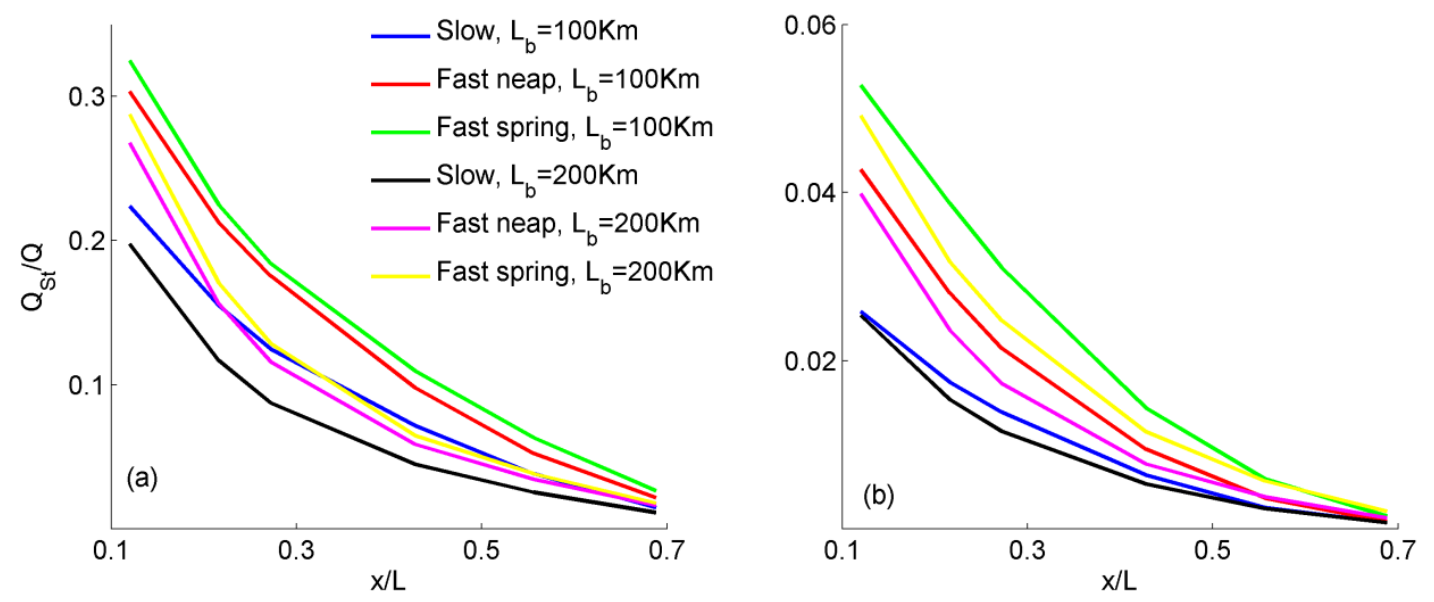

Figure 3-12: Along-channel variation in stokes drift flow compensation; (a) during a low flow event, and (b) during a high flow event. $Q_{s t}$ and $Q$ denote the Stokes drift flow compensation, and freshwater inflow to the estuary, respectively. 


\section{Chapter IV: Estimation of Historic Flows and Sediment Loads to San Francisco \\ Bay $^{2}$}

River flow and sediment transport in estuaries influence morphological development over decadal and secular time scales, but hydrological and sedimentological records are typically too short to adequately characterize long-term trends. In this study, we recover archival river-stage data measured in Sacramento, CA (1849 - 1862; 1881 - 1929) and develop a time-varying rating curve to make daily flow estimates that account for temporal changes in channel height due to human activities (e.g. hydraulic mining, and leveeing the channel). Temporally downscaled estimates of river flow based on San Francisco tide gauge data are used to fill the $1862-1881$ period and produce a continuous flow record from 1849 - 2011. Reconstructed daily delta inflow (1849 1929) and Net Delta Outflow Index (NDOI) records $(1930$ - 1955) are then used to estimate the net sediment influx to San Francisco (SF) Bay using sediment rating curve approach. The total load is constrained using bathymetric survey data to produce continuous daily sediment transport estimates for 1849 to 1955 , the time period prior to sediment load measurements. We estimate that $65 \%$ of the $\sim 1600 \pm 320$ million tons (Mt) of sediment delivered to the estuary between 1850 and 2011 was the result of anthropogenic alteration in the watershed that increased sediment supply. Sediment transport is strongly episodic, with $\sim 70 \%$ of the total sediment load being delivered during the top $10 \%$ of flow days. The timing of sediment flux events has shifted over

\footnotetext{
${ }^{2}$ Moftakhari, H. R., D. A. Jay, S. A. Talke, and D. H. Schoellhamer (2015), Estimation of historic flows and sediment loads to San Francisco Bay, Journal of Hydrology, under review.
} 
time because significant spring-melt floods have disappeared, causing estimated springtime transport (Apr. to Jun.) to decrease from $\sim 25 \%$ to $\sim 15 \%$ of the total. By contrast, wintertime sediment loads (Dec. to Mar.) have increased from $\sim 70 \%$ to $\sim 80 \%$. An approximately $25 \%$ reduction of annual flow since the $19^{\text {th }}$ century along with decreased sediment supply has resulted in a $\sim 60 \%$ reduction in annual sediment delivery. The methods developed in this study can be applied to other systems in which historic data likely exist, but remain unanalyzed.

\section{Introduction}

Sediment supplied to estuaries and the coastal zone impacts primary production, recreational and commercial fishing, nutrient supply, habitat restoration, human health, the fate and transport of pollutants, geomorphic evolution, and navigation [Fisher et al., 1982; Yang et al., 2003; Schoellhamer et al., 2007; Sherwood et al., 1990]. Climate change and watershed management practices modulate runoff and, therefore, the timing and magnitude of sediment delivery to estuaries [Syvitski et al., 2005; Wang et al., 2007; Ganju and Schoellhamer, 2009, McCulloch et al., 2002; Thrush et al., 2004]. Processes such as tidal currents, the spring-neap cycle, coastal upwelling, wind waves, watershed inflow and climatic variability cause suspended sediment concentration (SSC) to vary in time and space [Allen et al., 1980; Gelfenbaum, 1983; Pejrup, 1986; Vale and Sundby, 1987; Powell at al., 1989; Ruhl et al., 2001; Orton and Kineke, 2001; Chen et al., 2006; Ralston and Stacey, 2007; Talke and Stacey, 2008]. These processes act on multiple time scales, from seconds to years, and have diverse effects on SSC [Schoellhamer, 2002]. 
The lower reaches of a tidal river are difficult locations to determine net freshwater discharge and sediment transport for methodological reasons. The difficulties include the reversing tidal flow, the compensation flow for the tidal Stokes drift, springneap water storage effects, lateral circulation, and the presence in some systems of multiple distributaries or separate ebb/flood channels. While recent studies have introduced methods to calculate discharge in tidal rivers far from the mouth [Hoitink et al., 2009; Sassi et al., 2011; Kawanisi et al., 2010], it remains difficult to estimate net discharge or transport near the mouth of an estuary with conventional technology [Jay et al., 1997; Fram et al., 2007]. To address these difficulties, Moftakhari et al. [2013a] developed a method to estimate discharge at the mouth using the frictional perturbations that river flow imposes on tidal constituents [Kulkuka \& Jay, 2003a,b]. Cai et al. [2014] recently developed an alternative analytical approach for estimating freshwater discharge on the basis of tidal water level observations along the estuary, but this method is not easily adaptable to systems that have mixed diurnal and semidiurnal tides, like SF Bay.

The sediment load to San Francisco (SF) Bay is highly variable and difficult to estimate, in addition to the issues posed by river discharge determination. The processes contributing to variability of sediment input to SF Bay (with their percent contribution) include: diurnal, semidiurnal and higher frequency tides (24\%), semimonthly tidal cycles (21\%), monthly tidal cycles (19\%), semiannual tidal cycles (12\%) and annual pulses of sediment caused by freshwater inflow, deposition and wind-wave resuspension (13\%) [Schoellhamer, 2002; Ruhl et al., 2001]. Other studies have emphasized the role of wind, ocean swell, and storm time-scales [Talke and Stacey, 2003; Talke and Stacey, 2008]. In 
addition, sediment discharge data for key sub-basins are lacking and the sediment trapping characteristics of upland dams, flood control channels, sediment catch basins, and freshwater tidal marsh components are poorly characterized; sediment removal is poorly documented; and multiple natural and human alterations have occurred over time [McKee et al., 2013].

Daily suspended sediment concentration measurements and flux estimates are available for the Sacramento River near Sacramento, CA (177 km upstream from the Golden Gate) since 1956 [Schoellhamer, 2011]. A number of studies have estimated the total load or suspended sediment load for the late $19^{\text {th }}$ and $20^{\text {th }}$ centuries [Gilbert, 1917; Smith, 1965; Porterfield, 1980; McKee et al., 2006; Ganju et al., 2008; Schoellhamer, 2011; McKee et al., 2013]. These studies describe the increase in sediment flux due to hydraulic mining and land development, and a more recent sediment deficit due to sediment retention behind reservoirs. Nonetheless, retrospective studies beginning with Smith [1965] are based on proxies for daily river flow and/or an assumption that sediment loading characteristics have remained stationary, and neither the original river gauge record from Sacramento (starting in 1849) nor the tidal record from San Francisco (starting in 1854) has been used to improve estimates. Using historic tidal records for sediment load estimation was first tested in a preliminary way by Moftakhari et al. [2013b], this contribution represents the first detailed test of the method.

Despite the difficulties in estimating sediment loads delivered to SF Bay, several trends are evident. Depletion of erodible sediment from the Gold Rush period, trapping of sediment in reservoirs, channel stabilization, flood protection measures and altered land- 
use has caused sediment import from the Central Valley to decrease during the $20^{\text {th }}$ century [Jaffe et al., 2007; McKee et al., 2006; Wright and Schoellhamer, 2004]. Moftakhari et al. [2013a] suggest that climate change and human activities have resulted in a $\sim 30 \%$ decrease in annual average discharge $\left(\sim 2.1 \mathrm{~km}^{3} /\right.$ year $)$, compared to the $19^{\text {th }}$ century $\left(\sim 2.7 \mathrm{~km}^{3} /\right.$ year). The timing and magnitude of the annual peak flow have also changed over time, too, considerably altering sediment transport, as discussed below.

Long-term trends in SF Bay sediment loading have been inferred by differencing successive historic bathymetric charts [Gilbert, 1917; Fregoso et al., 2008; Ganju et al., 2008; Jaffe et al., 2007; Dallas and Barnard, 2011]. Schoellhamer [2011] compared successive bathymetric surveys presented by Cappiella et al. [1999], Fregoso et al. [2008], Foxgrover et al. [2004], and Jaffe et al. [1998] and estimated the changes in bed sediment volume in four sub-embayments of SF Bay from the 1850s to the 1980s. Prior to 1855 , SF Bay and its watershed are thought to have been relatively undisturbed and probably were in dynamic equilibrium with a small erodible sediment pool, although Spanish and Mexican livestock grazing practices produced widespread erosion in local watersheds beginning in the late $18^{\text {th }}$ century [Schoellhamer, 2011; Booker, 2013]. Hydraulic mining debris increased bed sediment volume by at least $260 \mathrm{Mm}^{3}\left(10^{6} \mathrm{~m}^{3}\right)$ in the late 1800s, almost entirely in Suisun and San Pablo Bay. Significant timber harvest occurred in the Sierra Nevada in support of mining but also for railroad construction and other industrial activities pre-1900 [Burns, 1972; Laudenslayer and Darr, 1990], and may have contributed to sediment loads. There was little change in total bed sediment volume from 1892 to 1925 as hydraulic mining sediment entered the bay at a smaller rate, and the 
pulse of hydraulic mining sediment moved into the Pacific Ocean. From the 1920s to 1940s, bay sediment volume increased by $160 \mathrm{Mm}^{3}$. This second pulse of sediment was about $60 \%$ as large as the hydraulic mining sediment pulse and has been attributed to urbanization or increased agricultural land use [Schoellhamer, 2011]. Large-scale clearcutting which began after $\sim 1935-1940$, after a relative lull in timber harvest in the early $20^{\text {th }}$ century [Burns, 1972; Laudenslayer and Darr, 1990], also contributed to renewed sediment export. The period from the 1950 s to the present has been characterized by erosion and loss of bed material [Schoellhamer, 2011]. Diminishment of the hydraulic mining and urbanization sediment pulses, sediment trapping behind dams and in flood bypasses, and bank protection all contribute to decreased sediment supply to the Bay [Schoellhamer, 2011; Singer et al., 2008]. The erodible pool of sediment in the Bay was largely depleted by the late 1990s, and produced a step decrease (36\%) in SSC from Water-Years (WY) 1991 - 1998 to 1999 - 2007 in SF Bay [Schoellhamer, 2011]. In summary, SF Bay experienced net deposition from the 1850s to 1950 s and net erosion after the mid- $20^{\text {th }}$ century.

There are strong seasonal variations in discharge and sediment transport to SF Bay. Previous studies suggest that $\sim 90 \%$ of precipitation and more than $80 \%$ of watershed sediment transport occurs during the wet season between December and April [Conomos and Peterson, 1977; Ganju et al., 2008; Lewicki and McKee, 2010; McKee et al., 2006; McKee et al., 2013]. This hydrologic characteristic of the system reflects the fact that the major portion of total annual load is transported by high flow periods of limited duration. However, flow seasonality has changed considerably since 1900 
[Moftakhari et al., 2013a], suggesting that the historical seasonality of sediment loading should be reevaluated, as we do.

The fraction of sediment load contributed by tributaries directly into SF Bay has increased through time, compared to the Sacramento-San Joaquin rivers system [Lewicki and McKee, 2010]. Prior to 1955, the sediment load from Central Valley was reported as approximately 89-92\% of the total load [Ogden Beeman and Associates, 1992], while Smith [1965] estimated that $85.5 \%$. Krone [1979] reported that in $1960,76 \%$ of the total load of SF Bay was from the Central Valley, and estimated that this ratio would decrease to $63 \%$ in 1990 and $54 \%$ by 2020 . More recent studies suggest that in the $21^{\text {st }}$ century tributaries adjacent to the Bay provide $7 \%$ of annual inflow, but account for $\sim 60 \%$ of the suspended sediment [McKee et al., 2013; McKee et al., 2006]. This reflects the effect of dams that block sediment load from $48 \%$ of the watershed, flow diversion, and regulation of peak flows [Minear, 2010], in contrast to the amplified precipitation-discharge characteristics of urbanized local tributaries.

There remains significant uncertainty regarding the history of sediment loading to SF, despite previous work. How has the total flow and sediment load to SF Bay changed over the last $160 y$ rs? What are the relative contributions of anthropogenic effects and natural processes to the total sediment budget? A method is needed to hindcast flow and sediment input with higher resolution in time, to provide a better understanding of the changes in inputs and related adjustments. In this study we have re-discovered and digitized $\sim 80$ years of Sacramento River daily water level data between 1849 and 1946 from which river discharge is estimated after adjusting for changes to the river channel. 
This discharge measure, which we call the Sacramento Discharge Estimates (SDE), is combined with the Net Delta Outflow Index (NDOI) estimates (1930-2011) and flow estimates from tidal data (1858-2011, downscaled to daily) to provide a more accurate version of SF Bay historic inflows from 1849-2011.This Composite Discharge Estimate (CDE) is then used, with integral constraints from observed SF Bay bathymetric change, to provide estimates of daily sediment discharge. These discharge estimates are used to describe how the timing and magnitude of sediment import into SF Bay has changed over time.

\section{Setting, Data Sources and Methods}

\subsection{Setting}

SF Bay consists of two distinct sub-estuaries. The northern reach, is partially mixed and dominated by seasonally varying fresh water inflows, while the southern part is a well-mixed tidal-lagoon estuary [Cheng and Gartner, 1985; Chua and Fringer, 2011]. Freshwater inflow occurs primarily from the Sacramento and San Joaquin rivers (Figure 4-1), with annual average flows of $492 \mathrm{~m}^{3} \mathrm{~s}^{-1}$ and $41.9 \mathrm{~m}^{3} \mathrm{~s}^{-1}$ between 1980 and 2013, respectively [http://wdr.water.usgs.gov/ ]. Flows in both systems have been reduced and altered considerably by diversion [Kimmerer, 2002]. Tides in SF Bay have a mixed diurnal-semidiurnal character. The present amplitude of the major semidiurnal constituent $\mathrm{M}_{2}$ at the Golden Gate is $0.57 \mathrm{~m}$, while the largest diurnal constituent $\mathrm{K}_{1}$ has an amplitude of $0.37 \mathrm{~m}$ [Moftakhari et al., 2013a]. At different times, human activities have likely 
resulted in both reduced sediment export and river discharge (damming, water diversion and river management) and increased sediment availability (mining, deforestation, agriculture and urbanization). Coupled with marked daily, seasonal and interannual variability of freshwater inflow, and anthropogenic alterations in wetland coverage, channel depth, and levee heights, SF Bay is a challenging and interesting scientific laboratory for analyzing sediment transport processes [Barnard et al., 2013]. Nonetheless, the availability of well-defined estuarine boundaries, digitized bathymetric data extending to pre-hydraulic mining conditions, recently re-discovered and processed historic river and tide data, and modern analyses provide the possibility of improving our knowledge of the past system trajectory and the effects of human interventions.

\subsection{Data Sources}

\subsubsection{Observed Water Level of Sacramento River, 1849-2011}

River stage measurements began in Sacramento, CA in September 1849 [Logan, 1872; Gilbert, 1917], but the $19^{\text {th }}$ century data have not been evaluated in nearly a century, likely because of the difficulty caused by hydraulic mining debris and anthropogenic alterations to the flood control system. Nonetheless, because the stage measurements in Sacramento integrate flow from a catchment basin of about $67,000 \mathrm{~km}^{2}$ from the states of California, Nevada, and Oregon, its use as a proxy for delta outflow from 1849 to 1929 is potentially useful in reconstructing historical sediment loads. In this contribution we have recovered and digitized flow hydrographs from pioneer physician Thomas M. Logan [Logan, 1872; Hunsaker and Curran, 2005] to obtain daily estimates of river stage between WY1849 and WY1862. Daily tabulations of river flow from 1881- 
1892 were recovered and digitized from US Signal Service records in the EV2 database at the National Climate Data Center (https://www.ncdc.noaa.gov/EdadsV2). Further data for 1893 forward were measured and documented by the US Weather Bureau (USWB) in their annual reports entitled "Daily river stages at river gage stations on the principal rivers of the United States". Extreme flood crest stages are listed since 1907. It is likely that a gauge was maintained between 1862 and 1881, because the Signal Service gauge (1881 - 1892) used low water from 1849 as their gauge zero. Moreover, annual peak water levels for WY1874-1881 are available [State of California, 1889], and estimates of average monthly river discharge and peak annual discharge are available from WY18781884 [State Engineering Department of California, 1886]. However, original records from WY1863-1881 have not yet been found, requiring that we augment this period using estimates of discharge obtained from the SF tide gauge [Moftakhari et al., 2013a].

Historic Sacramento gauges up to 1979 were located in Old-town Sacramento (USGS 11447500), at or near the present day location of the I-Street gauge operated by the California Department of Water Resources (http://cdec.water.ca.gov/cgiprogs/queryF?IST). Prior to 1900 , gauge zero was set to the low water mark of 1849 ( 1.5m above sea level). From 1900-1913, the zero was shifted to the low-water mark of October $23^{\text {rd }}, 1856(0.15 \mathrm{~m}$ below mean sea level or MSL), and since 1914 the zero has been considered equal to MSL. Levee heights before 1862 were 24 feet [Logan, 1872]. After the catastrophic flooding in 1862 , levee heights were progressively increased and the flood danger level in 1893 was considered to be at $7.6 \mathrm{~m}$ ( 25 feet), while in $1940 \mathrm{~s}$, flood stage was specified to be at $8.8 \mathrm{~m}$ (29 feet) [USWB, 1875 to 1947]. Available 
records suggest that the $1.2 \mathrm{~m}$ rise in flood stage is primarily the result of increased levee heights rather than changes in bottom level.

\subsubsection{Discharge Data}

This study uses the Net Delta Outflow Index (NDOI) available from WY1930present (http://www.water.ca.gov/dayflow/), as a proxy for tidally averaged daily river inflow to SF Bay from the Sacramento River delta. NDOI represents about $93 \%$ of the inflow to SF Bay, and accounts for river inflow, precipitation, evaporation, agricultural consumptive demand, and water exports from the Delta [Conomos and Peterson, 1977]. The remaining $7 \%$ of flow to SF Bay is sourced from local tributaries [McKee et al., 2013]. Because Shasta Dam came on-line in the mid-1940s and altered the hydrograph, we use data from 1930 - 1946 to develop a regression between Sacramento River stage and NDOI. However, because fewer stream gauge sites were in place before 1956, NDOI estimates for 1930-1955 are less certain than those for later periods [Moftakhari et al., 2013a].

For time periods without river stage measurements (September $1^{\text {st }}, 1862$ February $24^{\text {th }}, 1879$, March $28^{\text {th }}, 1879$ - August $31^{\text {st }}, 1880$, and May $1^{\text {st }}, 1888$ to December $\left.1^{\text {st }}, 1890\right)$, we use the $\sim 18$-day averaged estimates of NDOI obtained from the historic SF Bay tide gauge from 1858 - 1929 [Moftakhari et al., 2013a]. These estimates also represent an independent determination of outflow that can be used to diagnose or estimate error and bias during periods in which multiple hydrological measurements are available. Because the tidally based estimates are a roughly 18-day average, we 
downscale these estimates to the daily timescale using the procedure detailed in section 2-3-3.

\subsubsection{Sediment load data}

Suspended sediment concentration and sediment load data is available for the $\begin{array}{lllll}\text { Sacramento } & \text { River } & \text { at } & \text { Freeport } & \text { (USGS }\end{array}$ [http://waterdata.usgs.gov/usa/nwis/uv?site no=11447650] and the San Joaquin River near Vernalis (USGS 11303500) [http://waterdata.usgs.gov/ca/ nwis/uv/?site no=11303500] from 1956-present. We compare our estimated daily sediment load to the sum of these observed values to validate our proposed approach, and also to determine the contribution of the Central Valley to the total sediment load to SF Bay over the second half of the $20^{\text {th }}$ century.

\subsubsection{Other data}

For validation, our daily flow estimates will be compared to the following hydrologic quantities:

I) The Eight-River Index (ERI): Published by The California Department of Water Resources (http://cdec.water.ca.gov/cgi-progs/iodir/WSIHIST), the ERI combines the flows into the Sacramento Delta from the Sacramento and San Joaquin Rivers with major tributaries, including the Feather, Yuba, American, Stanislaus, Tuolomne, and Merced Rivers (Figure 4-1), after removing the effect of diversions, storage, export, and import. 
Monthly totals are available during the wet season (December - May) from 1906 to the present [Ganju et al., 2008].

II) The Six River Index (SRI): The State Engineering Department of California [1886] published monthly mean flow records, from November 1878 to October 1884 , for the six principle rivers that drain the Central Valley to SF Bay. These records include flows for the Sacramento River at Collinsville, CA, the San Joaquin River at Hamptonville, CA, and the Mokelumne, Stanislaus, Tuolumne, and Merced Rivers (Figure 4-1).

III) Daily Sacramento River discharge at Red Bluff: Daily discharge data are available at Red Bluff, CA from 1891 to the present (USGS 1377100) and extremes are available back to 1879. Though these data provide the longest independent data set for comparison with our flow estimates, the basin area at Red Bluff $\left(23,000 \mathrm{Km}^{2}\right)$ is only $14 \%$ of the area at Sacramento.

IV) Monthly rainfall totals at Sacramento: These data are available from the Global Historical Climatology Network of the National Climatic Data Center (http://www.ncdc.noaa.gov/). These data are composed of monthly surface station measurements, and began in January, 1850 for Sacramento [Ganju et al., 2008]. They provide the most comprehensive comparison in terms of time period, but are also the least direct. 


\subsection{Methods}

\subsubsection{Water level adjustment and estimating a stage-discharge rating}

curve

We use the daily WL data described in section 2-2-1 to estimate NDOI from 1849 - 1946. This time span can be divided into at least three stages. Before the 1862 floods, the delta system was minimally perturbed by human alteration [Booker, 2013] and probably in balance with sediment supply, though slow adjustments to tectonic changes or climate shifts were likely occurring. Anthropogenic sources of sediment appear to have been negligible compared to natural processes, and levees were too low to confine the flow within the main channels during large flow events. Between 1862 to about 1930, sediment spoils produced by placer and specially hydraulic mining between the $1850 \mathrm{~s}$ and 1884 released a huge volume of debris to SF Bay and its tributaries [Gilbert, 1917]. However, the lack of large floods between 1853 and 1862 produced a time lag between mining activities and sediment flux to the delta [James, 2006; James, 2010]. Flood levees in Sacramento were increased from their natural height of $24 \mathrm{ft}$ [Logan, 1872] up to 30ft by the 1890s using hydraulic mining debris [Booker, 2013]. During this time, flow confinement by the system of levees and aggradation of the main channel strongly affected the hydraulic characteristics of the system, such that tides ceased to propagate to Sacramento [Gilbert, 1917]. Tidal damping likely occurred due to increased hydraulic roughness, since an increase in friction produces a higher stage and smaller tide, for the same river flow and geometry [Jay et al., 2011]. By the beginning of the third period in 1930, most of the sediment pulse from hydraulic mining activities had moved out of the 
river channel and into the estuary [Schoellhamer, 2011, James, 2006]. Compared to the pre-Gold Rush situation, the primary difference affecting system hydraulics was flow confinement by the system of levees, and the loss of wetland floodplain. Channel infill and levee construction affected the system in at least two ways. Increased bed elevation raised the observed stage for all flows [Gilbert, 1917], but also altered the range of possible stage heights. Moreover, increased levee heights confined the flow to the channels and produced larger rises in river stage, for the same flow. However, levees often failed upstream of the Sacramento gauge, causing frequent flooding and affecting the river stage downstream [Rose, 1895]. We remove the effect of bed aggradation by subtracting a smooth curve fitted to the annual lowest observed water levels from 1849 1930, and then scale the WL data (prior 1930) to correct the WL range for the effect of leveeing, levee breaking and raised bed elevation (Figure 4-2).

Figure 4-2a displays the observed daily WL time series described in section 2-2-1. The lowest observed WL remains near zero in the $1850 \mathrm{~s}$, but increases from 1862 to a maximum of 2.9m above MSL in 1892. Between the 1890s and 1930, bed height returns to its original, pre-1862 level. The rise before 1892 presumably occurred due to sedimentation from hydraulic mining activities; although hydraulic mining was outlawed in 1884, aggradation continued for nearly a decade thereafter[Gilbert, 1917]. This change in lowest observed WL, which approximately represents the change in channel-bed elevation, is known as the Gilbert-Wave [James, 2006]. Figure 4-2a suggests that sedimentation occurred more rapidly $(1862-1892)$ than erosion $(1892-1930)$. Due to 
this asymmetric curve, we fit the time variation of the bed $\left(H_{b e d}\right)$ using a log-normal distribution curve

$$
H_{b e d}(t)=\frac{1}{t \sigma_{b e d} \sqrt{2 \pi}} e^{-\frac{\left(\ln [t]-\mu_{b e d}\right)^{2}}{2 \sigma_{b e d}^{2}}}
$$

and find that a location parameter $\left(\mu_{b e d}\right)$ and standard deviation $\left(\sigma_{b e d}\right)$ of 1892 and 15yrs, respectively, describe the low WL variation in time. Figure 4-2b compares our estimates for temporal low WL variation to the values tabulated by Gilbert [1917] and the State of California [1889]. Interannual variations in minimum discharge largely explain the fluctuation of the values around the smooth fit. To obtain a time series of river stage relative to the river bed, we subtract the above log-normal curve of the estimated low WL at each time from the observed WL.

Bed aggradation, changes to levee heights, wetland reclamation, and the development of managed floodplains such as the Yolo Bypass greatly altered not only stage heights, but also the annual variability in river stage. Before 1862, WL varied between zero and $7.5 \mathrm{~m}$ under natural conditions. By the $1880 \mathrm{~s}$, the range shrank, and WL varied between about 2 and 8m. By 1930, the channel bed returned to its pre-1862 level and WL ranged between zero and $9 \mathrm{~m}$ above gauge zero. Because insufficient information exists to model in detail changes to the stage/flow relationship over time and adjust for changing friction, we make statistically-based corrections to the data set and check the corrections ex-post-facto via an independent data set (the tidally-based TDE and the hydrologic data from section 2-2-4). Therefore, we scale the data before 1930 such that 
the range is the same as from 1930 to 1944, the calibration period. This period is appropriate for this calibration exercise because comparison of TDE flow estimates for the pre-1930 period with NDOI estimates from 1930-1944 suggest similar flow ranges. We use two different scaling functions for this purpose:

i) The adjustment for 1881-1930 data is made as follows. First, a rating curve from 1879 [Rose, 1895] indicates that an increase from low $\left(\sim 300 \mathrm{~m}^{3} \mathrm{~s}^{-1}\right)$ to high $\left(\sim 2700 \mathrm{~m}^{3} \mathrm{~s}^{-1}\right)$ river discharge caused the WL to rise from 3.7 to $10.7 \mathrm{~m}$ in 1879 (Fig. 4-3a). By contrast, the same variation in river discharge in the 1930 s produced a WL range of 1.5 to $10.1 \mathrm{~m}$ (Fig. 43a). Thus, the WL range was $23 \%$ larger in the 1930 s compared to 1879 . Assuming that hydrologic properties changed gradually over time, we use a log-normal scale function $\left(S c_{r}\right)$ as:

$$
S c_{r}(t)=\frac{1}{t \sigma_{r} \sqrt{2 \pi}} e^{-\frac{\left(\ln [t]-\mu_{r}\right)^{2}}{2 \sigma_{r}^{2}}}
$$

with the location parameter $\left(\mu_{r}\right)$ and standard deviation $\left(\sigma_{r}\right)$ of 1892 and 15yrs, respectively, to adjust WL range for 1880 - 1930 to be comparable to the $1930-1944$ period (Figure 4-2c). The annual WL range was then adjusted with scale function, to normalize the data, for comparison with the $1930-1944$ period. The net result of the adjustments related to the bed elevation and the range scale function is:

$$
W L_{a d j}(t)=S c_{r}(t) \times\left[W L_{o b s}(t)-H_{b e d}(t)\right]
$$


where $W L_{a d j}$ is the adjusted $W L, W L_{o b s}$ is the observed WL, $H_{b e d}$ is the lognormal curve describing the variation of bed elevation with time (Figure 4-2b) and $S c_{r}$ is the range adjustment scale (Figure 4-2c).

ii) The adjustment for $1849-1862$ is made as follows. Building levees after 1862 produced a larger WL range in the 1930s, relative to pre-1862 conditions. To adjust the 1849 - 1862 WL data, we match WY1859 1860 with WY1934 - 1935, since a similar number of moderately large flow events occurred, and total annual rainfall at Sacramento was similar (within $\sim 10 \%$ ). From these water years a statistical correlation is developed between tidally based (TDE) flow estimates and observed WL. This analysis shows that the standard deviation for WL observed over WY1859-1860 was, for approximately similar hydrologic events, 30\% lower than WY1934 - 1935. Thus, we scale the 1849 - 1862 WL by 1.3 before applying the 1930 - 1944 rating curve (described in the next paragraph).

Figure 4-2d shows the adjusted WL after all the adjustments mentioned above. Later we check the delta outflow estimate resulting from the adjusted data set against other estimates of flow, where available.

\subsubsection{Discharge Estimation}

We next develop an historic estimate of daily NDOI from 1849-1929 using the adjusted water level measured on the Sacramento River (Fig. 4-2d). A stage-discharge rating curve between NDOI and WL data for WY1930 - 1944 is first determined, using a 
least squares fit with the form of $W L=\alpha+\beta \times N D O I^{\gamma}$, to 100 evenly spaced binaveraged flows and water levels (Fig. 4-3b). During this time period, delta outflow was not significantly altered by flow regulation (reservoirs) or water diversion projects [Barnard et al., 2013]. Clearly, the data below and above $6.2 \mathrm{~m}$ have a different relationship with discharge. Thus, we divide the data into two subsets $(<6.2 \mathrm{~m}$ and $>6.2 \mathrm{~m})$ and fit the non-linear curve to each subset, separately. The change in slope above $6.2 \mathrm{~m}$ might be due to flooding of the Yolo Bypass floodplain upstream of Sacramento, using weirs that were completed between 1916 and 1934 [Russo, 2010]. Before this time period, flooding of this floodplain often occurred [Rose, 1895] due to levee breaches or overtopping.

The rating curve in Figure 4-3b is then used to convert the adjusted observed WL to SDE during periods for which WL data are available (e.g. 1849 - 1862, 1879, 1881 1888, and $1891-1929)$.

\subsubsection{Temporal downscaling of tidal discharge estimates}

As shown in Fig. 4-2, there are three gaps in daily observed WL data from 18621891: a) September 1862 to February 1879, b) March 1879 to August 1881, and c) May 1888 to December 1890 . These gaps were filled by TDE [Moftakhari et al., 2013a], an approximately 18-day average flow estimate based on tide gauge data (Figure 4-4). The $18 \mathrm{~d}$ averaged TDE is first linearly interpolated to daily values $\left(T D E_{1 d}\right)$. Then, a statistical relationship between an 18-day average and the daily peak flow during a flood was found using 31 high-flow events $\left(\mathrm{TDE}_{18 \mathrm{~d}}>3500 \mathrm{~m}^{3} \mathrm{~s}^{-1}\right)$ between 1930 and 2011 , yielding the following relationship between the peak daily NDOI and 18d averaged TDE: 


$$
N D O I_{1 d}=1.972 \times T D E_{18 d}+3563.3 ; R^{2}=0.71
$$

where, $N D O I_{1 d}$ and $T D E_{18 d}$ denote daily peak flow and 18-day averaged flow, respectively. This relationship is then applied to the peak flow measured by $\operatorname{TDE}_{18 \mathrm{~d}}$ to obtain an estimate of the daily peak flow for events $>3500 \mathrm{~m}^{3} \mathrm{~s}^{-1}$ (Figure 4-4). To conserve the volume of flow, we require that the area under hydrograph remains the same for both the 18-day averaged flow estimates and the associated daily estimates. Assuming that a flood wave can be approximated by a log-normal curve, we next determine the relationship between an $18 \mathrm{~d}$ average hydrograph and a daily hydrograph by fitting the 31 high-flow events to the following curves:

$$
\left\{\begin{array}{l}
T D E_{18 d}(\tau)=\frac{T D E_{p}}{\tau \sigma_{T D E} \sqrt{2 \pi}} e^{-\frac{\left(\ln [\tau]-\mu_{T D E}\right)^{2}}{2 \sigma_{T D E}^{2}}} \\
N D O I_{1 d}(\tau)=\frac{N D O I_{p}}{\tau \sigma_{N D O I} \sqrt{2 \pi}} e^{-\frac{\left(\ln [\tau]-\mu_{N D O I}\right)^{2}}{2 \sigma_{N D O I}^{2}}}
\end{array}\right.
$$

Where $T D E_{p}, \mu_{T D E}$ and $\sigma_{T D E}$ denote the peak flow, location parameter and standard deviation of the fitted distribution to the hydrograph of an 18d averaged TDE high flow event and, $N D O I_{p}, \mu_{N D O I}$ and $\sigma_{N D O I}$ denote the peak flow, location parameter and the standard deviation of daily NDOI high flow event. Results show that for similar location parameters, $\sigma_{N D O I}$ is half $\sigma_{T D E}$ for these events, on average. Assuming that the water resources management measures did not considerably changed this ratio after 1930, for the historic (pre-1930) high flow events (TDE $>3500 \mathrm{~m}^{3} \mathrm{~s}^{-1}$ ), we resample the downscaled TDE as: 


$$
T D E_{1 d}^{\prime}(\tau)=\frac{T D E_{18 d p}}{\tau \sigma_{S D E} \sqrt{2 \pi}} e^{-\frac{\left(\ln [\tau]-\mu_{T D E}\right)^{2}}{2 \sigma_{S D E}^{2}}}
$$

Where $T D E_{1 d}^{\prime}$ is the adjusted daily TDE, $\mu_{T D E}$ is the location parameter of the fitted lognormal curve to the associated TDE high flow event, $T D E_{18 d p}$ is the associated $18 \mathrm{~d}$ averaged peak TDE, and $\sigma_{S D E}=0.5 \times \sigma_{T D E}$. Figure 4-4 tests the applicability of the model for resampling TDE data, and shows that adjusted, downscaled TDE values (e.g. $T D E_{1 d}^{\prime}$ ) using Eqs. 4 - 6 match daily NDOI well. We next estimate daily Composite Discharge Estimate (CDE) during periods of missing WL data by adjusting TDE estimates using the procedure described in Eqs $4-6$. For other periods the tide-gauge based estimate (TDE) provides a bias check against Sacramento Discharge Estimate (SDE), which may become inaccurate when levee failures occur. In particular, we use $T D E_{1 d}^{\prime}$ estimates for peak flows during three periods of major levee failure. These include (a) the extremely high flow events in December 1861 and January 1862; (b) the floods of 1878, 1880 and 1881, which resulted in the construction of the First Comprehensive Flood Control Plan of Sacramento Valley; and (c) the destructive floods on 1907 and 1909, which resulted in authorization of the Sacramento Flood Control System by the Congress in 1917 [James and Singer, 2008].

We also develop and calibrate a model of flow standard deviation $\sigma$ to provide 95\% confidence intervals (CI) for the estimated daily flows (Figure 4-5). There is a correlation between the mean of NDOI (estimated via TDE) and $\sigma$, which increases non- 
linearly with NDOI. We use the $\pm 2 \sigma$ envelope to provide an estimate for $95 \%$ confidence interval for the daily estimated flows in Figure 4-5.

\subsubsection{Sediment-discharge rating curve parameters}

Ganju et al. [2008] employed hydrologic proxies (monthly unimpaired flows and rainfall records) to downscale the Gilbert [1917] decadal sediment load estimates and used the results of Porterfield [1980] to develop a daily estimated sediment load. Ganju et al. [2008] used a rating curve with the form of:

$$
Q_{s}=a Q_{p}^{b+1}
$$

to relate daily discharge $\left(Q_{p}\right)$ and daily sediment load $\left(Q_{s}\right)$, where the parameter $a$ represents the sediment supply and $b$ represents the erosive power of the stream [Muller \& Forstner, 1968; Syvitski et al., 2000; Ganju et al., 2008].

Ogden Beeman and Associates [1992] set parameter $b$ equal to 0.1 for the Sacramento and San Joaquin Rivers for 1955 - 1990; but their estimate is based on an annual sediment rating curve. Ganju et al. [2008] suggested that the parameter $b$ equals 0.13 , based on analysis of daily data from WY2000 - 2003. However, this time span was a relatively low flow period and occurred after the step-change in sediment concentrations in 1999 [Schoellhamer, 2011], and we find that this fit underestimates sediment load during historical high flow events.

In this study we use composite discharge estimate (CDE) and Eq. (4.7) to estimate sediment load, using improved estimates of net deposition by Schoellhamer [2011]. Schoellhamer [2011] estimated net sediment deposition within the SF Bay system 
(including Suisun Bay, San Pablo Bay, Central SF Bay and South SF Bay; Figure 4-1) during the periods $1861-1892,1892-1925,1925-1949$, and $1949-1984$ from the data of Cappiella et al. 1999, Foxgrover et al. 2004, Fregoso et al. 2008, and Jaffe et al. 1998. These values were $259 \mathrm{Mm}^{3},-2 \mathrm{Mm}^{3}, 161 \mathrm{Mm}^{3}$, and $-193 \mathrm{Mm}^{3}$, respectively; a negative result represents net erosion in the system. We employ an iterative approach and take the steps outlined below to calibrate the rating curve parameters $a$ and $b$.

$\underline{\text { Step I - Estimating rating curve parameter b: }}$ To estimate $b$, we re-analyze the sediment load from the Sacramento and San Joaquin rivers (described in 3-2-2). The observed data are divided into three time periods (Figure 4-6). The first period extends from the beginning of observations (1956) to 1968, the year that Oroville dam was completed, subsequently trapping large volumes of sediment and markedly altering sediment transport during large floods below both Oroville Dam and in the delta [James, 2006; James, 2010]. We choose the second period from 1969 to 1998, the time between the closing of Oroville Dam and a step decrease in SSC [Schoellhamer, 2011]. The third period from 1999 - 2011, represents the time in which the sediment pool is depleted and the system is largely supply limited [Schoellhamer, 2011]. To prevent the fitted curve being biased by low flow events, the NDOI and sediment load values were bin-averaged to 50 evenly spaced bins in term of NDOI values. Figure 4-6 shows the relationship between bin-averaged discharge and sediment load, and Table 1 represents the results of sediment rating curve regression analysis for parameter $b$. As a first estimate, we assume that $b$ is the same from $1862-1955$ as $1956-1968$. Throughout this whole period the system is transport capacity limited and Oroville dam has not yet changed the sediment 
supply. Below, we re-adjust $b$ for 1862 - 1956, for each time span that Schoellhamer [2011] estimated net sediment deposition within the SF Bay.

Step II - Estimating rating curve parameter a: We assume that parameter $a$ is constant within each time span. Thus, as parameter $b$ is known from steps I, we constrain $a$ by requiring that the net sediment transport $\left(I_{j}-O_{j}\right)$ be equal to the total deposited sediment over a time period $\left(\Delta S_{j}\right)$ :

$$
\Delta S_{j}=I_{j}-O_{j}=\int_{t=t_{1}}^{t=t_{2}} Q_{s i} d t-O_{j} \approx \int_{t=t_{1}}^{t=t_{2}} a_{j} Q_{i}^{b_{j}+1} d t-O_{j} \quad ; j=1,2,3,4
$$

where, $Q_{i}$ and $Q_{s i}$ denote daily discharge and sediment load for day $i$ (where $t_{1} \leq t \leq t_{2}$ ), respectively, $a_{j}$ and $b_{j}$ are rating curve parameters for time period $j$ that lasts from time $t_{1}$ to time $t_{2}, \Delta S_{j}$ denotes the net deposition or erosion within the system for each time span estimated by Schoellhamer [2011], and $j=1-4$ represents the periods $1861-1892$, $1892-1925,1925-1949$, and $1949-1984$.

The sediment output $\left(O_{j}\right)$ includes i) export to the Ocean through the Bay and ii) permanently removed materials from the SF Bay system (e.g. through dredging, aggregate mining, and borrow pit mining); thus:

$$
O_{j}=O_{\text {export }}+O_{\text {removed }}
$$

Due to difficulties inherent in measuring flow and sediment discharge close to the ocean, there are no measurements defining SF Bay sediment export to the Pacific Ocean. Schoellhamer [2011] argues that in well-mixed estuarine water with suspended sediment 
mass $S$ and outflow coefficient $c_{o}$ (with units of time ${ }^{-1}$ ), $O_{\text {export }}=S c_{o}$. In a transportcapacity regulated system, $S$ is assumed to be equal to its maximum value $\left(S_{\max }\right)$ due to transport regulation of suspended sediment; thus $O_{\text {export }}=S_{\max } c_{o}$. The study analyzed the historical sediment budget for SF Bay, and concluded that SF Bay was a transport regulated system from the 1850 s to the $1990 \mathrm{~s}$. An average sediment outflow of $8.4 \mathrm{Mtyr}^{-1}$ for SF Bay was estimated for 1860 - 1999, which we use in (4.9).

Dallas and Barnard [2011] compiled historical records and estimated that since 1900, a minimum of $200 \mathrm{Mm}^{3}$ of sediment has been permanently removed $\left(O_{\text {removed }}\right)$ from SF Bay via dredging and borrow pit mining. Specifically, about $64 \mathrm{Mm}^{3}$ and $90 \mathrm{Mm}^{3}$ of sediment were permanently removed during the periods 1900 - 1949, and 1949 - 1984, which we use in (4.9). However, due to poor documentation these are minimum estimates. Before 1900, Also, historic records show that $\sim 1.85 \mathrm{Mm}^{3}$ and $\sim 2.35 \mathrm{Mm}^{3}$ was permanently dredged from Rincon Rock, SF Harbor and Oakland Harbor, SF Bay between 1873 - 1889, and 1890 - 1899, respectively [US Army Corps of Engineers, 1915]. We use these values in equation (4.9) for pre-1900 estimates. An unknown amount of mining sediment was deposited on floodplains pre-1910 (e.g. due to levee failures), and was not considered in either the bathymetric surveys or in removed material. We are unable to correct for this loss due to lack of information.

To find the optimal rating curve parameter $a$ for each period, we test a range of values of $a$ from 0 to 1 with the step size of $10^{-8}$. We then calculate daily sediment transport $\left(Q_{s i}\right)$, and compare the integral estimated input $\left(I_{j}=\int_{t=t_{1}}^{t=t_{2}} Q_{s i} d t\right)$ with the sum of 
storage and output $\left(\Delta S_{j}+O_{j}\right)$. Next, we choose the rating curve parameter $a$ that provides the best estimate (i.e. results in the least difference between $I_{j}$ and $\Delta S_{j}+O_{j}$ ), as the best estimates of $a_{j}$.

Schoellhamer [2011] calculates the change in bed volume using bathymetric data before 1984. From 1984 - 2011 rating curves fitted to daily values (Figures 4-6b and 46c) suggest that $a$ should be about $2.07 \times 10^{-6}$ and 0.045 for periods $1984-1998$, and 1999 - 2011, respectively. As these values represent only the load from the Central Valley, we multiply them by 1/0.4 [McKee et al., 2013] to reflect the contribution of local tributaries in total load delivered to SF Bay from $1984-2011$.

Step III - Smoothing the variation of parameter a between periods: Estimated rating curve parameter $a$ step-wisely changes from one period to another (e.g. at the year that observation has made) which may cause an unrealistic sharp change in sediment supply over a short period of time (e.g. less than a year). Only under specific circumstances (e.g. beginning of hydraulic mining activities in the late 1850s, and depletion of sediment pool in the late 1990s) would sediment supply change drastically this way. Also, the bathymetric observations that Schoellhamer [2011] used for calculation of net sediment deposition were made over periods of $\sim 10$ years [Cappiella et al., 1999; Fregoso et al., 2008; Foxgrover et al., 2004; Jaffe et al.; 1998]. To avoid sharp changes in parameter $a$ between periods we assume that parameter $a$ changes over 10 years between periods. For example the parameter $a$ estimated for 1892 - 1925 linearly decreases between 1920 and 1930 to reach the value estimated for $1925-1949$. 
Step IV: Re-adjusting parameter b: The smoothing process for $a$ (described in Step III) causes the estimated sediment delivery for each time span to change. To conserve the mass in the system, we re-adjusted $b_{j}$ such that $I_{j}$ and $\Delta S_{j}+O_{j}$ are equal again. This estimated parameter $b$ was then compared to the previously estimated $b$. If the difference was $>10 \%$ a further iteration through steps II to IV was made, until the difference between estimated parameter $b$ for two following trials was than $10 \%$. Table 2 shows the final estimates for rating curve parameters from 1850 - 2011, that have been used in this study. Figures $4-7 \mathrm{a}, 4-7 \mathrm{~b}$, and $4-7 \mathrm{c}$ represent the estimated yearly maximum daily discharge, variation in rating curve parameters $a$ and $b$, and the estimated yearly maximum daily sediment load to SF Bay.

\section{Results}

\subsection{Discharge Estimation (CDE)}

SDE is first compared to NDOI data for 1930 to 1944, and is then validated using NDOI for 1945 - 1946 and 18d averaged TDE 1881 - 1929 to confirm its applicability for discharge estimation. Then pre-1930 CDE (SDE and TDE combined) is validated using four series of data (a) ERI 1906 - 1944, (b) observed discharge at Red Bluff, CA 1891 - 1944, (c) total monthly precipitation $1851-1944$, and (d) SRI $1879-1884$ (see section 2-2-4 for more information). For cases in which we compare the estimated/observed values of a parameter from two different sources/approaches (section 3-1-1), the Nash-Sutcliffe efficiency coefficient is used to describe the reliability of 
estimates; for comparisons of two different variables (e.g. discharge and rainfall in section 3-1-5) we use a correlation coefficient to assess the reliability.

Comparison to NDOI: Comparison of SDE with NDOI data for 1930 to 1944, the calibration time period yields a Nash-Sutcliff efficiency coefficient of 0.89 , supporting the applicability of the model (Fig. 4-8a). Over the 1945-1946 validation period, the Nash-Sutcliff efficiency coefficient is 0.92 (Fig. 4-8b).

Comparison to TDE: Monthly averaged flow (TDE) estimates from Moftakhari et al. [2013a] from 1881 - 1929 are compared against monthly averaged SDE in Figure 49a. The correlation coefficient for this period is 0.84 , validating the SDE estimate.

Comparison to the Eight-River Index (ERI): To assess the robustness of CDE we compare it to measures of unimpaired SF Bay inflow. Figure 4-9b shows the monthlyaverage of CDE versus ERI (December-May) for the periods 1906-1944. The correlation coefficient is 0.82 , and a linear regression yields $Y=0.648 X+465.42$ with an $\mathrm{R}^{2}$ of 0.67 .

Comparison to Flow at Red Bluff, CA: To compare Red Bluff flows with CDE, and reduce the effect of time-lags we plot weekly-averaged Red Bluff flows against weekly-averaged CDE over the period 1891 - 1944 (Figure 4-9c). The correlation coefficient is 0.88 , and a linear regression yields $Y=0.252 X-90.39$ with an $\mathrm{R}^{2}$ of 0.77 . Apparently, almost $25 \%$ of the flow from the entire basin enters the river above Red Bluff, even though the gauge at Red Bluff drains $\sim 14 \%$ of the total watershed.

Comparison with Precipitation Data: Figure 4-9d shows annual total precipitation at Sacramento, CA versus CDE, 1850-1944. In this case, the correlation coefficient is 
0.82 , and a linear regression yields $Y=0.057 X+37.79$ with an $\mathrm{R}^{2}$ of 0.67 . Thus, years with high rainfall at Sacramento produce correspondingly large annual flows, despite soil storage effects and basin-wide variability in precipitation.

Comparison with SRI: The SRI provides a valuable historical check on flow estimates during the peak of hydraulic mining activities $1879-1884$. Though similar to a monthly averaged NDOI it does not consider exports and precipitation. Figure 4-10 compares monthly-averaged CDE (with errorbars) to SRI 1879 - 1884; the Nash-Sutcliff efficiency coefficient for this period is 0.78 . The downscaled TDE is plotted as well to show the compatibility of these flow estimates.

To summarize these comparisons, $\mathrm{CDE}$ is closely comparable to diverse hydrologic measures for SF Bay and the Sacramento River over the last 160 years; thus it provides a reliable method for hindcasting historic daily flows.

\subsection{Sediment Transport Estimation}

The CDE validated in section 3-1 are next used to estimate daily sediment flux into SF Bay from WY1850 to 2011 (see section 2-3-4 for methods). Figure 4-11 shows the yearly-average estimated load 1956-2011 using NDOI and the integral sediment constraints vs. the average annual load estimated from observed data described in 2-2-3. The results suggest that the contribution of the Central Valley to the delivered load SF Bay is different during high load WYs (e.g. >10,000 ton/day), and low load WYs $(<10,000$ ton/day). During low load periods the correlation coefficient is 0.80 , and a linear regression yields $Y=0.58 X-912.2$ with an $\mathrm{R}^{2}$ of 0.84 . The regression therefore 
suggests that $\sim 60 \%$ of the load delivered to the Bay during low load conditions comes from the Central Valley and the rest from local tributaries. By contrast, the transport capacity limitation of sediment delivery from the Central Valley causes this percentage to change over high load periods. Since 1956 , local tributaries contribute $\sim 80 \%$ of sediment delivered to SF Bay during high load years, compared with $\sim 40 \%$ during low load years.

Figure 4-12a shows CDE estimates for WY1850 to WY1929, and Figure 4-12b shows the estimated daily sediment flux to SF Bay from WY1850 to WY2011. Also, Figures $4-12 \mathrm{a}$ and $4-12 \mathrm{~b}$ show the yearly maximum discharge and yearly maximum sediment flux to SF Bay between 1850 and 2011, respectively. These results suggest that the largest daily sediment flux $\left(115,000 \mathrm{kgs}^{-1}\right)$ from 1849 occurred in January 1862 (Fig. 4-7c), due to the second largest daily peak flow $\left(17,600 \mathrm{~m}^{3} \mathrm{~s}^{-1}\right)$ and the largest 18-day averaged peak flow in the last 160yrs [Moftakhari et al., 2013]. However, a significant uncertainty must be ascribed to the 1862 discharge level, because the amount of floodplain inundated was much larger than any subsequent flood. Thus, the flood may have been significantly larger than our estimate and large amounts of sediment may also have been deposited throughout the Central Valley. Regardless, the largest measured daily peak flow that occurred in $1986\left(17,900 \mathrm{~m}^{3} \mathrm{~s}^{-1}\right)$ is slightly larger than the estimated peak flow on 1862.

Although other large floods occurred between 1849 and 1859, the system was more supply limited (compared to the late $19^{\text {th }}$ century) and no large sediment flux peak is evident. Large peak flows in WY 1878, 1879, 1880, 1881, 1890 coincided with the huge amount of sediment that was released to the watershed due to hydraulic mining, 
producing very large annual sediment fluxes in the late $19^{\text {th }}$ century. Though hydraulic mining was banned in 1884, the sediment supplied by previous mining activities continued to move downstream during high flow events. Land development, timber harvest and agricultural activities along with delayed debris from hydraulic mining activities produced large daily sediment loads during floods in WYs 1927, 1928, 1938, 1940, 1941, 1942, and 1945. None of these events supplied as much sediment as the 1862 flood, however.

\section{Discussion}

Since 1998, San Francisco Bay has become significantly less turbid [Schoellhamer, 2011] and is facing the prospect that contaminated mercury sediments may begin to erode if annual sediment export (through the Golden Gate or from sand mining and dredging) is less than input (see Bouse et al. [2010]). Our evaluation of sediment export over time suggests that the parameters $a$ (sediment supply) and $b$ (stream power) and the river flow have significantly changed over time (Figure 4-7b), and that these changes have contributed to the diminished annual export of sediment from the Bay. A related change, with possible implications for nutrient transport and the biogeochemical cycle in the bay and coastal ocean, is that significant snow-melt driven freshets and spring season sediment pulses have disappeared. Long term, decadal cycles in river flow, and hence sediment flux, are also evident in the data; relatively low flows from 1910 to 1937 were followed by large flows from 1938 to 1945.

Overall, our estimates of sediment fluxes using an integral constraint shows that the total sediment load delivered to SF Bay because of hydraulic mining and land 
development activities was much larger than previous estimates, especially during the first half of the $20^{\text {th }}$ century (Figure 4-7c). Urbanization, timber harvest and land development appear to have contributed to the second pulse of sediment supply from the 1920s to 1950 s, about $60 \%$ as large as the pulse that happened due to hydraulic mining activities, between 1862 and 1892 [Schoellhamer, 2011]. The area of reclaimed land in the Bay area almost doubled by the late $1920 \mathrm{~s}\left(\sim 1700 \mathrm{Km}^{2}\right)$, relative to the beginning of the $20^{\text {th }}$ century $\left(\sim 950 \mathrm{Km}^{2}\right)$ [Thompson, 1957 ]; loss of access to both floodplain and intertidal areas reduced the area over which sediment can deposit, possibly focusing sediment deposition in the remaining wetted areas and inflating the observed deposition. The elevated mid-century sediment load, while possibly augmented by the effects of urbanization and agricultural activities, may also reflect the residual effects of hydraulic mining and other land-management practices such as logging. Folsom dam on the American River only began capturing sediment in 1956, and Oroville dam on the Feather River was only finished in 1968. In fact, large sediment concentrations on the Feather River during the floods in 1950s and early 1960s were attributed to the residual effects of hydraulic mining [James, 2004]. It is also possible that greatly increased logging and clear-cutting between 1940-1970 [Burns, 1972; Laudenslayer and Darr, 1990] increased sediment fluxes during the mid- $20^{\text {th }}$ century. While further research is needed to determine the cause of the mid-century pulse, it seems clear that it was augmented by significant river flow events, compared to the relatively low flow from 1912 to 1937 . As suggested by Schoellhamer [2011], depletion of the sediment pool reduced the largest daily peak flows in 1986 and 1997 to only $15,000 \mathrm{kgs}^{-1}$ and 12,000 kgs ${ }^{-1}$, respectively, which are small values considering the magnitude of flooding (Figure 4-7c). 
Figure 4-13 compares our cumulative sediment load estimate from 1849 to 2011 , with those estimated by Ganju et al. [2008] (G08). They have estimated sediment load from the Central Valley, while we have estimated total sediment load from both the Central Valley and local tributaries adjacent to the Bay. To compare our results with their estimates we have divided their estimates by 0.9 to reflect the contribution of local tributaries into total load [Ogden Beeman and Associates, 1992]. This comparison quantifies the effect of employing different approaches and inclusion of historic water level records in flow estimation and temporal downscaling of sediment transport estimates. The results of our model are different from G08 for four main reasons. First, the approach that we have employed and the proxies that we have used to estimate historic daily flows are different, which affects the estimation of sediment load. To demonstrate this difference, we applied G08's rating curve to CDE (G08-prime in Figure 4-13), and divided the results by 0.9 to reflect the contribution of local tributaries. The cumulative load estimates by G08-prime for 1849 - 1955 is, however, only $10 \%$ larger than G08, indicating that the effect of using different discharge estimates is fairly small. Second, inclusion of sediment pulse in the mid- $20^{\text {th }}$ century, reflected in Schoellhamer [2011] results, but not in Porterfield [1980], produces a huge difference in mass balance that affects the estimation of rating curve parameter $a$, and thus the sediment load estimates. Another difference is the assumption that we have made about the variation of rating curve parameters $a$ and $b$ over time. In G08 parameter $a$ gradually increased and decreased, before and after 1890, respectively, while we assumed rating curve parameter $a$ to be constant during each time span and to linearly increases/decreases between the 
time spans. G08 assumed that $b$ is constant over time, while we allowed $b$ to vary between time periods (Table 2).

We also analyze cumulative sediment load estimated under different scenarios; this allows us, using a hypothetical scenario ( $\mathrm{S} 1)$, to determine the contribution of natural processes and human activities to the variation of contemporary sediment load compared with historic loads. Scenario S1 (Fig. 4-13) shows the cumulative sediment load that would have occurred under natural sediment conditions, given the measured flow. Sediment supply (parameter $a$ ) and stream power (parameter $b$ ) are kept at the "natural", pre-1862 values between 1862 and 2011. S1 produces a cumulative load of $\sim 570 \mathrm{Mt}$, $\sim 35 \%$ of the actually estimated $\sim 1600 \mathrm{Mt}$. Hence, $\sim 65 \%$ of the cumulative sediment load is directly attributable to anthropogenic alteration of sediment supply.

Strong seasonality in the flow regime in SF Bay causes the larger portion of sediment load to be transported during high flow events. Specifically, Figure 4-14 shows the portion of the total load that moves during high flow days. Results suggest that on average $40 \%, 75 \%$, and $85 \%$ of the total load moves during top $1 \%, 10 \%$, and $50 \%$ flow days, respectively. Thus on average, $85 \%$ of the yearly load moves during the wet half of the year, while only $15 \%$ moves during the dry season. The results also suggest a shift in seasonality over time. While $\sim 45 \%$ of the total load was delivered during top $1 \%$ flow days 1850 - 1945, flow regulation measures have reduced the seasonality of sediment transport in the modern system to $\sim 30 \%$.

Moftakhari et al. [2013a] suggested that the timing and magnitude of the annual peak flow has changed considerably over time, and flood control projects, diversion for 
irrigation and human consumption, and climate change effects (i.e. changes in the amount and timing of precipitation and the seasonal temperature cycle [Knowles, 2002]) have resulted in a $\sim 30 \%$ decrease in annual average discharge. The CDE and sediment load hindcasts allow us evaluate long-term changes in the annual hydrograph and sediment load to the Bay. Figure 4-15a compares CDE hindcasts averaged by year-day for historic flows (1849-1945; the period that Shasta Dam has not altered the hydrograph), and the modern flow regime (1946-2011). Both the timing of the annual peak flow and the total volume of water changed considerably in modern era compared with the late $19^{\text {th }}$ century and early $20^{\text {th }}$ century. Snowmelt-driven spring freshets produced annual peak flows in many years prior to 1940s. Diversions have reduced, the total volume of water delivered to SF Bay in modern system by $\sim 25 \%$ compared with historic system $\left(\sim 3.2 \mathrm{Km}^{3} / \mathrm{yr}\right.$ versus $\sim 2.4 \mathrm{Km}^{3} / \mathrm{yr}$ total inflow in modern system). This reduction is compatible with the value ( $\sim 30 \%$ reduction) proposed by Moftakhari et al. [2013a]. Figure 4-15b compares sediment load hindcasts averaged by year-day for the late $19^{\text {th }}$ century and the early $20^{\text {th }}$ century with the modern era. The results suggest that the timing of peaks has changed over time. Storms and snow-melt produced peaks from February to May in the historic system have now being shifted to an earlier year date, and are mostly associated with winter storm events. An approximately $25 \%$ reduction of annual flow since the $19^{\text {th }}$ century along with decreased sediment supply has resulted the contemporary average annual volume of sediment to be $\sim 60 \%$ less in the modern system ( 4.9 Mt/yr) compared with the late $19^{\text {th }}$ century and the early $20^{\text {th }}$ century ( 11.4 Mt/yr). Figure $4-15 \mathrm{~b}$ supports the results of Figure 4-14, and suggests that the seasonality has shifted over time because spring-melt floods have disappeared, and most sediment input now occurs in winter. 
While historically $\sim 70 \%$ of the total annual load was delivered in Winter (Dec. to March), and $\sim 25 \%$ was delivered in Spring (Apr. to June), $\sim 80 \%$ of the load is delivered during winter storm driven flows in the modern system and less than $15 \%$ in Spring.

Evaluating the significance of our sediment load estimate requires understanding the magnitude of likely errors, which may be systematic (due to bias) or random. The mean of random errors such as bathymetric measurement errors and digitization errors are assumed to be close to zero when averaged spatially. Thus, systematic errors are likely to be the most important limitation to the accuracy of our results. A likely issue is bias in the reference level of bathymetric measurements, here Mean Lower Low Water (MLLW) for one or more time periods. In the four studies that Schoellhamer [2011] used to calculate the bathymetric change over time in the Bay area, MLLW is assumed to be constant over each subembayment. Nonetheless, both tidal theory and observations suggest tides typically damp as they propagate along a strongly frictional channel [Kukulka \& Jay, 2003a], unless the convergence of cross-sectional area is very strong. In the modern system the greater diurnal tidal range at NOAA gauges at San Francisco (Fort point), Redwood City, Richmond, Mare Island, and Collinsville are $1.78 \mathrm{~m}, 2.50 \mathrm{~m}$, $1.84 \mathrm{~m}, \quad 1.77 \mathrm{~m}, \quad$ and $\quad 1.21 \mathrm{~m}, \quad$ respectively [http://tidesandcurrents.noaa.gov/tidetables/2012/wctt2012book.pdf]. Table 2 presents the surface area and variation of MLLW over each of four sub-embayments of SF Bay based on these recent observations. However, frictional effects were likely stronger in the past (due to sedimentation effects) and tides more strongly damped [Gilbert, 1917], and variations in MLLW may have been larger in the historic Bay system. Historic records of 
the observed tides recorded during bathymetric surveys have recently been re-discovered [Talke \& Jay, 2013], and may in the future provide better estimates of historic variations in MLLW in the Bay. Nonetheless, using the present-day spatial variations in MLLW, we may evaluate the errors in shoaling volumes estimated from historic bathymetric charts as:

$$
\text { Error }=\gamma \times \sum_{i=1}^{4} \mid \Delta M L L W_{i} \times \text { Area }_{i} \mid
$$

where $\gamma$ denotes the bulk density of sediment $\left(\sim 850 \mathrm{Kgm}^{-3}\right.$ [Porterfield, 1980; Jaffe et al., 2007]), $i=1-4$ represents the four subembayments, and $A r e a_{i}$ and $\triangle M L L W_{i}$ denote the surface area and variation in MLLW over each sub-embayment (Table 2), respectively. Using plausible values for the parameters in (4.10) yields an estimated survey error of about \pm 100 Mt. Since errors between successive surveys are additive, the error in Bay sediment load due to surveys is approximately $\pm 200 \mathrm{Mt}$. The other sources of error is the mass balance error, the difference between estimated input $\left(I_{j}\right)$ and the sum of storage and output $\left(\Delta S_{j}+O_{j}\right)$ in equation (4.8). Table 2 represents the estimated error associated with estimated rating curve parameters for each time span that we have iteratively calibrated rating curve parameters. Thus, the total (e.g. cumulative) mass balance error associated with our sediment load estimates is approximately $\pm 120 \mathrm{Mt}$. Our results therefore suggest that $\sim 1600 \pm 320$ Mt of sediment was released into the SF Bay system over the last $160 y$ rs. However, other factors contributing to the error, such as estimated sediment export to the ocean, or datum shifts associated with plate tectonics (e.g., due to the 1906 earthquake) cannot easily be evaluated. We note also that historic 
surveys in the $19^{\text {th }}$ century typically did not survey intertidal areas or flood plains, and thus may have undercounted total sedimentation.

\section{Conclusions}

This study provides new, improved estimates of daily inflow and sediment delivery to SF Bay, using approximately 80 years of daily water stage data for Sacramento, CA from as early as WY 1850. After correcting for changes to channel depth and water level variance, water level based discharge estimates are combined with NDOI and TDE flow estimates to provide a composite delta inflow record back to WY 1850. Our estimates suggest that natural processes combined with hydraulic mining and agricultural activities released $\sim 1600 \pm 320$ Mt of sediment to SF Bay from $1849-2011$. The average annual volume of delivered sediment is $\sim 60 \%$ lower in the modern system than during the peak hydraulic mining sediment pulse. The results also suggest that since 1956 , local tributaries contribute $\sim 80 \%$ of sediment delivered to SF Bay during high flow years, compared with $\sim 40 \%$ during low flow years. We estimate that $65 \%$ of the sediment delivered to the estuary between 1849 and 2011 was the result of anthropogenic alteration in the watershed that increased sediment supply. The large increases in sediment input due to hydraulic mining, urbanization, logging, and other anthropogenic developments emphasize how far the system has departed from its natural conditions prior to 1862. 
Table 4-1: Rating curve parameter $b\left(Q_{s}=a Q_{p}{ }^{b+1}\right)$

\begin{tabular}{c|cccc}
\hline Parameters & $1956-1968$ & $\mathbf{1 9 6 9 - 1 9 9 8}$ & $\mathbf{1 9 9 9 - 2 0 1 1}$ & $\mathbf{1 9 5 6 - 2 0 1 1}$ \\
\hline$b$ & 1.927 & 1.007 & 0.011 & 0.687 \\
\hline
\end{tabular}

Table 4-2: Rating curve parameters $\left(Q_{s i}=a Q_{i}^{b+1}\right)$

\begin{tabular}{||c|c|c|c|c|c|c|c|c||}
\hline \hline PARAMETERS & $\begin{array}{c}1849- \\
1861\end{array}$ & $\begin{array}{c}1862- \\
1892\end{array}$ & $\begin{array}{c}1893- \\
1925\end{array}$ & $\begin{array}{c}1926- \\
1949\end{array}$ & $\begin{array}{c}1950- \\
1968\end{array}$ & $\begin{array}{c}1969- \\
1984\end{array}$ & $\begin{array}{c}1985- \\
1998\end{array}$ & $\begin{array}{c}1999- \\
2011\end{array}$ \\
\hline$a$ & 0.1125 & $2.07 \times 10^{-8}$ & $5.10 \times 10^{-8}$ & $8.18 \times 10^{-8}$ & \multicolumn{2}{|c|}{$4.08 \times 10^{-6}$} & $6.13 \times 10^{-6}$ & 0.1125 \\
\hline$b$ & 0.011 & 2.029 & 1.931 & 1.951 & 1.392 & 1.289 & 1.007 & 0.011 \\
\hline $\begin{array}{c}\text { Mass balance } \\
\text { relative error }\end{array}$ & - & 0.084 & 0.135 & 0.077 & 0.053 & - & - \\
\hline $\begin{array}{c}\text { Estimated mass } \\
\text { balance error }(\mathrm{M} t)\end{array}$ & - & 38.55 & 43.47 & 26.36 & 12.81 & - & - \\
\hline
\end{tabular}

Table 4-3: Surface area and along channel variation of MLLW in the modern SF Bay

\begin{tabular}{c|cccc}
\hline Parameters & Central SF Bay & South Bay & San Pablo Bay & $\begin{array}{c}\text { Suisun } \\
\text { Bay }\end{array}$ \\
\hline $\begin{array}{c}\text { Surface area }\left(\mathrm{Km}^{2}\right) \\
\text { Along channel variation of } \\
\text { MLLW }(\mathrm{m})\end{array}$ & 304 & 410 & 290 & 142 \\
& -0.06 & 0.78 & -0.07 & -0.57 \\
\hline
\end{tabular}




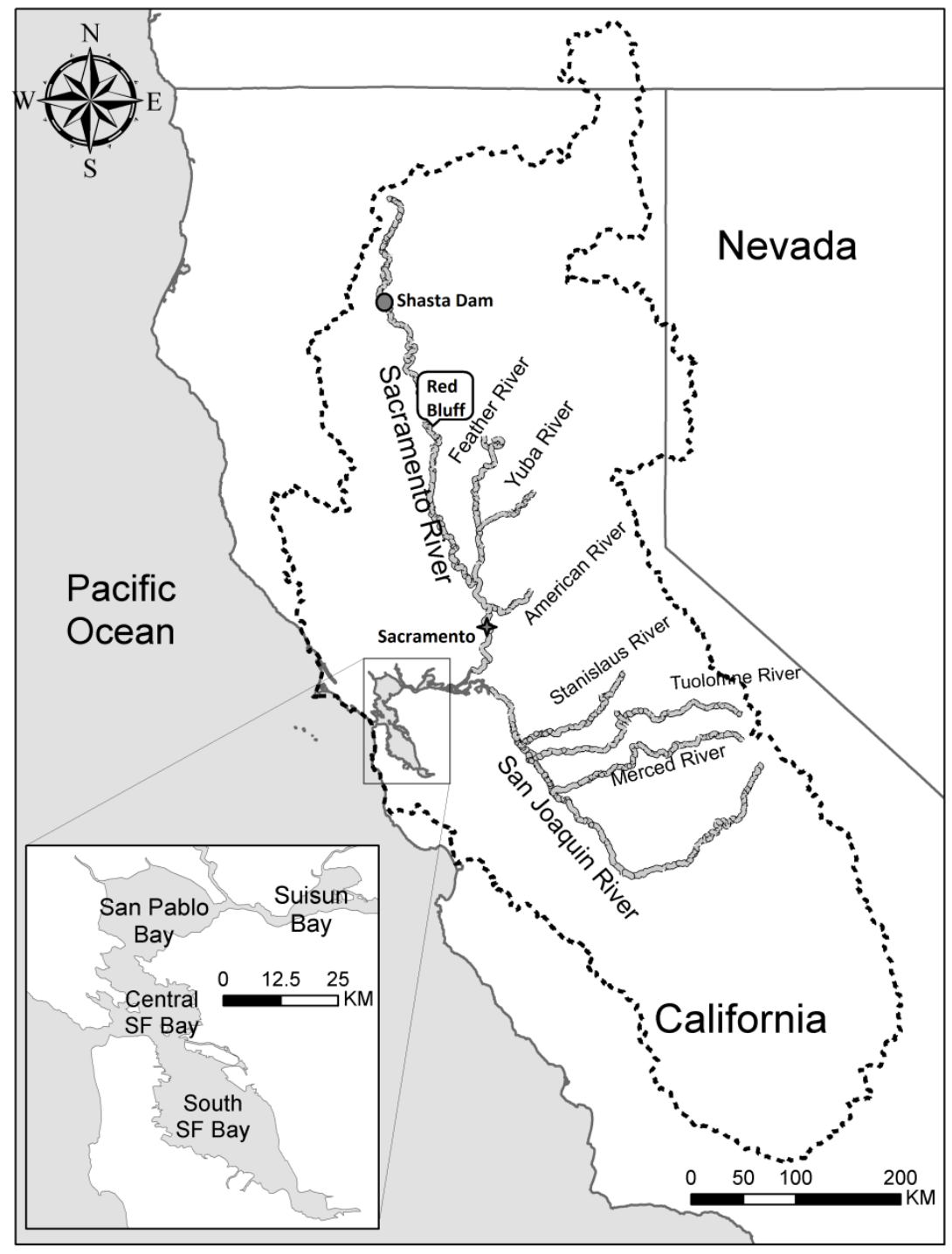

Figure 4-1: San Francisco Bay study area and the eight rivers used for the Eight-River-Index drain the Central Valley through SF Bay to the Pacific Ocean; dashed-line shows the boundary of watershed 

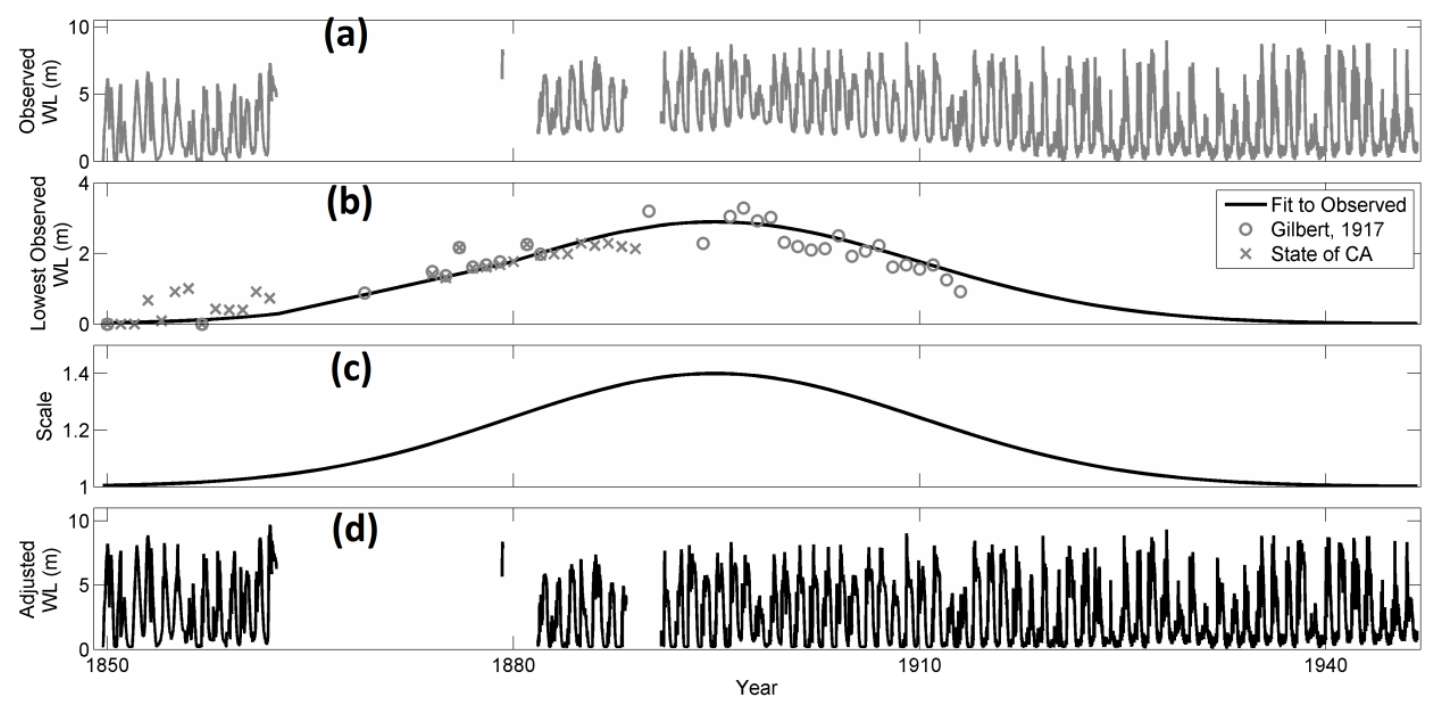

Figure 4-2: Panel (a): daily observed Sacramento water level (WL) variation, 1849 - 1949. Panel (b): variation of annual minimum WL with time. Panel (c): WL range adjustment scale. Panel (d): Adjusted WL for the effects of sedimentation and/or leveeing, with reference to 1930's.
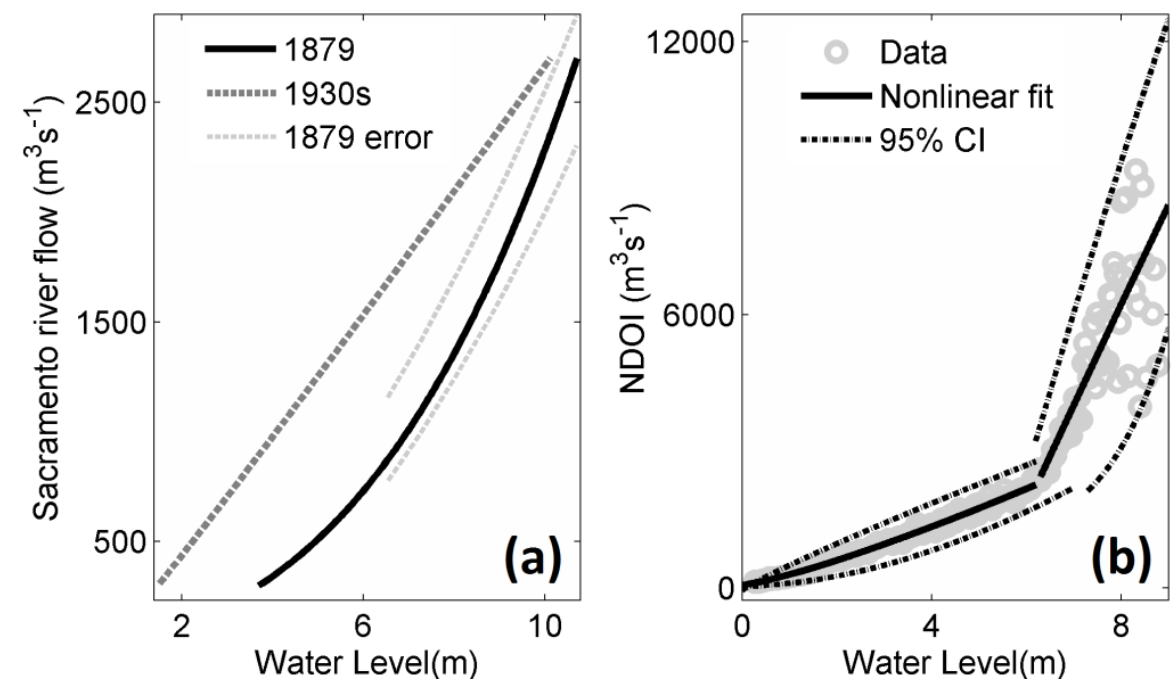

Figure 4-3: Panel (a): Calibrated Discharge-WL rating curve at Sacramento, CA during the peak of hydraulic mining activities (solid line) vs dredged channel fifty-years later (dash-dot line).

Panel (b): WL-NDOI rating curve calibrated to daily data over 1930 - 1944. 


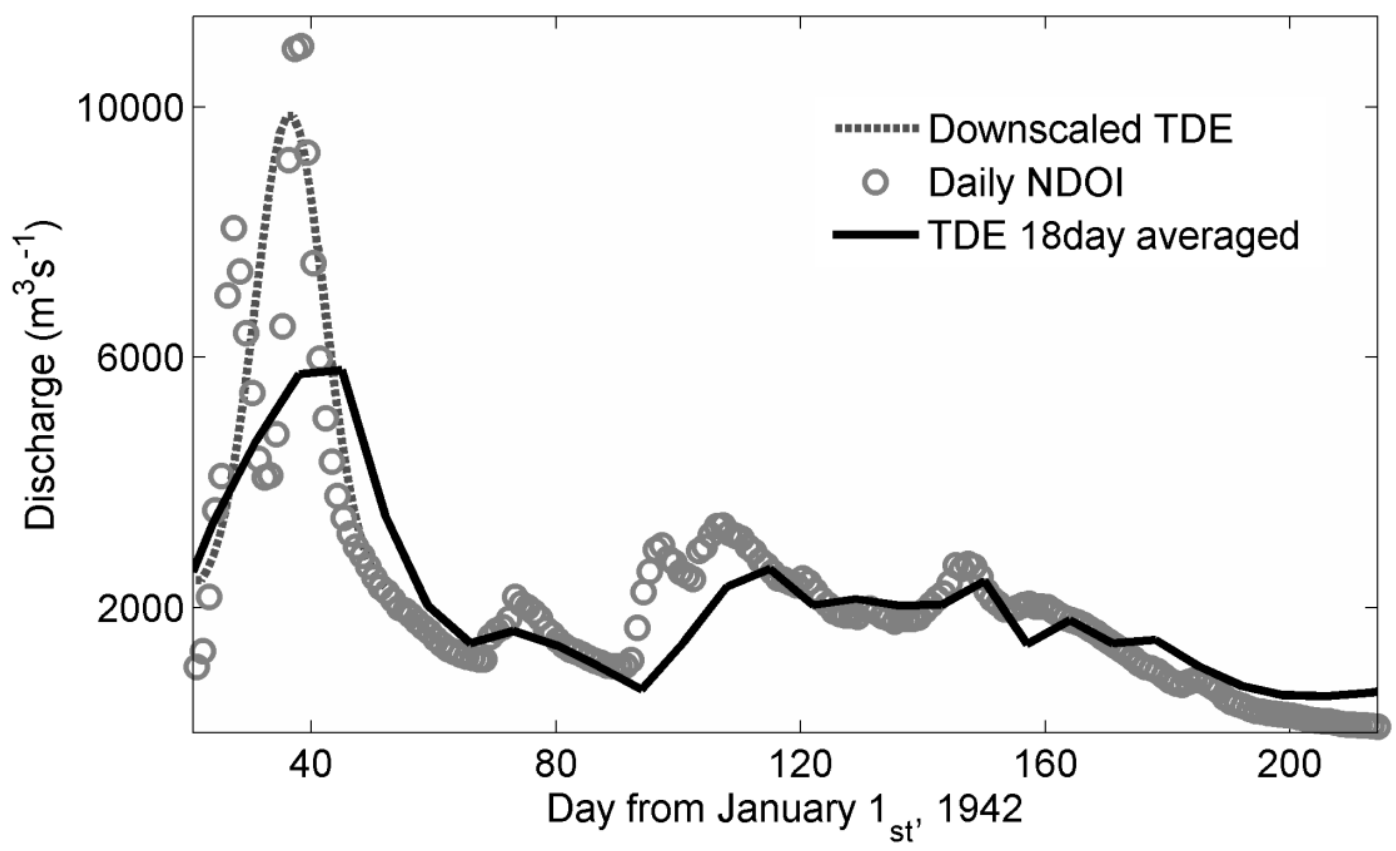

Figure 4-4: Original TDE (solid line) and adjusted temporally downscaled TDE (dotted line) vs NDOI estimate (circles)

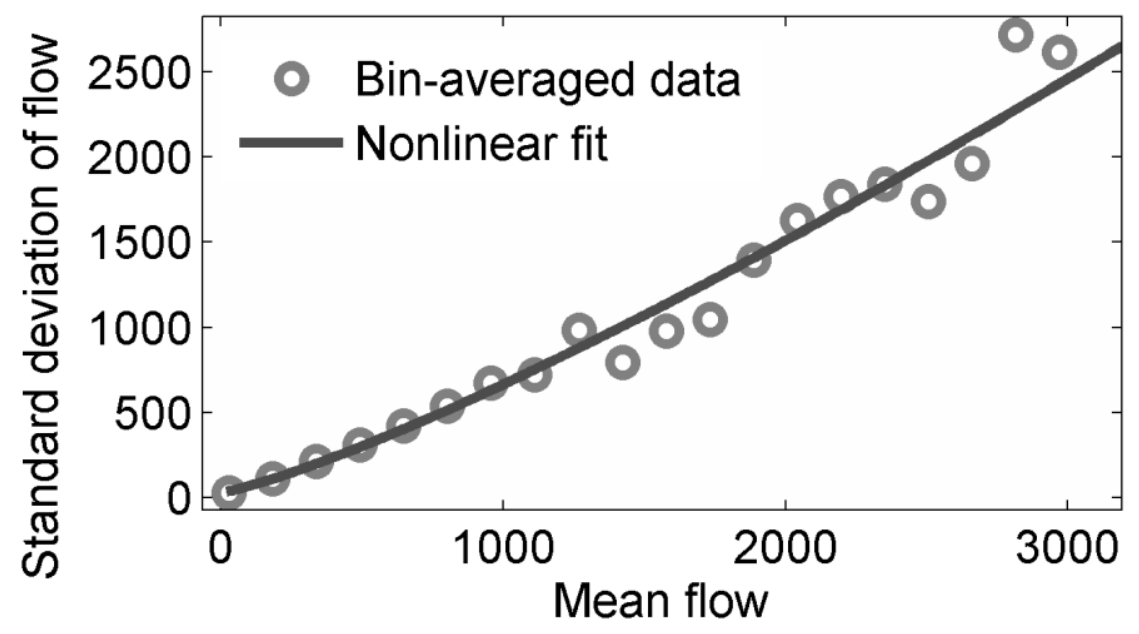

Figure 4-5: The relationship between mean and standard deviation within an 18-day calculating window 

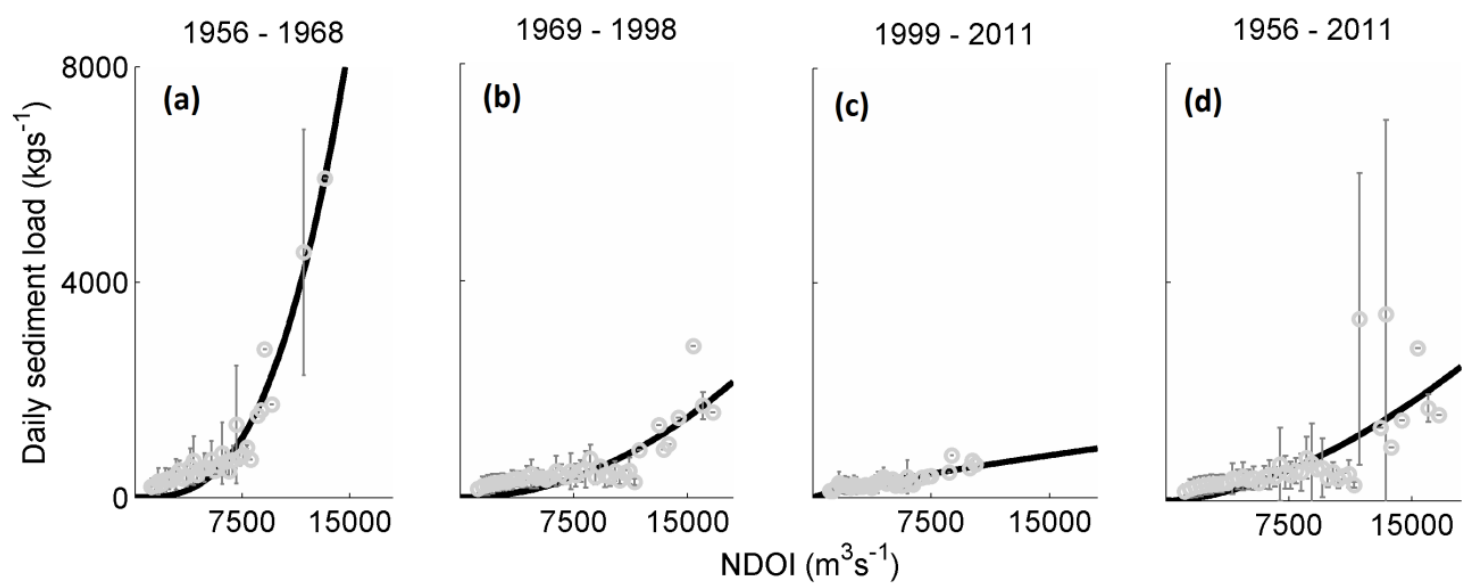

Figure 4-6: Sediment transport rating curve; bin-averaged NDOI vs sediment load from Sacramento and San Joaquin rivers; where circles and bars show the mean and range of variability within averaging-bins, respectively.

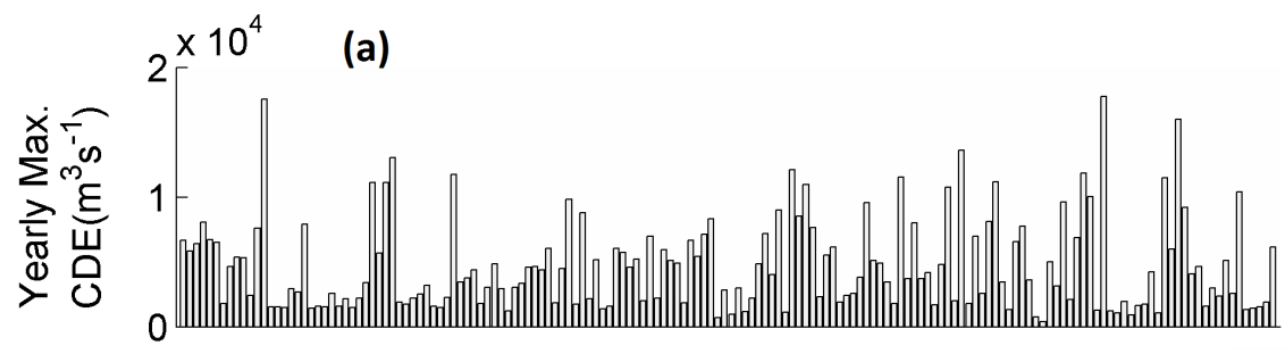

(b) $\log _{10}(a)$
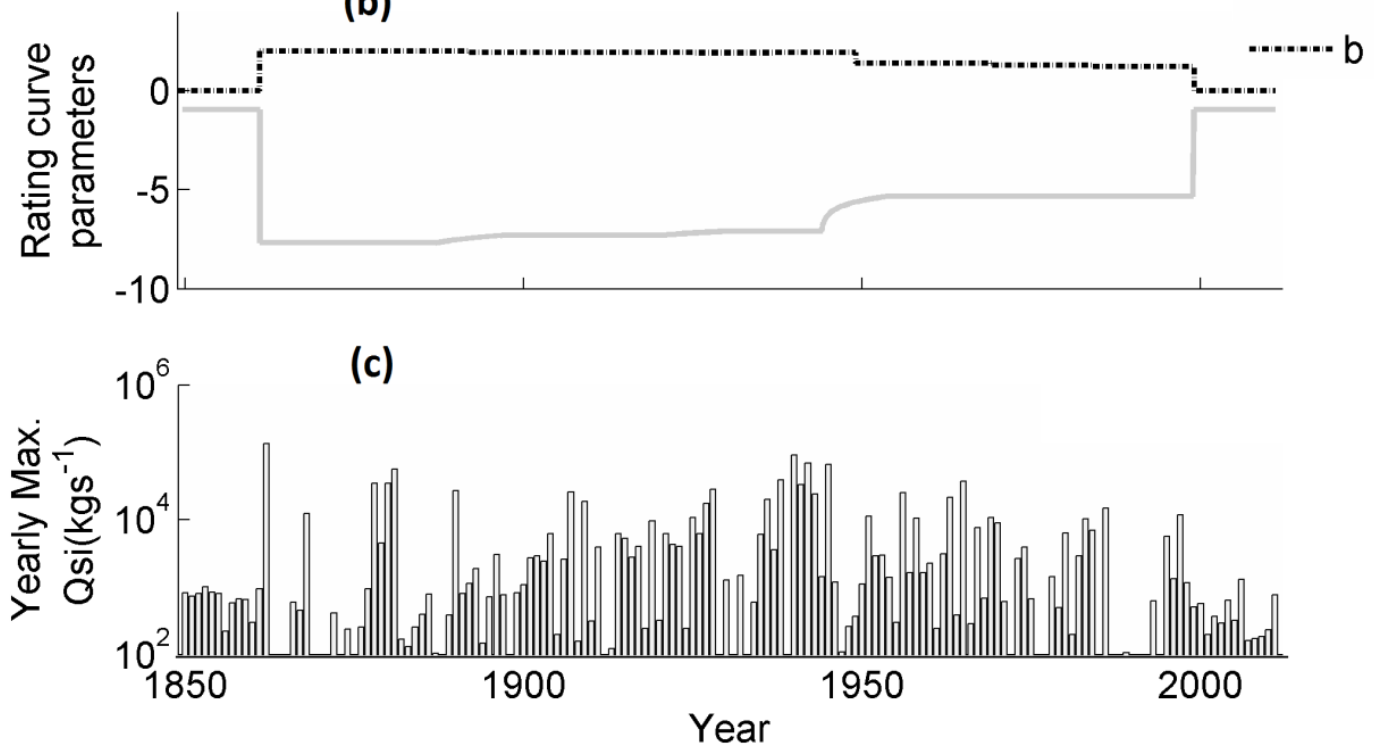

Figure 4-7: Estimated yearly maximum discharge (Panel a), rating curve parameters (Panel b) and sediment load (Panel c) to SF Bay (1849-2011) 

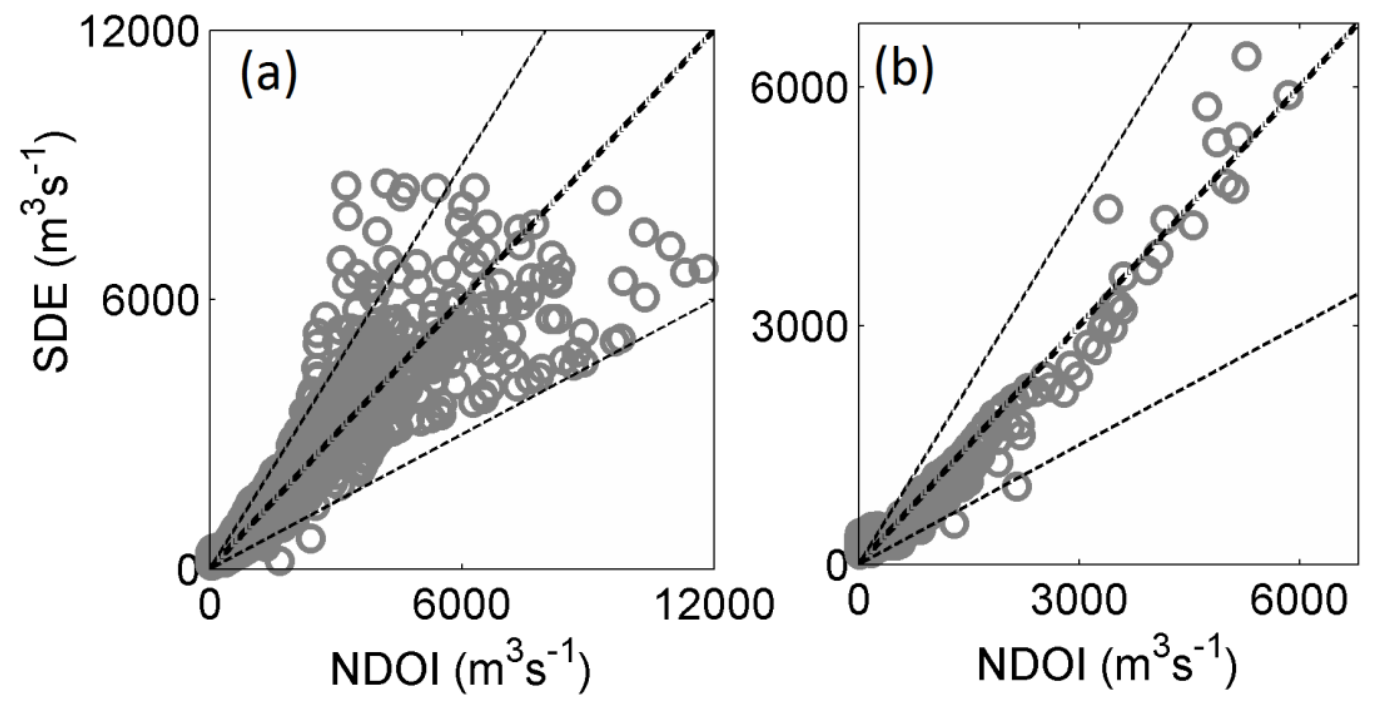

Figure 4-8: Panel (a): checks the applicability of SDE; Panel (b) compares daily SDE for WY 1945 - 1946 to NDOI to validate the model. Circles show the daily values, dash-dot line shows the equal line and dashed lines show the estimated 95\% confidence interval. 

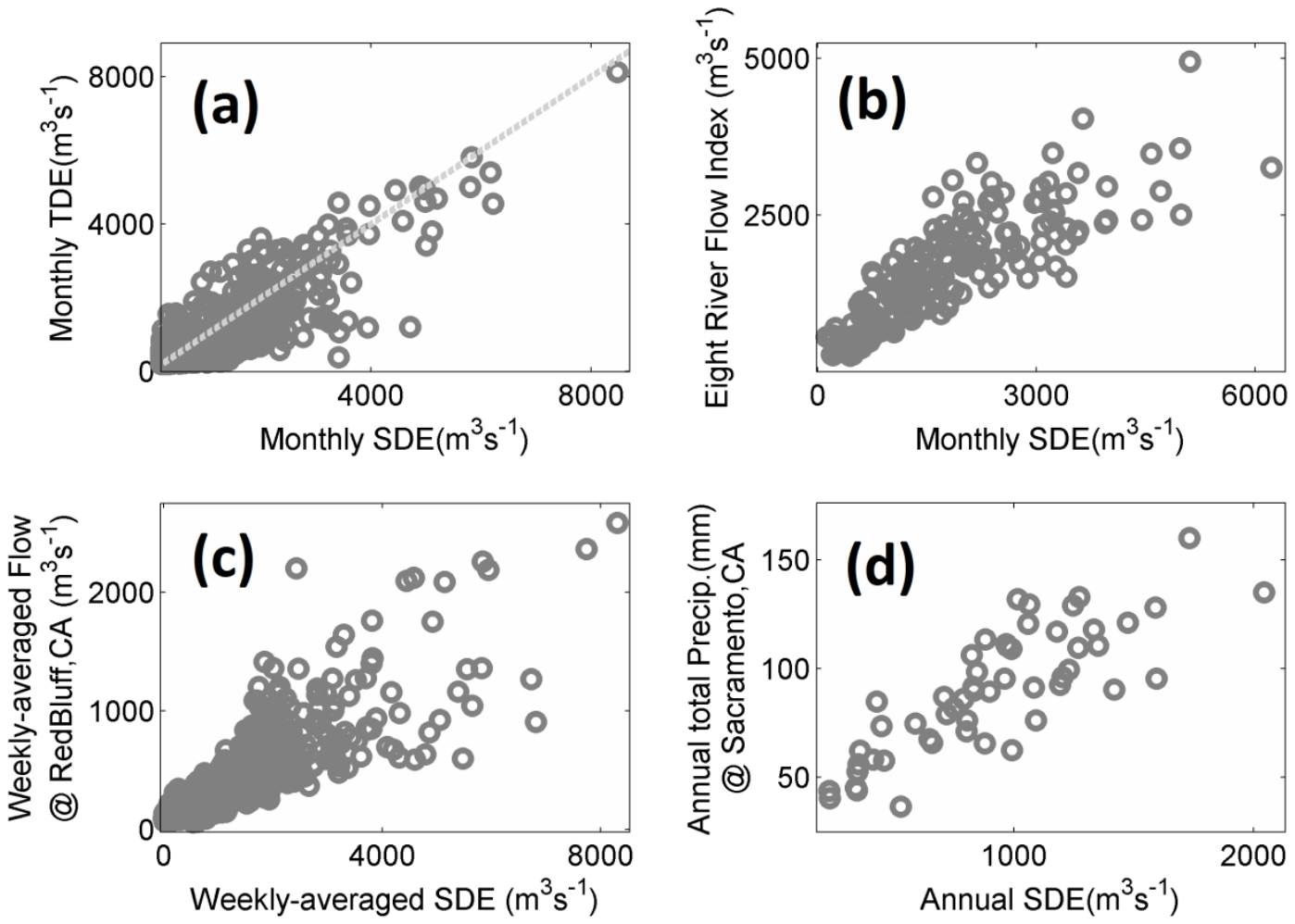

Figure 4-9: Validation of CDE via comparison to four hydrologic measures; panel (a): vs TDE; panel $(b)$ : vs ERI; panel $(c)$ : vs discharge observed at Red Bluff, CA; panel $(d)$ : vs annual total precipitation.

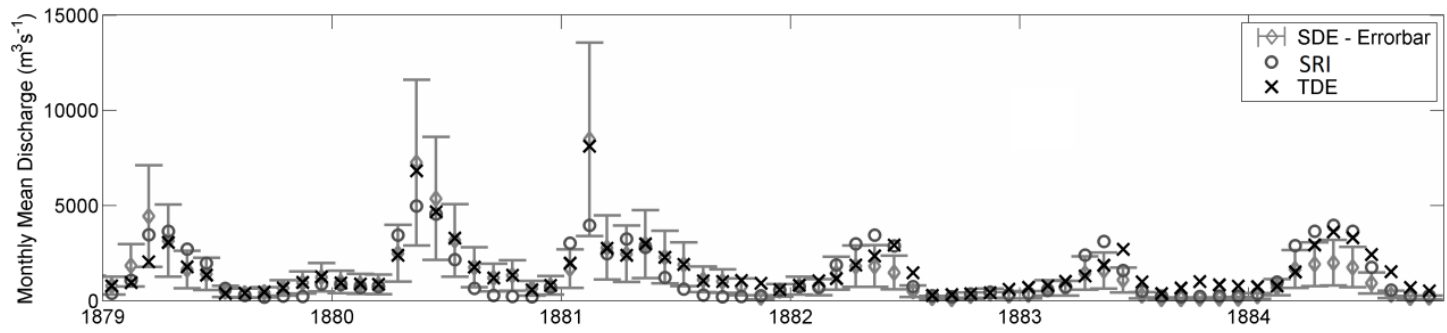

Figure 4-10: Monthly-averaged CDE vs monthly mean discharge (aka Six-River index) from the Central Valley and adjusted downscaled TDE. 


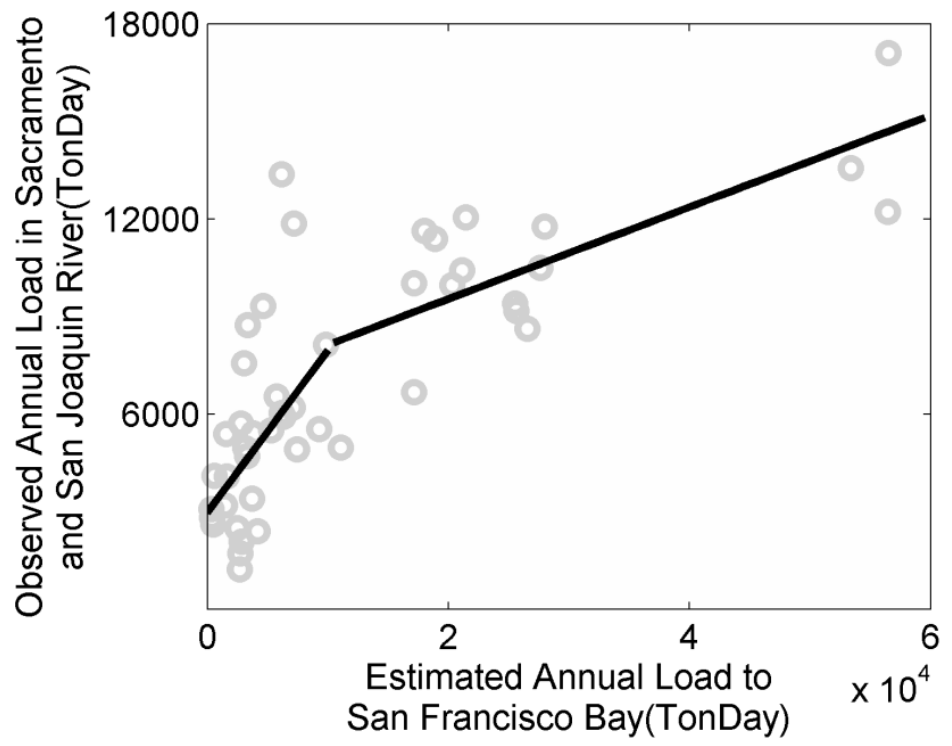

Figure 4-11: Estimated annual load vs annual SSC load observed at Sacramento, CA (19562011).
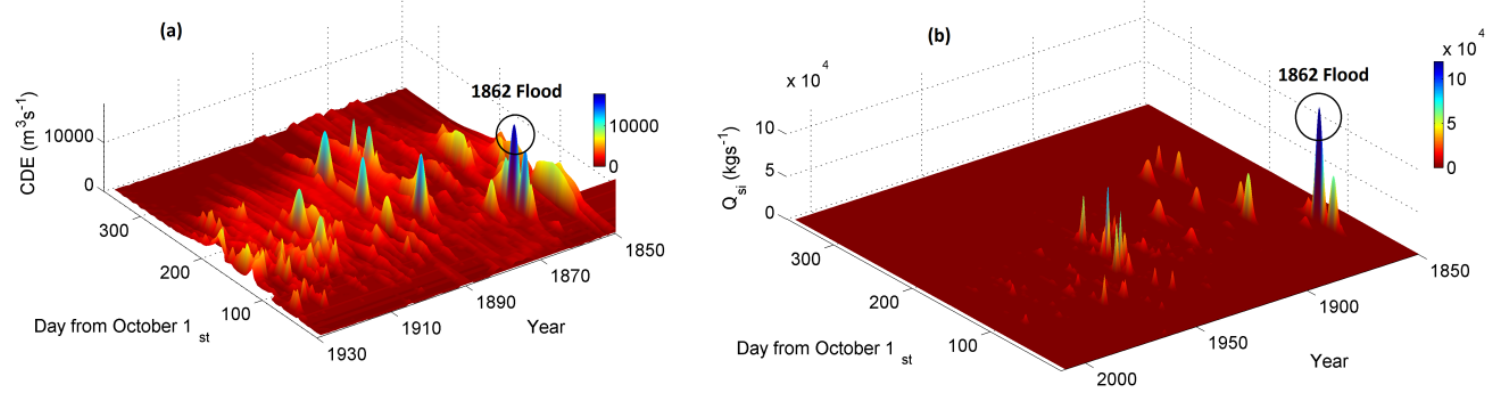

Figure 4-12: Panel (a): CDE (1849 - 1929); Panel (b): daily sediment transport to SF Bay (1849 - 2011). 


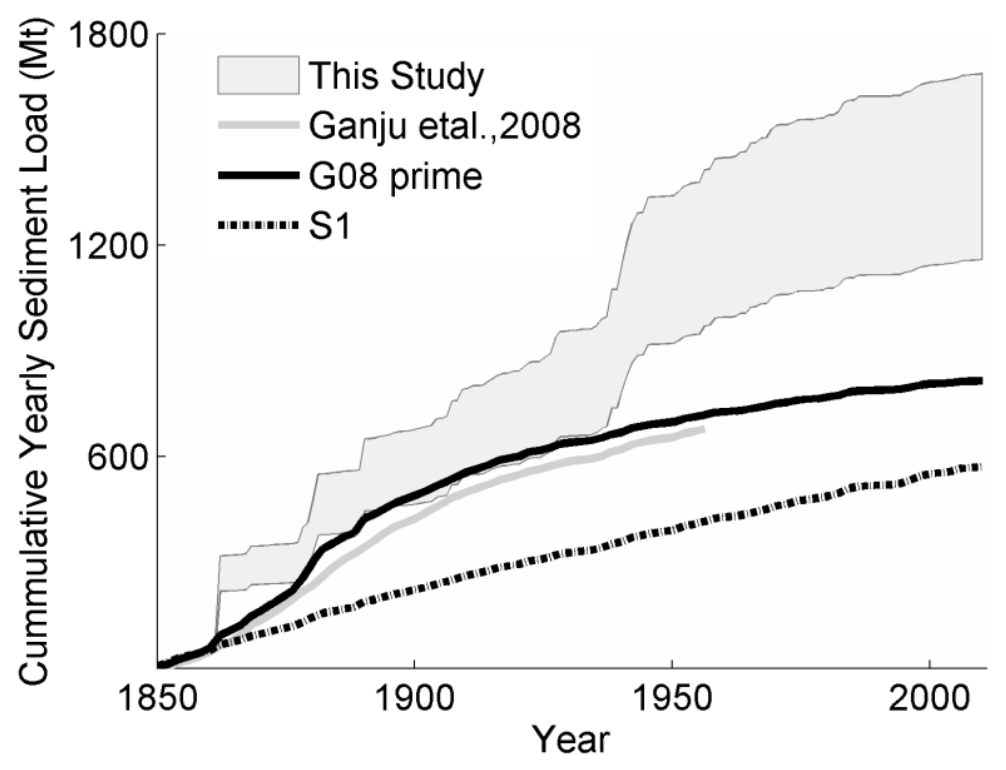

Figure 4-13: comparison of our cumulative sediment load estimate (aka reality scenario) with the previous studies and load under the assumption that rating curve parameters remain the same as pre-Gold rush values (Scenario S1); bulk density of $850 \mathrm{Kgm}^{-3}$ [Porterfiled, 1980; Jaffe et al., 2007]; G08 shows the results of Ganju et al. [2008] divided by 0.9; G08_prime is the result of applying suggested rating curve by G08 to SDE divided by 0.9 ;

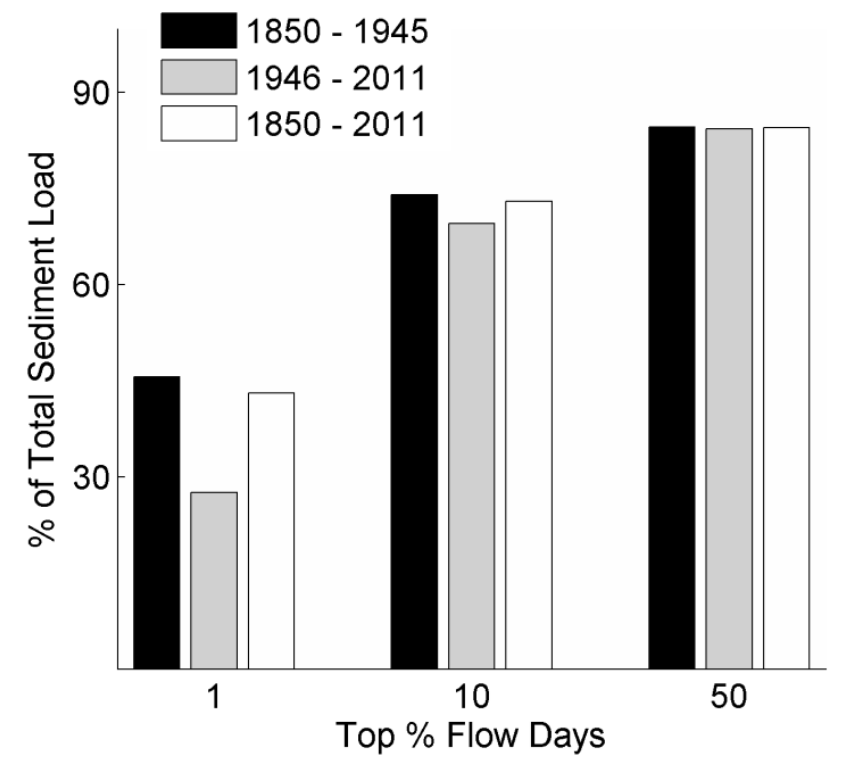

Figure 4-14: Contribution of high flow days in total sediment load. 

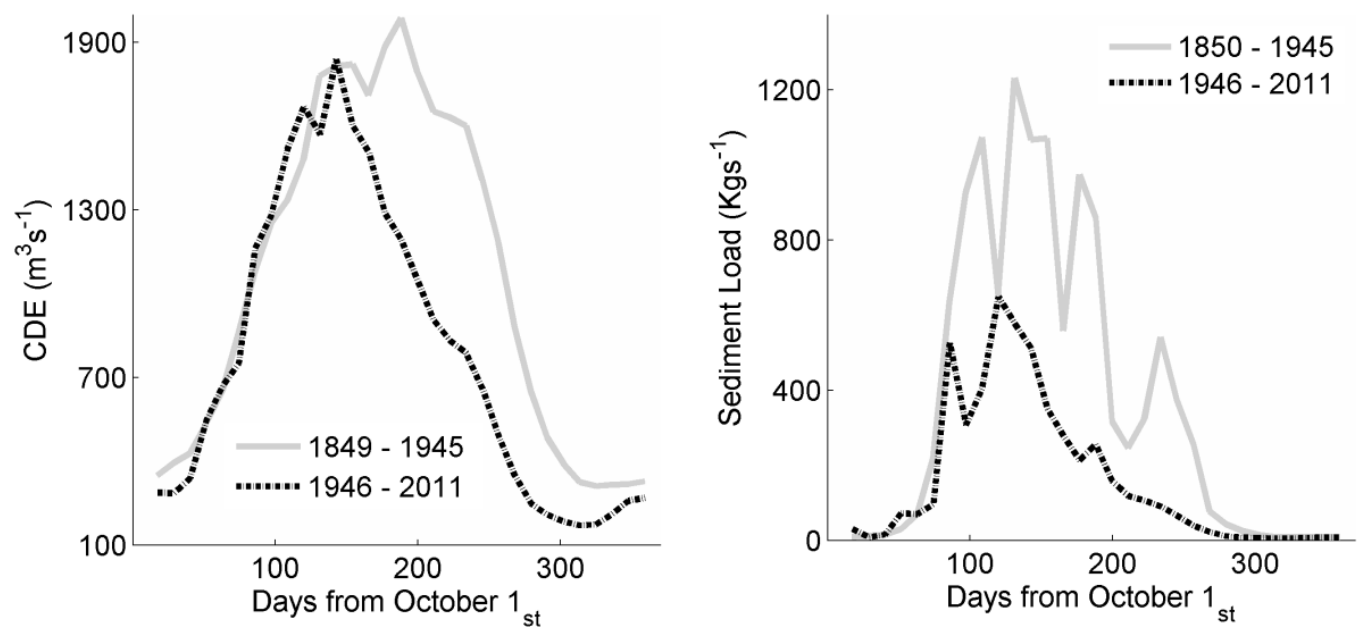

Figure 4-15: Panel (a): CDE by year-day, averaged over 1849 - 1945, and 1946 - 2011; Panel (b): Sediment load estimates by year-day, averaged over the same periods. 


\section{Chapter V: Concluding Remarks and Future Directions}

In this study I have proposed a novel approach to estimate freshwater discharge (TDE and MTDE) and sediment loads in tidal rivers. This approach is simple and applicable to a variety of tidal-fluvial systems with semidiurnal and mixed diurnalsemidiurnal tides. Comparison of the estimated flow to a number of hydrologic proxies supports the applicability of TDE (Chapter 2). TDE suggests that annual hydrograph of inflow to SF Bay has changed considerably over time, and the largest flood on record occurred in Jan. 1862 (as measured by an 18 day average) and was about 25\% larger than the 1997 flood. However, TDE works based on tidal data observed at one single gauge, and a considerable uncertainty is associated with its application to low flow periods. Due to limitations associated with Harmonic Tidal Analysis, TDE time resolution is 18days and the magnitude of high flow events that occur on timescales of a week or less must be inferred statistically. MTDE (Chapter 3), by use of multiple tidal gauges and a continuous wavelet transform (CWT) determination of tidal properties, improves on TDE in terms of time resolution and methodology, and enables us to predict low river discharge more accurately.

To understand the conditions under which MTDE is practical, MTDE performance was evaluated in terms of non-dimensional variables representing friction, river flow, and convergence length scale, using a numerical model. The model (Delft3D), was implemented on a schematic, convergent 2D grid representative of tidal river conditions. The results show that the time scale of a river flow strongly affects the applicability of MTDE for a given set of non-dimensional numbers. MTDE is more 
successful in flow prediction when the high flow event occurs over a larger time span (e.g. spring freshets), compared with fast floods (Figure 5-1); while fast flood cases (Figure 5-1b,c) the peak flow occurrs during neap, and spring tides, respectively (see Figure 3-3). The results also suggest that MTDE is best implemented using at least three gauges: a reference station near the river mouth, and two upstream gauges that respond strongly to river flow variations over a different dynamic range.

In Chapter 4, I combined daily delta inflow estimates from $\sim 80$ years of recovered and digitized historical Sacramento River daily water level data with temporally downscaled TDE to reconstruct daily delta inflows to SF Bay 1849 - 1929, the time prior to robust flow measurements into SF Bay. These historical daily delta inflow estimates, along with Net Delta Outflow Index (NDOI) records (1930 - 1955), were then used to estimate the net sediment influx to San Francisco (SF) Bay through use of a sediment rating curve. The sediment rating curve parameters were chosen iteratively based on topographic mass balance constraints derived from historic bathymetric surveys [Schoellhamer, 2011]. This approach produces daily sediment transport estimates for 1849 to 1955 , the time period prior to sediment load measurements. The results suggest that the timing and magnitude of freshwater to SF Bay has changed greatly over the last 160 years. The change in freshwater inflow to SF Bay, and anthropogenic alterations in the watershed that first increased sediment supply also, considerably changed the timing and magnitude of sediment flux to SF Bay. Although sediment loading was very high between about 1862 and 1950, SF Bay now exhibits a negative sediment balance, with sediment removal (export to the ocean, dredging removal and sand mining) greater than 
supply [Schoellhamer, 2011]. This study, building on Ganju et al. [2008] and Schoellhamer [2011], provides for the first time, a detailed accounting of the historic changes that have occurred.

Chapters II to IV together demonstrate the applicability of tidal discharge estimate methods (TDE and MTDE) for freshwater discharge and sediment load estimation in tidal-rivers, with application to the three largest river estuaries on the West Coast of North America. While the mechanism underlying both is the frictional interactions of tides and river flow, we still do not completely understand the underlying processes that make the TDE/MTDE functional, especially for an estuarine tide gauge, as in SF Bay. Thus, there are several questions that remain to be answered. For example, why does TDE works, and what tidal statistics should be used in different situations? Can TDE/MTDE be improved using statistics from more than two gauges, or with more than one tidal statistic? Are TDE and MTDE usable in river with diurnal tidal regimes (e.g., the Mississippi and some Asian rivers)? These are still unanswered questions. Future studies based on data analysis are needed to explore the applicability and accuracy of TDE and MTDE, while underlying mechanisms might best be explored using numerical models. Numerical modeling of idealized/real prototype tidal-rivers could quantify the contribution of different components on variability of tidal properties, and show how this contribution might change between low and high flow events. Use of a 3D numerical model is needed to determine the impacts of coastal processes and time-varying salinity intrusion on the tidal-frictional interactions on which TDE and MTDE are based. 
All three real tidal-rivers that I analyzed in this thesis work have mixed diurnal/semidiurnal tidal characteristics, and results show that $\mathrm{M}_{2}$ works the best amongst all other constituents, in term of flow prediction. This raises a question as to why $M_{2}$ better reflects variations in river flow than other tidal constituents? What is the physical explanation for this? Future studies may apply the TDE/MTDE to other large tidal-rivers all over the world with different tidal characteristics to find the tidal statistics that best describe the variations in river flow in each system, and find a rule that describes the performance of diverse tidal statistics. Analysis of the tidal wave equation may help describe the physics of the problem, and assist in addressing this question. It will also be necessary, however, to develop new tidal analysis methods that are actually capable of determining short-term (order days to weeks) fluctuations in tidal properties. The CWT methods used here describe only tidal species $\left(\mathrm{D}_{1}, \mathrm{D}_{2}\right.$, etc.), whereas harmonic analysis methods do not presently resolve variability on scales of $<18 \mathrm{~d}$.

The performance of TDE and MTDE was analyzed for tidal-fluvial systems, where the effect of salinity intrusion is negligible. Our 2D numerical model in Delft3D was developed for barotropic conditions (using vertically integrated equations and ignoring density-related currents). This work does not fully explain the success of TDE in SF Bay, where the gauge is located almost at the mouth of the estuary. It is possible that changes in salinity intrusion length and/or stratification and friction on the tidal wave are, at least in part, responsible for the success of TDE is this system. Running a 3D model for scenarios in which gauges are located in lower reaches of the estuary and salinity 
intrusion affects water levels and currents would help understand the effects of estuarine circulation on applicability of TDE/MTDE.

The physical meaning of sediment rating curve parameters should be investigated and revised in future studies. The rating curve approach uses a simple load law (with $a$ and $b$ as its coefficients) to cover a wide range of situations with varying degrees of supply limitation, various stream power levels, and different size distributions. My results suggest that $a$ and $b$ counter-vary to satisfy the mass balance equation, as previously noted by Syvitski et al. [2000]. However, an increase in parameter $a$ does not necessarily reflect an increase in sediment supply, contrary to previous results, because changes in $b$ more than compensate those in $a$. Future load models should also consider hysteresis effects in sediment transport; i.e., the fact that transport is usually higher on the rising arm of a flood hydrograph than on the falling arm. Load laws should perhaps also be represented differently in tidal rivers.

In summary this thesis proposed a novel approach to flow and sediment load estimation, and demonstrated its applicability to a variety of tidal fluvial systems with different morphological and hydrological characteristics. The proposed approach has been used to characterize historical variations in freshwater and sediment input to SF Bay and quantify the contribution of anthropogenic alterations to these variations. This approach, however robust, is based on very simple dynamical ideas that do not include a number of factors (e.g. effects of stratification and changes in salinity intrusion length). This thesis also does not fully explain the underlying processes that make the 
TDE/MTDE functional, and further studies are needed to understand the effects of coastal/estuarine processes and fluvial components on the applicability of this approach.
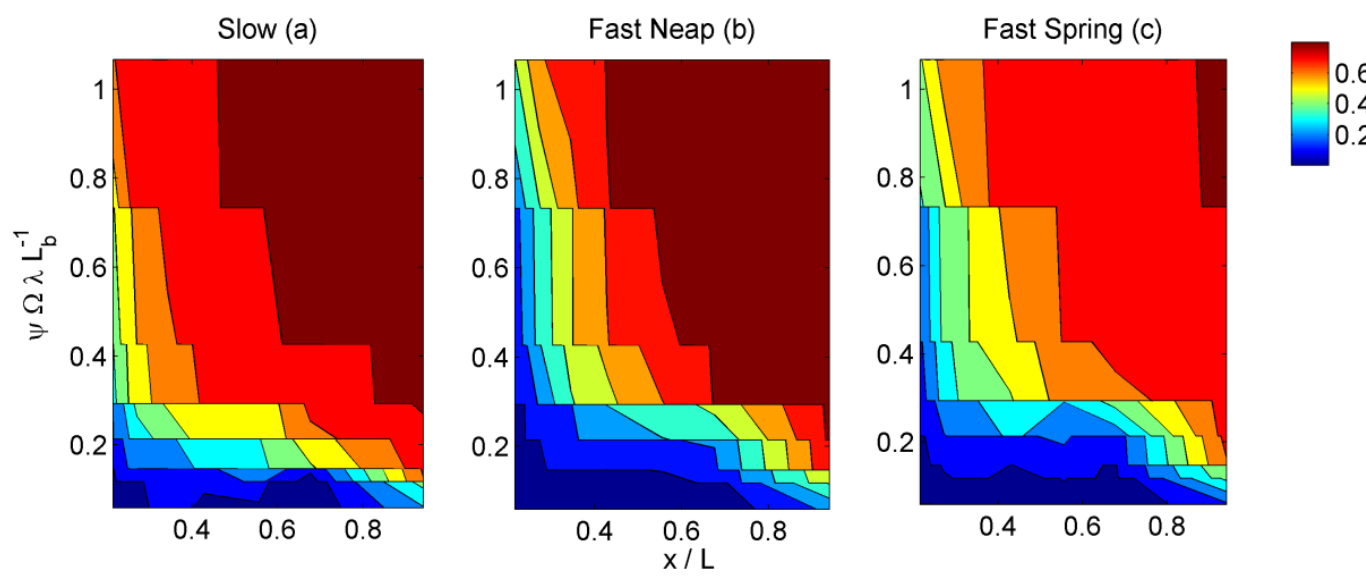

Figure 5-1: Applicability of MTDE; where color-bar show the Nash-Sutcliffe efficiency coefficient of the prediction, vertical axis and horizontal axis show the nondimensional damping modulus and nondimensional distance from the mouth. 


\section{References}

Aguado, E., D. Cayan, L. Riddle and M. Roos (1992), Climatic fluctuations and the timing of West Coast streamflow, Journal of Climate, 5, 1468-1483.

Allen, G.P., Salomon, J.C., Bassoullet, P., Du Penhoat, Y., De Grandpre, C. (1980), Effects of tides on mixing and suspended sediment transport in macrotidal estuaries, Sediment. Geol., 26, 69-90.

Alsdorf, D.E., and D.P. Lettenmaier (2003), Tracking fresh water from space, Science, 301 (5639): 1491 - 1494, DOI: 10.1126/science.1089802.

Barnard, P. L., Schoellhamer, D. H., Jaffe, B. E., McKee, L. J. (2013), Sediment Transport in the San Francisco Bay Coastal System: An Overview, Marine Geology 345, 3-17. doi: 10.1016/j.margeo.2013.04.005.

Barnett, T.P., Pierce, D.W., Hidalgo, H.G., Bonfils, C., Santer, B.D., Das, T., Bala, G., Wood, A.W., Nozawa, T., Mirin, A.A., Cayan, D.R., Dettinger, M.D. (2008), Human-Induced Changes in the Hydrology of the Western United States, Science 319, 1080-1083. DOI: 10.1126/science.1152538.

Booij, N., R. C. Ris, and L. H. Holthuijsen (1999), A third-generation wave model for coastal regions: 1. Model description and validation, J. Geophys. Res., 104(C4), 7649-7666, doi:10.1029/98JC02622.

Booker, M.M. (2013), Down by the Bay: San Francisco's History between the Tides, University of California Press, Berkeley, California. 
Bouse, R.M., Fuller, C.C., Luoma, S.N., Hornberger, M.I., Jaffe, B.E., Smith, R.E. (2010), Mercury-contaminated hydraulic mining debris in San Francisco Bay, San Francisco Estuary and Watershed Science, 8(1), jmie_sfews_11015.

Bromirski, P. D., R. E. Flick, and D. R. Cayan (2003), Storminess variability along the California coast: 1858 - 2000, J. Clim., 16, $982-993$.

Bromirski, P. D., and R. E. Flick (2008), Storm surge in the San Francisco Bay/Delta and nearby coastal locations, Shore and Beach 76: 29-37.

Burns, J.W. (1972), Some effects of logging and associated road construction on Northern California streams, Transactions of the American Fisheries Society, 101(1), DOI:10.1577/1548-8659(1972)101<1:SEOLAA>2.0.CO;2.

Buschman, F. A., A. J. F. Hoitink, M. van der Vegt, and P. Hoekstra (2009), Subtidal water level variation controlled by river flow and tides, Water Resour. Res., 45, W10420, doi:10.1029/2009WR008167.

Buschman, F. A., A. J. F. Hoitink, M. van der Vegt, and P. Hoekstra (2010), Subtidal flow division at a shallow tidal junction, Water Resour. Res., 46, W12515, doi:10.1029/2010WR009266.

Cai, H., H.H.G. Savenije, and C. Jiang (2014), Analytical approach for predicting fresh water discharge in an estuary based on tidal water level observations, Hydrol. Earth Syst. Sci. Discuss. 11, 7053 - 7087, doi:10.5194/hessd-11-7053-2014.

Cameron, W.M. and D.W. Pritchard (1963), Estuaries. In M.N. Hill (ed.), The Sea, Vol. 2. John Wiley \& Sons, New York, pp. 306 - 324. 
Cappiella, K., Malzone, C., Smith, R., Jaffe, B. (1999), Sedimentation and bathymetry changes in Suisun Bay (1867-1990), U.S. Geological Survey, Open-File Report $99-563$.

Cartwright, D. and A. C. Eden (1973), Corrected table of tidal harmonics, Geophys. J. R. Astr. Soc., 33, $253-264$.

Cayan, D. R., S. A. Kammerdiener, M. D. Dettinger, J. M. Caprio, and D. H. Peterson (2001), Change in the onset of spring in the western United States, Bull. Amer. Meteor. Soc., 82, $399-415$.

Chen, S., Zhang, G., Yang, S., Shi, J.Z. (2006), Temporal variations of fine suspended sediment concentration in the Changjiang River estuary and adjacent coastal waters, China, J. of Hydrology 331(1-2), $137-145 . \quad$ DOI: 10.1016/j.jhydrol.2006.05.013.

Chen, Y., S. Yu, H. Yang, J. Kuo, and M. Zeng (2014), Fast and Minimally Intrusive Method for Measuring Tidal-Stream Discharge, J. Hydrol. Eng. , 10.1061/(ASCE)HE.1943-5584.0001079, 06014011.

Cheng, R. T., and J. F. Gartner (1985), Harmonic analysis of tides and tidal currents in south San Francisco Bay, California, Estuarine, Coastal and Shelf Science, 21, 57 -74 .

Chua, V. P., and O. B. Fringer (2011), Sensitivity analysis of three-dimensional salinity simulations in North San Francisco Bay using the unstructured-grid SUNTANS model, Ocean Modelling, 39, 332 - 350. 
Cloern, J. E., A. E. Alpine, B. E. Cole, R. L. J. Wong, J. F. Arthur and M. D. Ball (1983), River discharge controls phytoplankton dynamics in the northern San Francisco Bay estuary, Estuarine, Coastal and Shelf Science, 16, 415 - 429.

Cloern J. E., T. M. Powell and L. M. Huzzy (1989), Spatial and temporal variability in south San Francisco Bay (USA). II. Temporal change in salinity, suspended sediments, and phytoplankton biomass and productivity over tidal time scales, Estuarine, Coastal and Shelf Science, 28, 599 - 613. doi: 10.1016/02727714(89)90010-3.

Conomos, T.J., and D.H. Peterson (1977), Suspended-particle transport and circulation in San Francisco Bay, an overview. Estuarine Processes 2:82-97. New York, Academic Press.

Dallas, K. L., Barnard, P. L. (2011), Anthropogenic influences on shoreline and nearshore evolution in the San Francisco Bay coastal system. Estuarine, Coastal and Shelf Science 92, 195 - 204, doi:10.1016/j.ecss.2010.12.031.

Di Baldassarre, G. and A. Montanari (2009), Uncertainty in river discharge observations: a quantitavtive analysis, Hydrology and Earth System Science, 13, 913 - 921.

Doodson, A. T. (1957), The analysis and prediction of tides in shallow water, International Hydrographic Review, 33, 85-126.

Dronkers, J. J. (1964), Tidal Computations in Rivers and Coastal Waters, North-Holland, New York, 296-304.

Dyer, K.R. (1973), Estuaries: A Physical Introduction, John Wiley \& Sons, New York. 
Fisher, T.R., Carlson, P.R., Barber, R.T. (1982) Sediment nutrient regeneration in three North Carolina estuaries, Estuarine, Coastal and Shelf Science 14(1), 101 - 116. DOI: $10.1016 / \mathrm{S} 0302-3524(82) 80069-8$.

Flick, R.E. and L.C. Ewing (2009), Sand volume needs of southern California beaches as a function of future sea-level rise rates, Shore \& Beach, 77(4), 36-45.

Flinchem, E.P., and D.A. Jay (2000), An introduction to wavelet transform tidal analysis methods, Estuarine, Coastal and Shelf Science, 51(2), 177 - 200, doi:10.1006/ecss.2000.0586.

Foxgrover, A.C., Higgins, S.A., Ingraca, M.K., Jaffe, B.E., Smith, R.E. (2004), Deposition, erosion, and bathymetric change in South San Francisco Bay: 18581983, U.S. Geological Survey, Open-File Report 2004-1192.

Fram, J.P., M.A. Martin, and M.T. Stacey (2007), Dispersive Fluxes between the Coastal Ocean and a Semienclosed Estuarine Basin, J. Phys. Oceanogr. 37, 1645-1660. doi: $\underline{\text { http://dx.doi.org/10.1175/JPO3078.1. }}$.

Fregoso, T.A., Foxgrover, A. C., Jaffe, B. E. (2008), Sediment deposition, erosion, and bathymetric change in central San Francisco Bay: 1855-1979. U.S. Geological Survey Open-File Report 2008-1312.

Friedrichs, C. T., and D. G. Aubrey (1994), Tidal propagation in strongly convergent channels, J. Geophys. Res., 99, 3321 - 3336. 
Gan, J., L. Li, D. Wang, X. Guo (2009), Interaction of a river plume with coastal upwelling in the northeastern south China Sea, Continental Shelf Research, 29, $728-740$.

Ganju, N.K., Schoellhamer, D.H. (2009), Calibration of Estuarine Sediment Transport Model to Sediment Fluxes as an Intermediate Step for Simulation of Geomorphic Evolution, Continental Shelf Research 29, 148 - 158.

Ganju, N. K., N. Knowles and D. H. Schoellhamer (2008), Temporal downscaling of decadal sediment load estimates to daily interval for use in hindcast simulations, Journal of Hydrology, 394, 512 - 523.

Gelfenbaum, G. (1983), Suspended-sediment response to semidiurnal and fortnightly tidal variations in a mesotidal estuary: Columbia River, USA, Marine Geology 52(1-2), 39 - 57, DOI: 10.1016/0025-3227(83)90020-8.

Gilbert, G. K. (1917), Hydraulic-mining debris in the Sierra Nevada: U.S. Geological Survey Professional Paper, 105, 148 p.

Giese, B. S. and D. A. Jay (1989), Modeling tidal energetics of the Columbia River Estuary, Estuar. Coast. Shelf Sci. 29: 549-571.

Godin, G. (1985), modification of river tides by the discharge, Journal of Waterway, Port, Coastal and Ocean Engineering, 111(2), 257 - 274.

Godin, G. (1999), The propagation of tides up rivers with special considerations on the upper Saint Lawrence River, Estuarine, Coastal and Shelf Science, 48, 307 - 324. 
Guinon, J. L., E. Ortega, J. Garcia-Anton, V. Perez-Herranz (2007), Moving average and Savitzki-Golay smoothing filters using Mathcad, Proceedings of International Conference on Engineering Education - ICEE 2007, Coimbra, Portugal, September 2007.

Hamlet, A. F., P. W. Mote, M. P. Clark and D. P. Lettenmaier (2005), Effects of temperature and precipitation variability on snowpack trends in the western United States, Journal of Climate, 18, 4545 - 4561.

Hamlet, A. F. and D. P. Lettenmaier (2007), Effects of 20th century warming and climate variability on flood risk in the western U.S., Water Resources Research, 43, W06427, doi: 10.1029/2006WR005099.

Hansen, D. V., and M. Rattray (1966), New dimensions in estuary classification, Limnol. Oceanogr. 11,319-326.

Hoitink, A. J. F., F. A. Buschman, and B. Vermeulen (2009), Continuous measurements of discharge from a horizontal ADCP in a tidal river, Water Resour. Res., 45, W11406.

Huijts, K.M.H., H.M. Schuttelaars, H.E. de Swart, and A. Valle-Levinson (2006), Lateral trapping of sediment in tidal estuaries: An idealized model study, J. Geophys. Res., 111(C12016), doi: 10.1029/2006JC003615.

Hunsaker, L. and C. Curran (2005), Lake Sacramento_ Can it happen again?, Academy Printing, Grants Pass, Oregon, pp. 105. 
Ianniello, J.P. (1979), Tidally induced residual currents in estuaries of variable breadth and depth, J. of Physical Oceanography, 9, $962-974$.

Inman, D.L., and S.A. Jenkins (1999), Climate of small California rivers, J. Geology, 107, 251-70.

Jaffe, B.E., Smith, R.E., Torresan, L.Z. (1998), Sedimentation and bathymetric change in San Pablo Bay, 1856-19831, U.S. Geological Survey, Open-File Report 98-759.

Jaffe, B. E., Smith, R.E., Foxgrover, A.C. (2007), Anthropogenic influence on sedimentation and intertidal mudflat change in San Pablo Bay, California: 18561983, Estuarine Coastal Shelf Sci. 73, 175-187, doi:10.1016/j.ecss.2007.02.017.

James, A. L. (2004), Decreasing sediment yields in north California: vestiges of hydraulic gold-mining and reservoir trapping, Sediment Transfer through the Fluvial System symposium, Moscow, Russia. IAHS publ. 288.

James, A. L. (2006), Bed waves at the basin scale: implications for river management and restoration, Earth Surf. Process. Landforms 31, 1692 - 1706, doi: 10.1002/esp. 1432 .

James, A. L. (2010), Secular sediment waves, channel bed waves, and legacy sediment, Geography Compass 4(6), 576-598, doi: 10.1111/j.1749-8198.2010.00324.x.

James, A. L., and Singer, M. B. (2008), Development of the Lower Sacramento Valley Flood-Control System: Historic Perspective, Natural Hazards Review 9(3), 125 135, doi: 10.1061/ASCE1527-698820089:3125. 
Jay, D. A. (1991), Green's law revisited: tidal long wave propagation in channels with strong topography. J. Geophys. Res. 96: 20,585-20,598.

Jay, D. A. (2009), Evolution of tidal amplitudes in the eastern Pacific Ocean, Geophys. Res. Lett., 36, L04603, DOI: 101029/2008GL036185.

Jay, D. A. and E. P. Flinchem (1997), Interaction of fluctuating river flow with a barotropic tide: A test of wavelet tidal analysis methods, J. Geophys. Res. 102: $5705-5720$.

Jay, D. A. and Flinchem, E. P. (1999), A comparison of methods for analysis of tidal records containing multi-scale non-tidal background energy, Contin. Shelf Res. 19: $1695-1732$.

Jay, D. A., and T. Kukulka (2003), Revising the paradigm of tidal analysis - the uses of non-stationary data, Ocean Dynamics 53: 110-123.

Jay, D. A., and P. Naik (2011), Distinguishing human and climate influences on hydrological disturbance processes in the Columbia River, USA, Hydrological Sciences Journal, 56, 1186-1209.

Jay, D. A., B. S. Giese and C. R. Sherwood (1990), Energetics and sedimentary processes in the Columbia River estuary, Prog. Oceanog., 25, 157 - 174.

Jay, D. A., R.J. Uncles, J. Largier, W.R. Geyer, J. Vallino,W.R. Boynton (1997), A review of recent developments in estuarine scalar flux estimation, Estuaries 20(2), $262-280$. 
Jay, D. A., Geyer, W. R., and Montgomery, D. R. (2000), An ecological perspective on estuarine classification, Estuarine science: a synthetic approach to research and practice, Island Press, Washington DC, 149-176.

Jay, D. A., K. Leffler and S. Degens (2011), Long-term evolution of Columbia River tides, ASCE Journal of Waterway, Port, Coastal, and Ocean Engineering, 137: 182-191; doi: 10.1061/(ASCE)WW.1943- 5460.0000082.

Jay, D.A., K. Leffler, H.L. Diefenderfer, and A.B. Borde (2014), Tidal-Fluvial and Estuarine Processes in the Lower Columbia River: I. Along-Channel Water Level Variations, Pacific Ocean to Bonneville Dam, Estuaries and Coasts, DOI 10.1007/s12237-014-9819-0.

Jay, D.A., R.E. Flick, \& T. Kukulka, (2006), A Long-Term San Francisco Bay Inflow Record Derived From Tides: Defining the Great Flood of 1862, GC13B-1228, Fall AGU Meeting, San Francisco.

Jay, D. A., R. J. Uncles, J. Largier, W. R. Geyer, J. Vallino and W. R. Boynton (LMER Scalar Transport Working Group) (1997), A review of recent developments in estuarine scalar flux estimation, Estuaries 20: 262-280.

Kaiser, J. F. (1974), Nonrecursive Digital Filter Design Using the - sinh Window Function, Proc. 1974 IEEE Symp. Circuits and Systems, pp.20-23.

Kawanisi, K., M. Razaz, A. Kaneko, and S. Watanabe (2010), Long-term measurement of stream flow and salinity in a tidal river by the use of the fluvial acoustic tomography system, J. Hydrol., 380(1-2), 74-81 
Kimmerer, W. J. (2002), Physical, biological, and management responses to variable freshwater flow into the San Francisco estuary, Estuaries, 25(6B), 1275 - 1290.

Kisi, O. and M. Cimen (2011), A wavelet-support vector machine conjunction model for monthly streamflow forecasting, J. of Hydrology, 399, $132-140$.

Knowles, N., Cayan, D.R. (2004), Elevational dependence of projected hydrologic changes in the San Francisco Estuary and watershed, Climatic Change 62, 319 336.

Knowles, N. (2002), Natural and management influences on freshwater inflows and salinity in the San Francisco Estuary at monthly to interannual scales, Water Resources Res., 38(12), 1289, doi:10.1029/2001WR000360.

Kostaschuk, R., and J. Best (2005), Response of sand dunes to variations in tidal flow: Fraser Estuary, Canada, J. of Geophysical Research, 110, F04S04, doi:10.1029/2004JF000176.

Krone, R. B. (1979), Sedimentation in the San Francisco Bay system. In San Francisco Bay: The Urbanized Estuary, edited by T. J. Conomos, Pacific Division of the American Association for the Advancement of Science, San Francisco, California, pp. 85-96.

Kukulka, T., and D. A. Jay (2003a), Impacts of Columbia River discharges on salmonid habitat: 1. a nonstationary fluvial tidal model, J. of Geoph. Res., 108(C9), 3293, doi:10.1029/2002JC001382, 2003. 
Kukulka, T., and D. A. Jay (2003b), Impacts of Columbia River discharges on salmonid habitat: 2. Change in shallow-water habitat, J. of Geoph. Res., 108(C9), 3294, doi:10.1029/2003JC001829, 2003.

Laize, C. L., R., D. M. Hannah (2010), Modification of climate-river flow associations by basin properties, $\quad J . \quad$ of Hydrology, $389, \quad 186 \quad-\quad 204$. doi:10.1016/j.jhydrol.2010.05.048

Lanzoni, S., and Seminara, G. (1998), On tide propagation in convergent estuaries, $J$. Geophys. Res. Oceans, 103(C13), 30793-30812.

Laudenslayer, W.F., and Darr, H.H. (1990), Historical effects of logging on the forests of the cascade and Sierra Nevada Ranges of California, Transactions of the western section of the wildlife society, 26, $12-23$.

LeBlond, P. H. (1978), On tidal propagation in shallow rivers, Journal of Geophysical Research, 83, 4717-4721.

Leffler, K. E. and D. A. Jay (2009), Enhancing tidal harmonic analysis: Robust (hybrid $\mathrm{L}^{1} / \mathrm{L}^{2}$ ) solutions, Continental Shelf Research, 29, $78-88$.

Leung, L. R., Y. Qian, X. D. Bian, W.M. Washington, J. G. Han, and J. O. Roads (2004), Mid-century ensemble regional climate change scenarios for the western United States. Climate Change, 62, 75-113.

Lewicki, M., and McKee, L. (2010), New methods for estimating annual and long-term suspended sediment loads from small tributaries to San Francisco Bay, IAHS Publication 337, 5 pp. 
Logan, T. M. (1864), Contributions to the physics, hygiene and thermology of the Sacramento River, Pacific Medical and Surgical Journal, 7, 145 - 151.

Logan, T. M. (1872), Report on the physics, hygiene, and thermology of the Sacramento River, Proceedings of the Agassiz Institute of Sacramento, CA, K. G. Jefferis \& Co., Book and Job Printers, $75-82$.

Loitzenbauer, E., C. A. B. Mendes, (2012), Salinity dynamics as a tool for water resources management in coastal zones: An application in the Tramandaí River basin, southern Brazil, Ocean \& Coastal Management, 55, 52 - 62. doi:10.1016/j.ocecoaman.2011.10.011

Longuet-Higgins, M.S. (1969). On the transport of mass by time-varying ocean currents, Deep-Sea Research 16, 431-447.

MacCready, P. (2011) Calculating estuarine exchange flow using isohaline coordinates*. J. Phys. Oceanogr., 41, 1116-1124. doi: $\underline{10.1175 / 2011 J P O 4517.1}$

MacDonald, D. G., and W. R. Geyer (2004), Turbulent energy production and entrainment at a highly stratified estuarine front, J. Geophys. Res., 109, C05004, doi:10.1029/2003JC002094.

Madsen, H. and C. Skotner (2005), Adaptive state updating in real-time river flow forecasting - a combined filtering and error forecasting procedure, J. of Hydrology, 308, $302-312$. 
Martin, J.M., and M. Whitfield (1983), The significance of the river input of chemical elements to the ocean, Trace Metals in Sea Water, NATO conference series, 9, $265-296$.

McCulloch, M., Fallon, S., Wyndham, T., Hendy, E., Lough, J., Barnes, D. (2002), Coral record of increased sediment flux to the inner Great Barrier Reef since European settlement, Nature 421, 727 - 730, doi:10.1038/nature01361.

McKee, L. J., Ganju, N. K., Schoellhamer, D. H. (2006), Estimates of suspended sediment flux entering San Francisco Bay from the Sacramento-San Joaquin Delta, San Francisco Bay, California, J. of Hydrology 323, 335 - 352.

McKee, L.J., Lewicki, M., Schoellhamer, D. H., Ganju, N. K. (2013), Comparison of sediment supply to San Francisco Bay from watersheds draining the Bay Area and the Central Valley of California, Marine Geology 345, 47-62.

Milliman, J.D. (1980), Sedimentation in the Fraser River and its estuary, southwestern British Columbia (Canada), Estuarine and Coastal Marine Science, 10, 609 - 633.

Minear, J.T. (2010), The downstream geomorphic effects of dams: a comprehensive and comparative approach, Dissertation submitted to Department of Landscape Architecture and Environmental Planning, University of California, Berkeley, 207 pp.

Moftakhari, H. R., D. A. Jay, S. A. Talke, T. Kukulka, and P. D. Bromirski (2013a), A novel approach to flow estimation in tidal rivers, Water Resour. Res., 49, doi:10.1002/wrcr.20363. 
Moftakhari, H. R., Jay, D. A., Talke, S. A., Madadgar, S. (2013b), Changes in the Seasonal Variation of Suspended Sediment Transport to San Francisco Bay in the last 150 years, Abstract \#H31B-1147 presented at 2013 Fall Meeting, AGU, San Francisco, CA, USA.

Monismith, S. G., W. Kimmerer, J. R. Burau, M. T. Stacey (2002), Structure and flowinduced variability of the subtidal salinity field in Northern San Francisco Bay, $J$. Phys. Oceanogr., 32, 3003-3019. doi:10.1175/1520-0485(2002)032

Mooney, C. Z. (1997), Monte Carlo Simulation, Sage University Paper Series on Quantitative Application in the Social Sciences, 07-116, doi: $10.4135 / 9781412985116$.

Muller, G., and Forstner, U. (1968), General relationship between suspended sediment concentration and water discharge in the Alpenrhein and some other rivers, Nature 217, 244-245.

Nash, J. E. and J. V. Sutcliffe (1970), River flow forecasting through conceptual models part I: A discussion of principles, Journal of Hydrology, 10 (3), 282-290.

Nichols, F. H., J. E. Cloern, S. N. Luoma and D. H. Peterson (1986), The modification of an estuary, Science, 231, $567-573$.

Ogden Beeman \& Associates, Inc. (1992), Sediment budget study for San Francisco Bay, Ogden Beeman \& Associates, Inc., Portland, OR and Ray B. Krone \& Associates, Inc., Davis, CA. 
Oki, T., K. Musiake, H. Matsuyama and K. Masuda (1995), Global atmospheric water balance and runoff from large river basins. Hydrological Process., 9: 655-678. doi: 10.1002/hyp.3360090513.

Orem, H.M. (1968), Discharge in the Lower Columbia River basin, 1928-65, U.S. Geological Survey Circular 550, p. 24.

Orton, P.M., Kineke, G.C. (2001), Comparing calculated and observed vertical suspended-sediment distributions from a Hudson River Estuary turbidity maximum, Estuarine, Coastal and Shelf Science 52(3), 401 - 410. DOI: 10.1006/ecss.2000.0747.

Palma, W., R. Escribano, S. A. Rosales (2006), Modeling study of seasonal and interannual variability of circulation in the coastal upwelling site of the El Loa River off northern Chile, Estuarine, Coastal and Shelf Science, 67, 93 - 107.

Parker, B. B. (1991), The relative importance of the various nonlinear mechanisms in a wide range of tidal interactions, in Progress in Tidal Hydrodynamics, edited by B. B. Parker, 237 - 268, John Wiley, New York.

Parker, B. B. (2007), Tidal analysis and prediction, NOAA Special Publication NOS COOPS 3, Silver Spring, Maryland.

Pawlowicz, R., B. Beardsley and S. Lentz (2002), Classical tidal harmonics analysis including error estimates in MATLAB using T-TIDE, Computer \& Geosciences, $28,929-937$. 
Pejrup, M. (1986), Parameters affecting fine-grained suspended sediment concentrations in a shallow miro-tidal estuary, Ho Bugt, Denmark, Estuarine, Costal and Shelf Science 22(2), 241 - 254. DOI: 10.1016/0272-7714(86)90115-0.

Peng, M., L. Xie, L. J. Pietrafesa (2004), A numerical study of storm surge and inundation in the Croatan-Albemarle-Pamlico estuary system, Estuarine, Coastal and Shelf Sciences, 59, $121-137$.

Porterfield, G. (1980), Sediment transport of streams tributary to San Francisco, San Pablo, and Suisun bays, California, 1909- 1966, U.S. Geological Survey Water Resources Investigations 91, 64-80.

Powell T.M., Cloern, J. E., Huzzy, L. M. (1989), Spatial and temporal variability in south San Francisco Bay (USA). I. Horizontal distribution of salinity, suspended sediments, and phytoplankton biomass and productivity, Estuarine, Coastal and Shelf Science 28, 583-597.

Prandle, D. (1985), On salinity regimes and the vertical structure of residual flows in narrow tidal estuaries, Estuarine, Coastal and Shelf Science, 20, 615 - 635.

Prandle, D. (2000), Operational Oceanography - a view ahead, Coastal Engineering, 41, $353-359$.

Prandle, D. (2004), How tides and river flows determine estuarine bathymetries, Progress in Oceanography, 61, 1-26.

Prandle, D. and Rahman, M. (1980), Tidal response in estuaries. Journal of Physical Oceanography 10, 1522-1573. 
Pritchard, D. W. (1952), Estuarine hydrography, Adv. Geophys. 1, 243 - 280.

Pritchard, D. W. (1955), Estuarine circulation patterns, Proc. Am. Soc. Civil Eng. 81 (717), 1-11.

Ralston, D.K., Stacey, M.T. (2007), Tidal and Meteorological Forcing of Sediment Transport in Tributary Mudflat Channel, Continental shelf Research 27, 1510 1527.

Rose, A. H., Manson, M., Grunsky, C. E. (1895), Report of the Commissioner of Public Works to the Governor of California, State Office, Sacramento, CA.

Ross, D. A. (1995), Introduction to Oceanography, Harper Collins, New York.

Ruhl, C.A., Schoellhamer, D. H., Stumpf, R. P., Lindsay, C. L. (2001), Combined Use of Remote Sensing and Continuous Monitoring to Analyze the Variability of Suspended-Sediment Concentrations in San Francisco Bay, California, Estuarine, Coastal and Shelf Science 53, 801-812.

Russo, M. (2010), Fact Sheet: Sacramento River flood control project weirs and flood relief structures, State of California, Department of Water Resources, Division of Flood Management, http://www.water.ca.gov/newsroom/docs/WeirsReliefStructures.pdf.

Sassi, M. G., and A. J. F. Hoitink (2013), River flow controls on tides and tide-mean water level profiles in a tidal freshwater river, J. Geophys. Res. Oceans, 118, 4139-4151, doi:10.1002/jgrc.20297. 
Sassi, M. G., A. J. F. Hoitink, B. Vermeulen, and Hidayat (2011a), Discharge estimation from $\mathrm{H}$ - ADCP measurements in a tidal river subject to sidewall effects and a mobile bed, Water Resour. Res., 47, W06504, doi:10.1029/2010WR009972.

Sassi, M. G., A. Hoitink, B. de Brye, B. Vermeulen, and E. Deleersnijder (2011b), Tidal impact on the division of river discharge over distributary channels in the Mahakam Delta, Ocean Dyn., 61, 2211-2228, doi:10.1007/s10236-011-0473-9.

Savitzky, A. and M. J. E. Golay (1964), Smoothing and differentiation of data by simplified least squares procedures, Analytical Chemistry, 36(2), p.1627.

Schoellhamer, D.H. (2002), Variability of Suspended-Sediment Concentration at Tidal to Annual Time Scales in San Francisco Bay, USA, Continental Shelf Research 22, $1857-1866$.

Schoellhamer, D.H. (2011), Sudden clearing of estuarine waters upon crossing the threshold from transport to supply regulation of sediment transport as an erodible sediment pool is depleted: San Francisco Bay, 1999, Estuaries and Coasts 34(5), 885-899.

Schoellhamer, D. H., T. E. Mumley and J. E. Leatherbarrow (2007), Suspended sediment and sediment-associated contaminants in San Francisco Bay, Environmental Research, 105, $119-131$.

Sherwood, C.R., Jay, D A., Harvey, R.B., Hamilton, P., Simenstad, C.A. (1990), Historical changes in the Columbia River estuary, Progress in Oceanography 25, 299-352. 
Singer, M. B., Aalto, R., James, L. A. (2008) Status of the Lower Sacramento Valley flood-control system within the context of its natural geomorphic setting. Natural Hazard Review 9(2), 104 - 115. doi: 10.1061/(ASCE)1527-6988(2008)9:3(104).

Smith, R. (2002), Historical Golden Gate tidal series, NOAA Technical Report NOS COOPS 035, Washington, D.C.

State Engineering Department of California (1886), Physical data and statistics of California; tables and memorandum. pp. $405-477$.

State of California (1889), Appendix to the journals of the State and assembly of the twenty- eight session of the legislature of the State of California, Volume VII, Sacramento, CA.

Syvitski J.P.M (2003), Supply and flux of sediment along hydrological pathways: research for the $21^{\text {st }}$ century, Global and Planetary Change, 39(1 - 2), $11-11$, doi:10.1016/S0921-8181(03)00008-0.

Syvitski, J. P., Morehead, M. D., Bahr, D. B., Mulder, T. (2000), Estimating fluvial sediment transport: The rating parameters, Water Resour. Res. 36(9), 2747-2760. doi:10.1029/2000WR900133.

Syvitski J.P.M, S.D. Peckham, R. Hilberman (2003), Predicting the terrestrial flux of sediment to the global ocean: a planetary perspective, Sedimentary Geology 162(1-2):5-24. 
Syvitski, J. P. M., S. D. Peckham, R. Hilberman and T. Mulder (2003), Predicting the terrestrial flux of sediment to the global ocean: a planetary perspective, $J$. of Sedimentary Geology, 162, 5 - 24. doi: 10.1016/S0037-0738(03)00232-X.

Syvitski, J.P.M., Vörösmarty, C.J., Kettner, A.J., Green, P. (2005), Impact of humans on the flux of terrestrial sediment to the global coastal ocean, Science 308(5720), 376 - 380, DOI: $10.1126 /$ science. 1109454 .

Taylor, J. R. (1997), An introduction to error analysis: The study of uncertainty in physical measurements, University Science Books, second edition, USA, pp. 325.

Talke, S.A., Stacey, M. T. (2003), The influence of oceanic swell on flows over an estuarine intertidal mudflat in San Francisco Bay, Estuarine, Coastal, and Shelf Science 58, 541-554.

Talke, S.A., Stacey, M. T. (2008), Suspended Sediment Fluxes at an Intertidal Flat: The Shifting Influence on Wave, Wind, Tidal and Freshwater Forcing, Continental Shelf Research 28(6), 710 - 725. http://dx.doi.org/10.1016/j.csr.2007.12.003.

Talke, S. A. and D. A. Jay (2013), Nineteenth century Pacific and North American tidal data: Lost or just forgotten?, in press, J. Coastal Res.

Talke, S.A., H.E. de Swart, and H.M. Schuttelaars (2009), Feedback between residual circulations and sediment distribution in highly turbid estuaries: An analytical model, Continental Shelf Research 29(1), $119 \quad-\quad$ 135, doi:10.1016/j.csr.2007.09.002. 
Thrush, S.F., Hewitt, J.E., Cummings, V.J., Ellis, J.I., Hatton, C., Lohrer, A., Norkko, A. (2004), Muddy waters: elevating sediment input to coastal and estuarine habitats, Frontiers in Ecology and the Environment 2, 299-306. http://dx.doi.org/10.1890/1540-9295(2004)002[0299:MWESIT]2.0.CO;2

Thompson. J. (1957), The settlement geography of the Sacramento-San Joaquin delta, California, PhD Dissertation, Stanford University.

Uncles, R. J. and D. H. Peterson (1996), The long-term salinity field in San Francisco Bay, Continental Shelf Research, 16(15), 2005 - 2039.

US Army Corps of Engineers (1915), Reports of the chief of engineers, US Army 1866 1912; Volume I: Rivers and Harbors, Government Printing Office, Washington, DC.

Vale, C., Sundby, B. (1987), Suspended sediment fluctuations in the Tagus Estuary on semi-diurnal and fortnightly time scales, Estuarine, Coastal and Shelf Science 25(5), 495 - 508. DOI: 10.1016/0272-7714(87)90110-7.

Valle-Levinson, A. (2010), Contemporary issues in estuarine physics, Cambridge University Press, New York.

Wang, H., Yang., Z., Saito., Y., Liu, J.P., Sun, X., Wang, Y. (2007), Stepwise decreases of the Huanghe (Yellow River) sediment load (1950 - 2005): Impacts of climate change and human activities, Global and Planetary Change 57(3-4), 331 - 354, DOI: 10.1016/j.gloplacha.2007.01.003. 
Wang, W.C., K. W. Chau, C. T. Cheng and L. Qiu (2009), A comparison of performance of several artificial intelligence methods for forecasting monthly discharge time series, J. of Hydrology, 374, 294 - 306.

Woodworth, P. L. (2010), A survey of recent changes in the main components of the ocean tide, Continental Shelf Research, 30 (15), 1680 - 1691. doi: 10.1016/j.csr.2010.07.002.

Wright, S.A., Schoellhamer, D. H. (2004), Trends in the sediment yield of the Sacramento River, California, 1957-2001, San Francisco Estuary and Watershed Science 2(2), $14 \mathrm{pp}$.

Yang, S.L., Belkin, I.M., Belkina, A.I., Zhao, Q.Y., Zhu, J., Ding, P.X. (2003), Delta response to decline in sediment supply from the Yangtze River: evidence of the recent four decades and expectations for the next half-century, Estuarine, Coastal and Shelf Science 57(4), 689 - 699. DOI: 10.1016/S0272-7714(02)00409-2. 